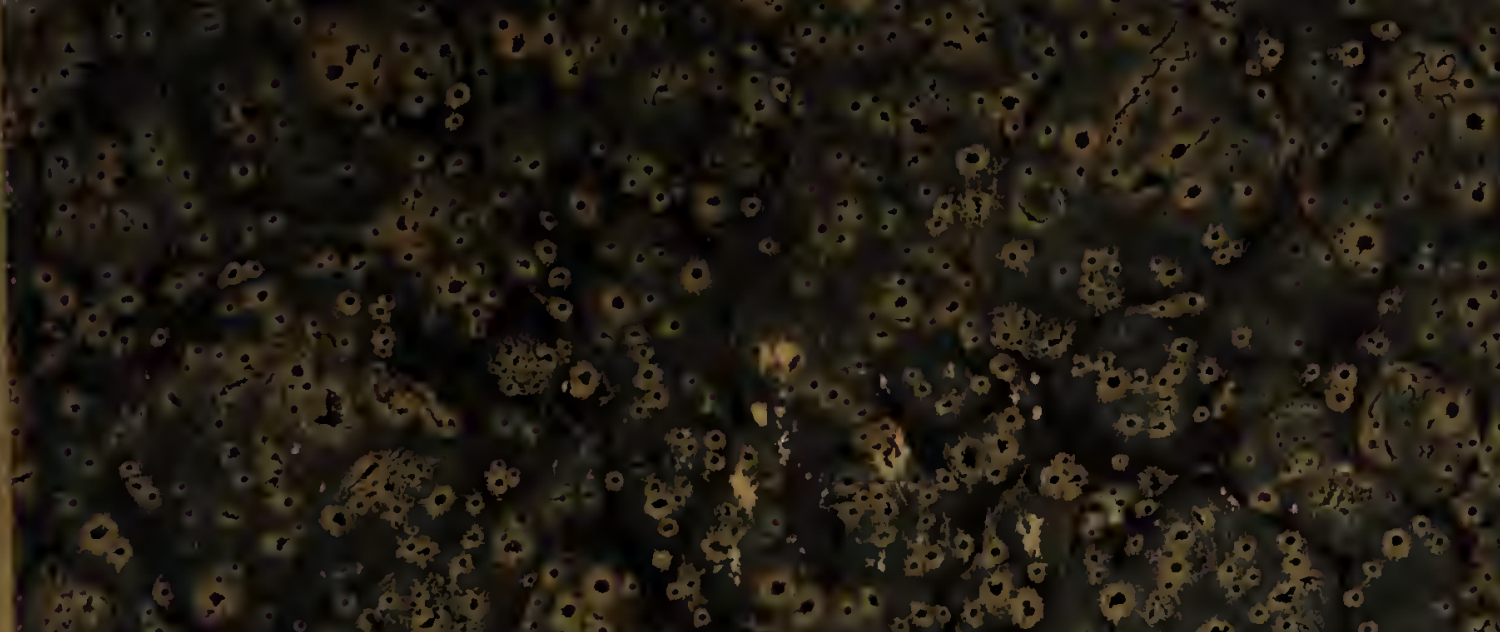

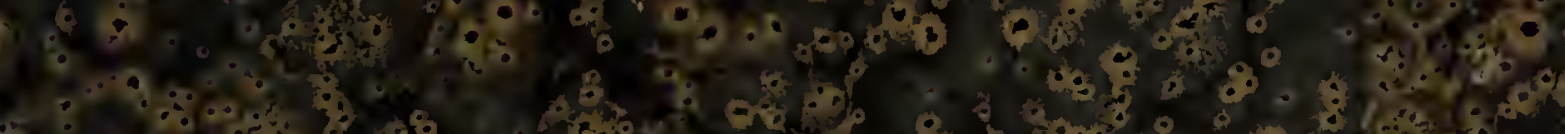

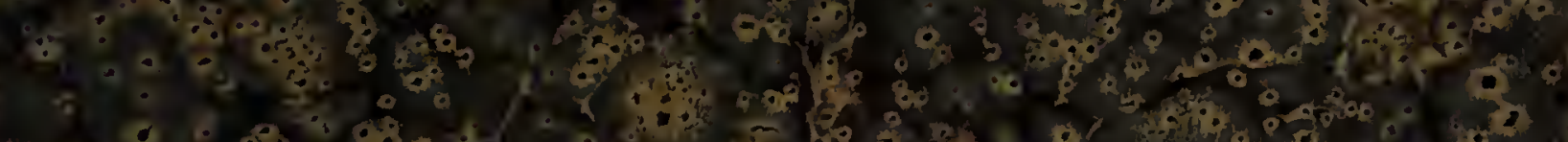

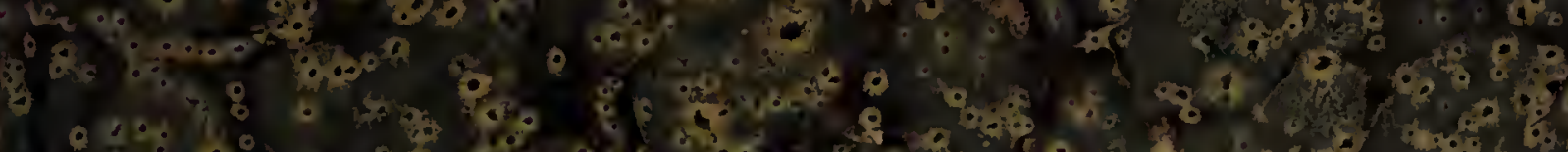
* $0: 0 \%$

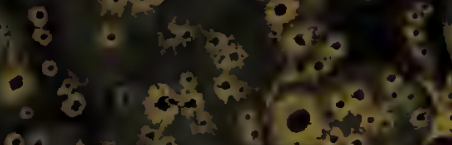 \\ 40}

20.?

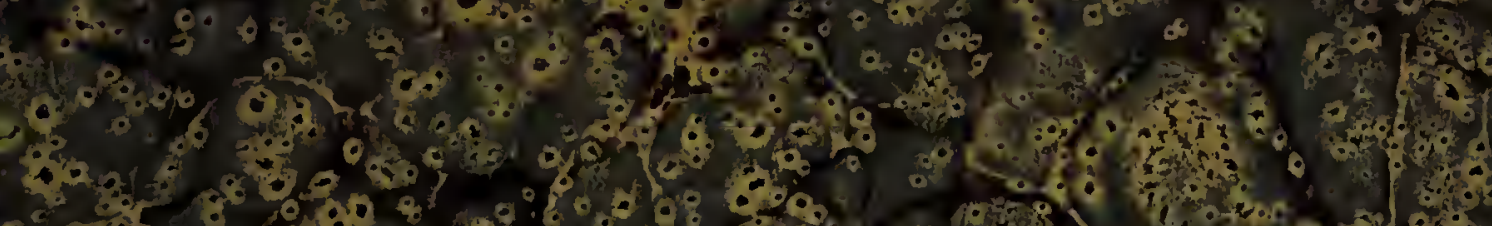

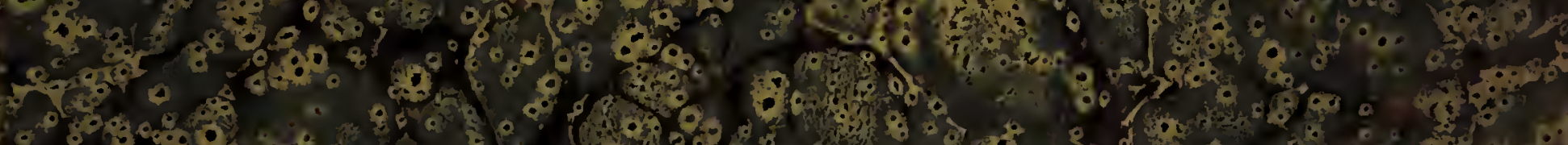

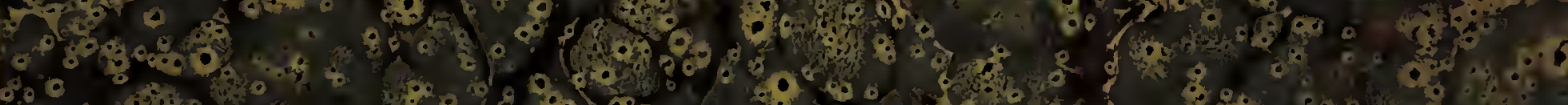

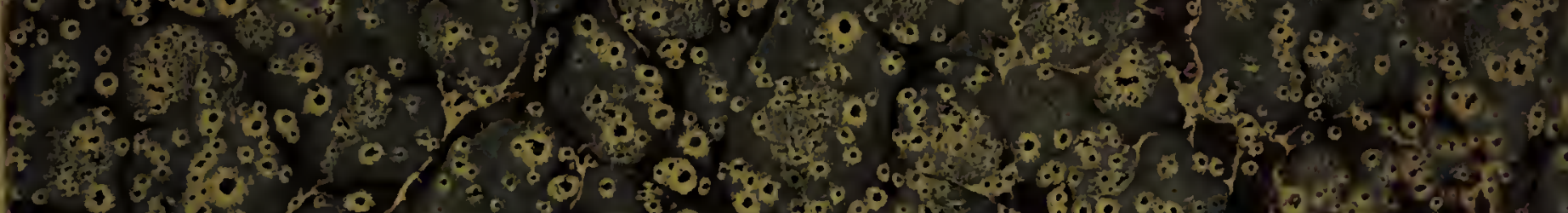

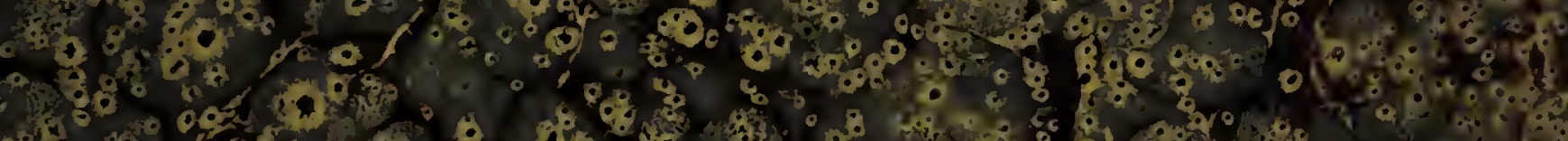

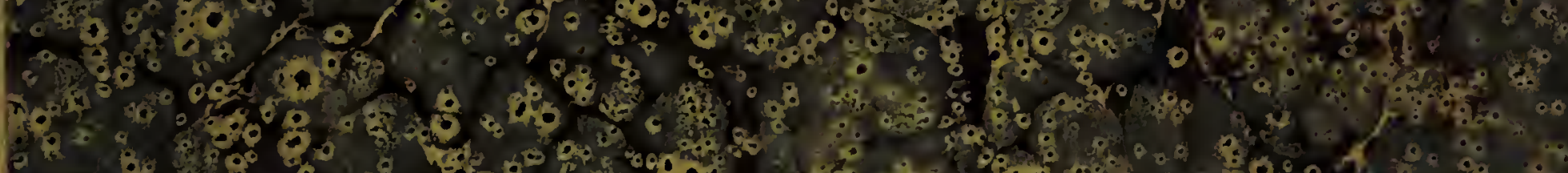

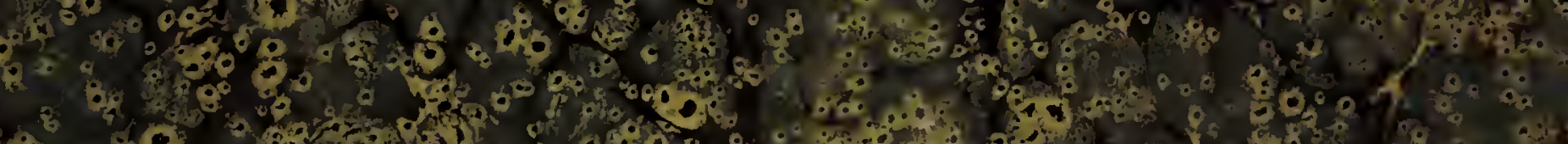

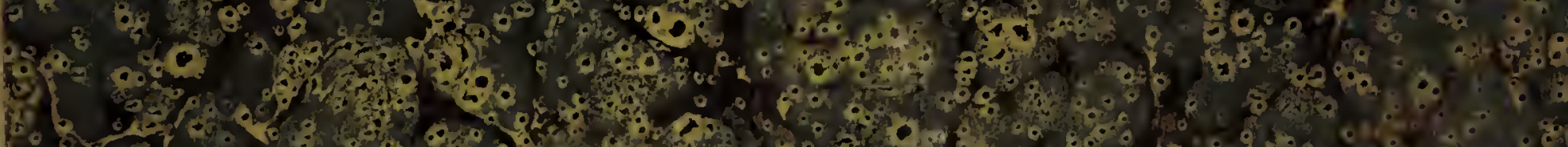

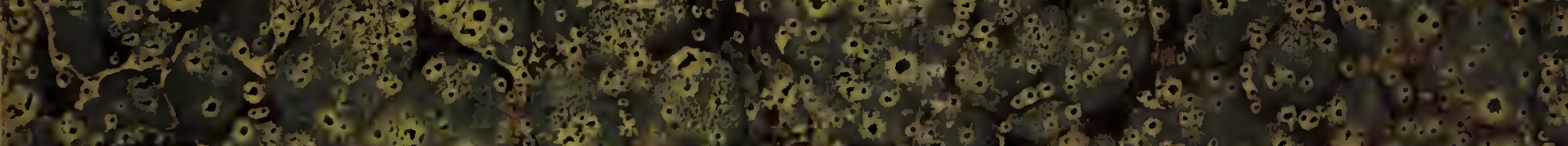

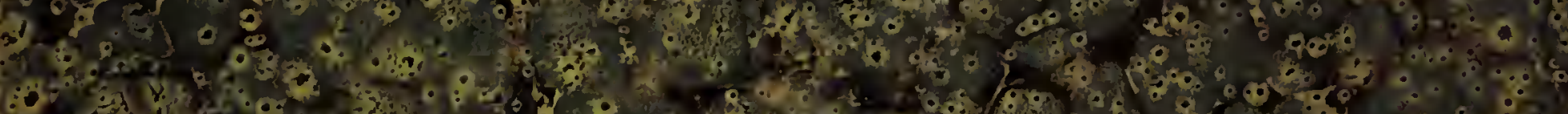

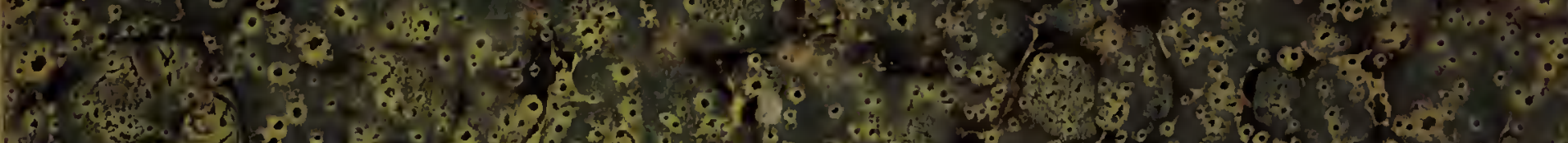

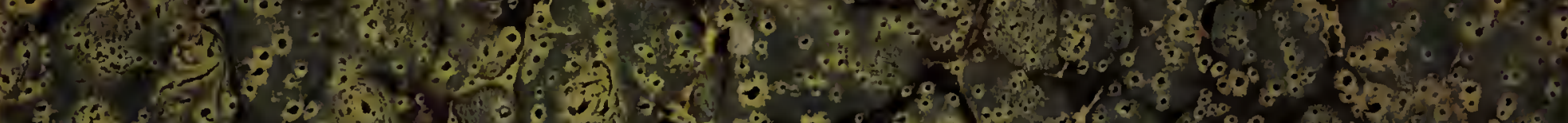

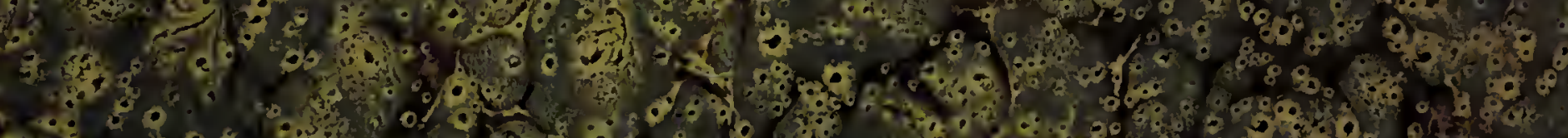

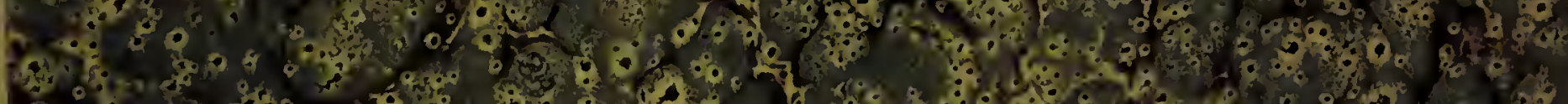

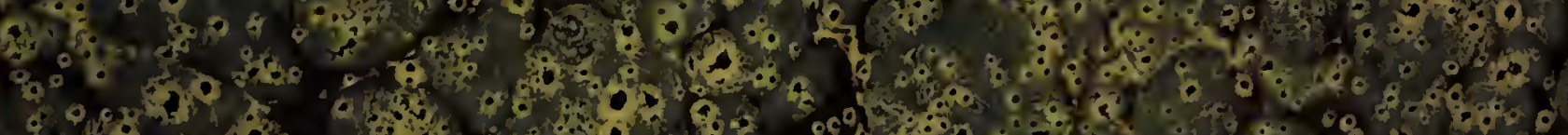

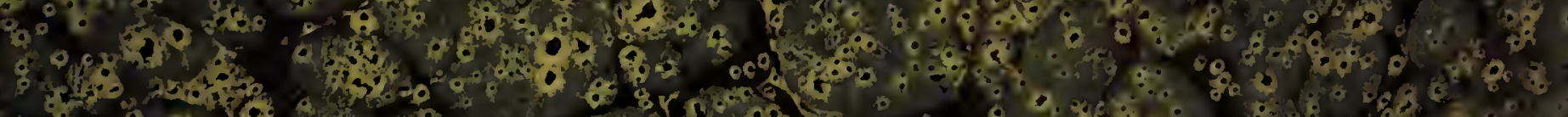

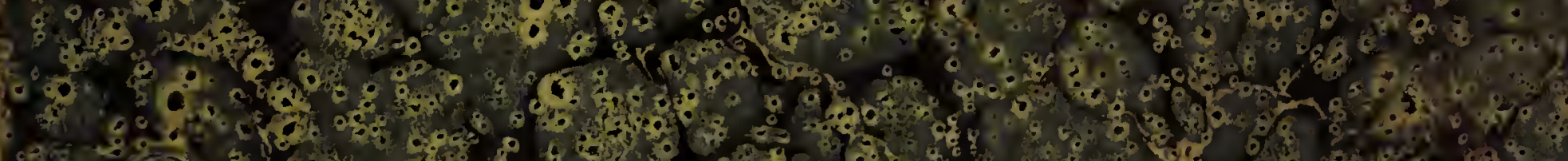
os

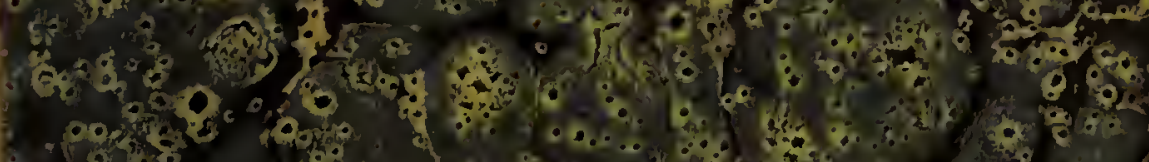

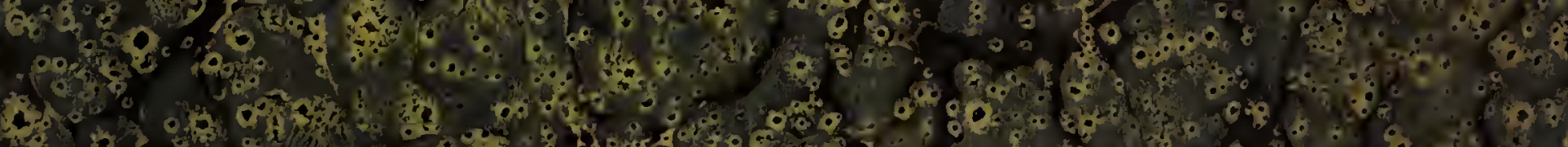

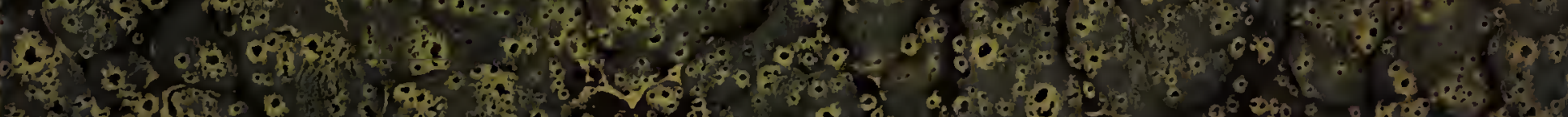

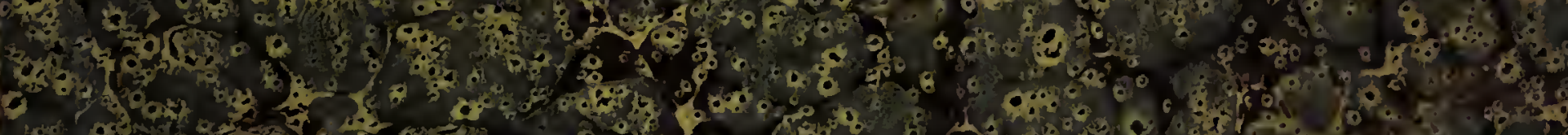

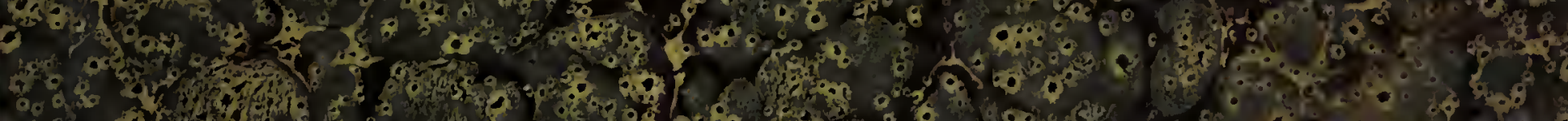

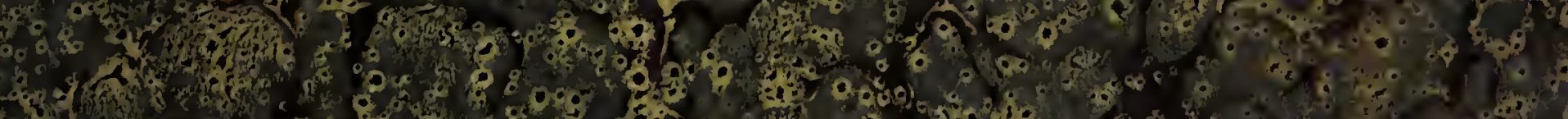

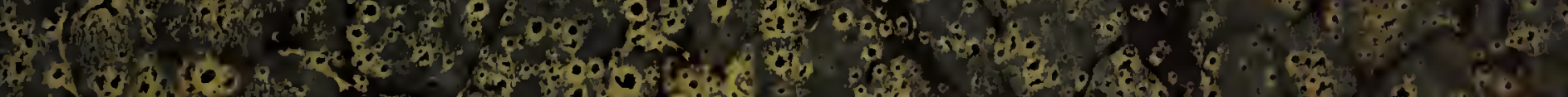

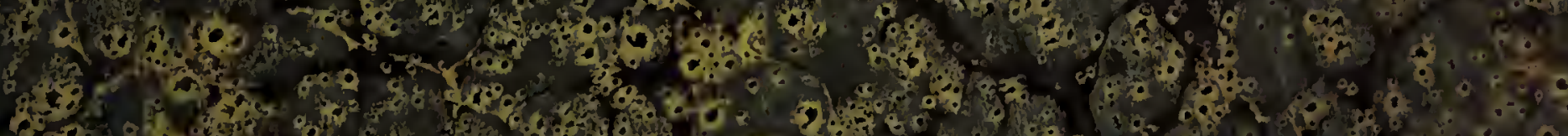

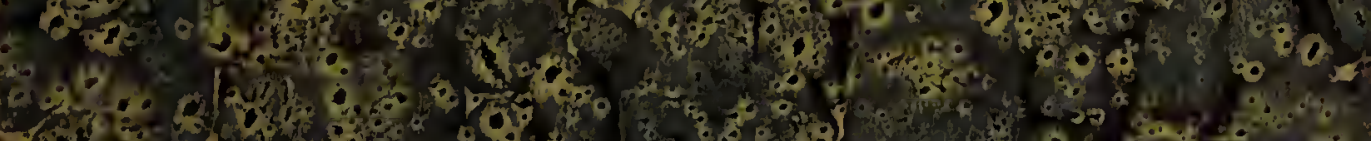

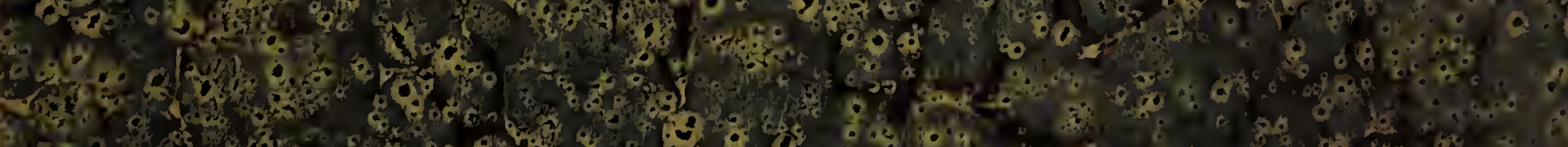

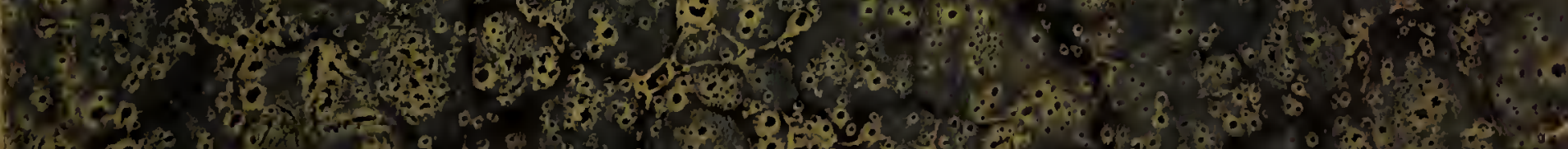
to 0 o 


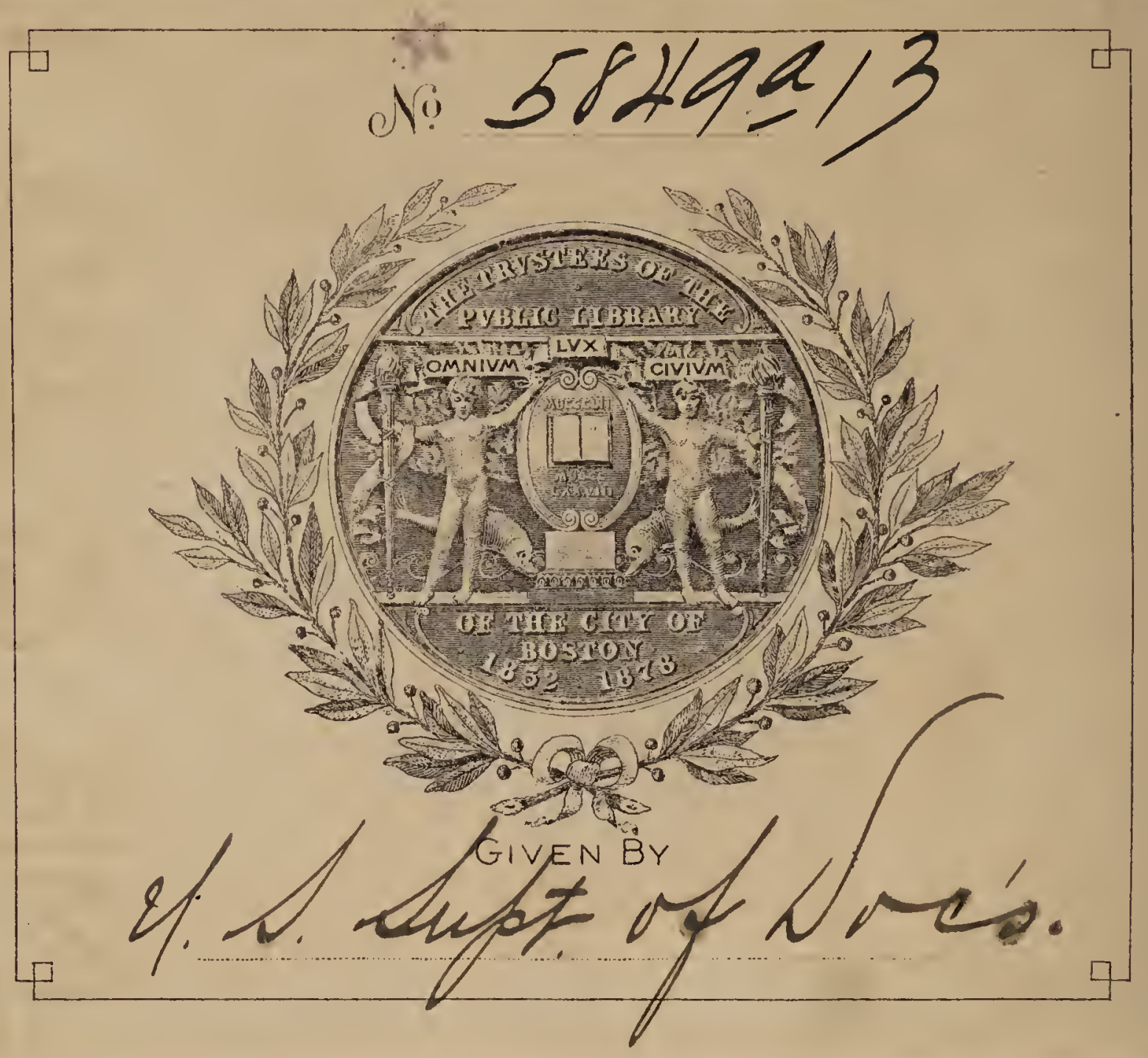




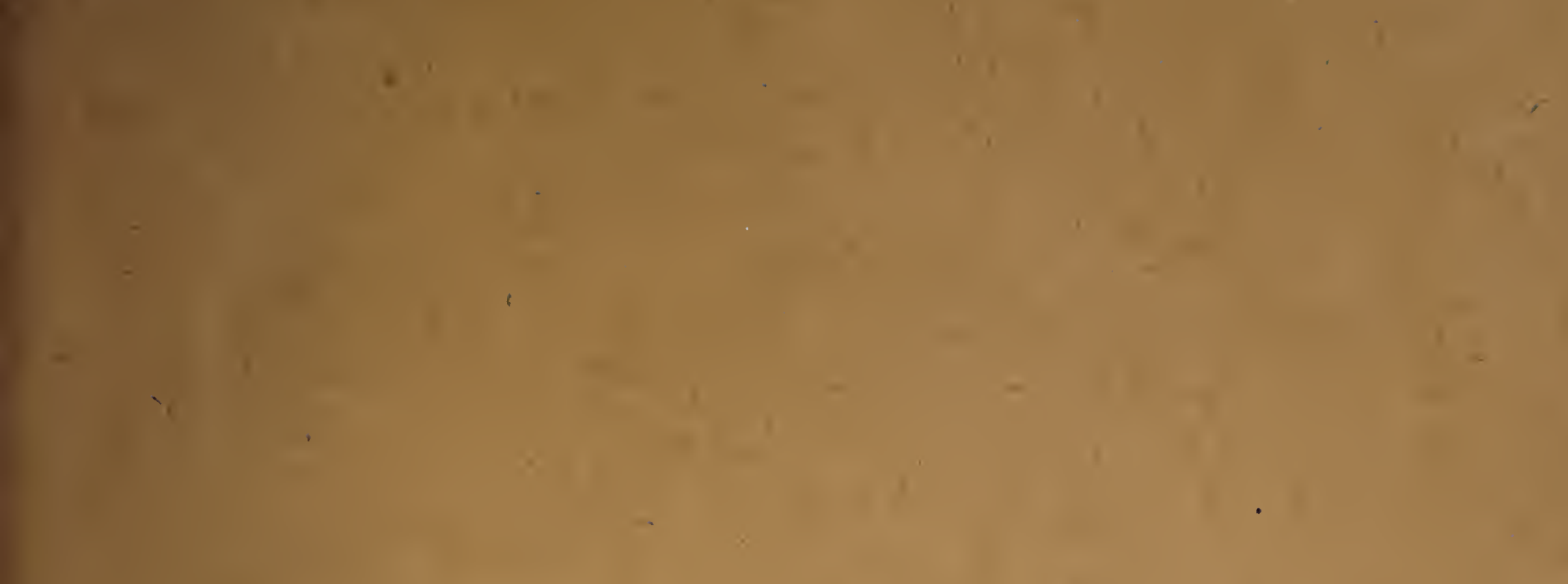

$+1$

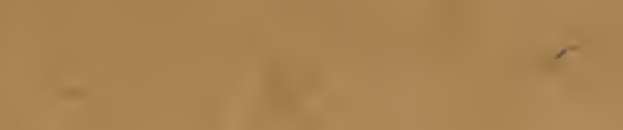

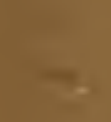

$\rightarrow$

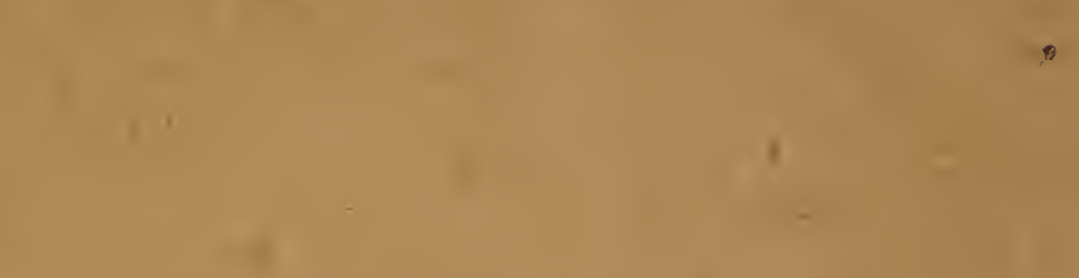

.

$\cdot$

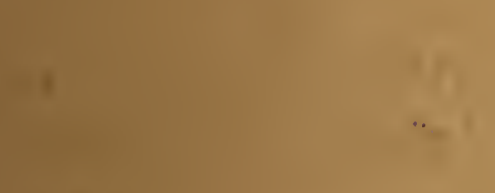

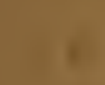

$$
12 \frac{1}{12}+4
$$
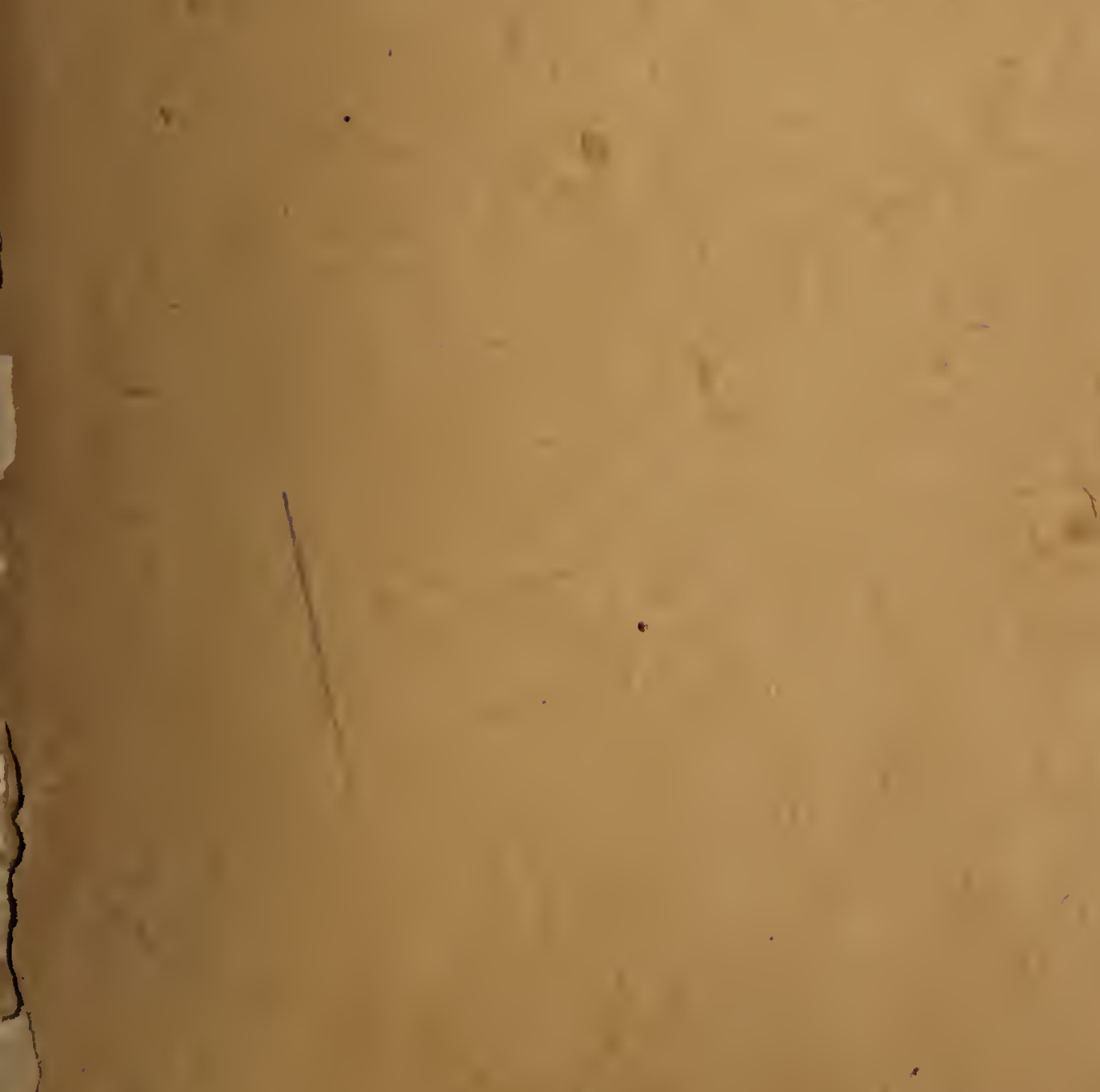

Miss. $0-6$.

U. S. DEPARTMENT OF AGRICULTURE, FOREST SERVICE.

\section{TRAIL CONSTRUCTION ON THE NATIONAL FORESTS.}

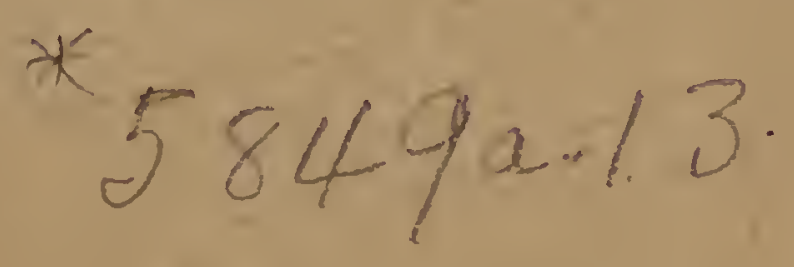

WASHINGTON:

GOVERNMEN'T PRINTING OFFIOE.

1915. 

Miss. $0-6$.

U. S. DEPARTMENT OF AGRICULTURE, FOREST SERVICE.

\section{TRAIL CONSTRUCTION ON THE NATIONAL FORESTS.}

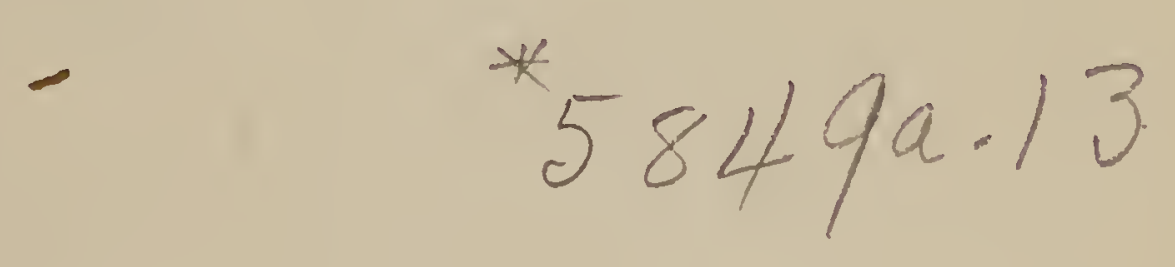

WASHINGTON:

GOVERNMENT PRINTING OFFIOE.

191:. 


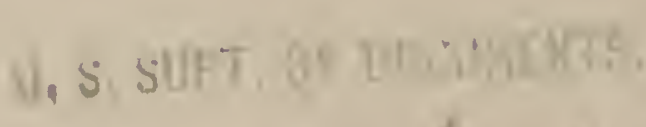
$004+16,1915$ 


\section{O N T E N TS.}

Purpose......

Classification and general specifications............................ 7

Definition of a trail....................................... 8

Importance of classification.................................... 8

Classification based on use..................................... 8

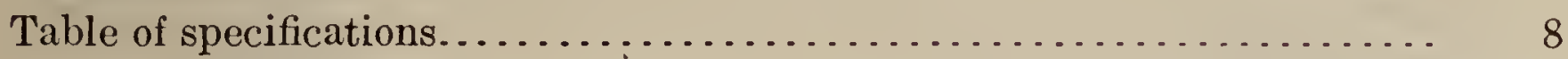

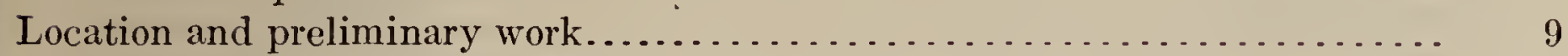

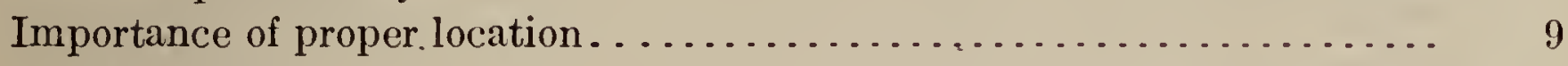

Limit of cost................................................. 9

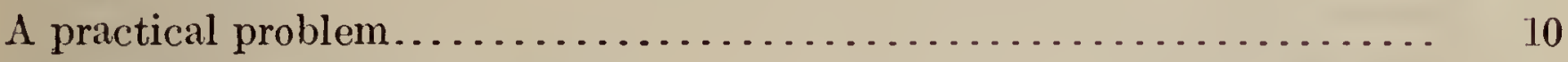

Competent men for trail locating.......................... 10

Thorough field examination in advance.................... 10

Important points to consider............................. 11

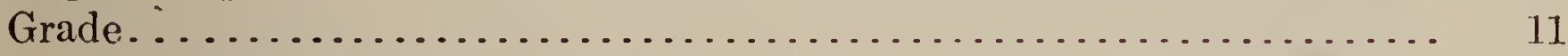

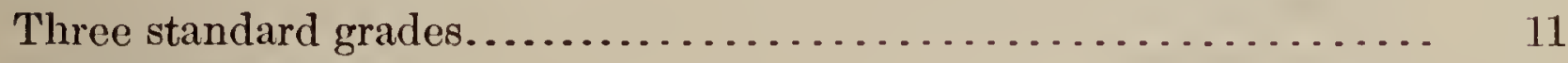

Long steep grades......................................... 11

Evenly supported grades............................ 12

Réverse grades...................................... 12

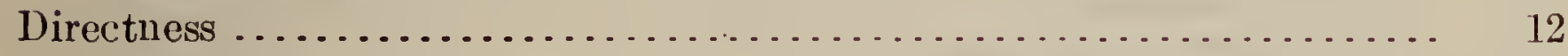

Intermediate objectives........................... 13

Rock............................................... 13

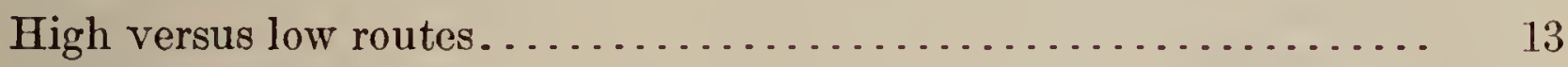

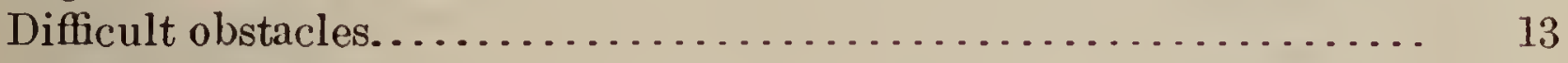

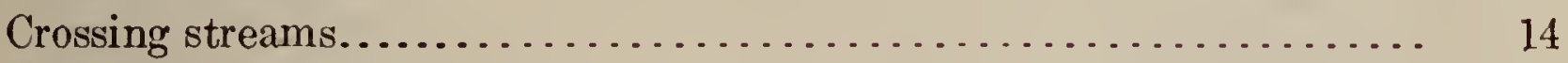

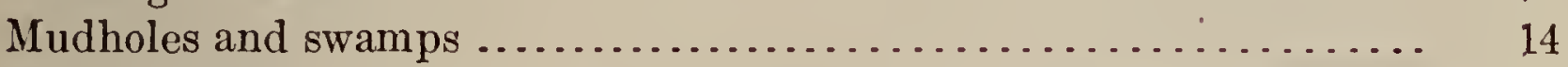

Alluvial flats........................................... 14

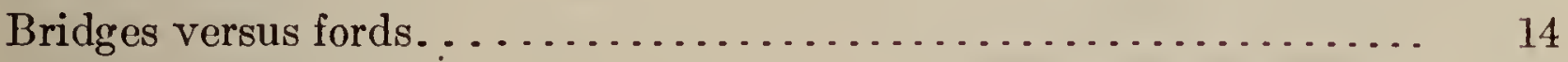

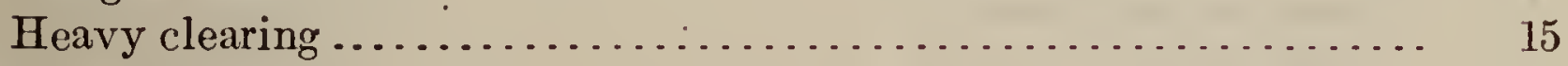

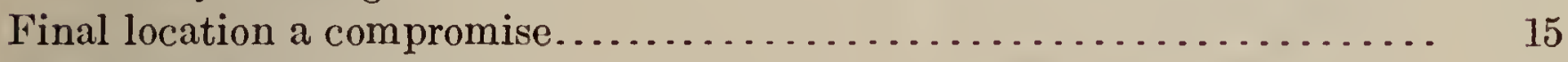

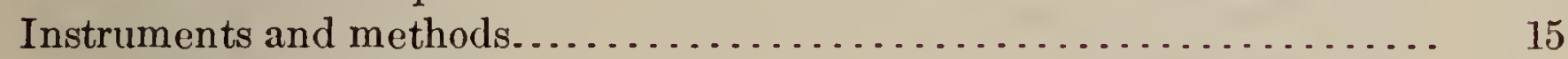

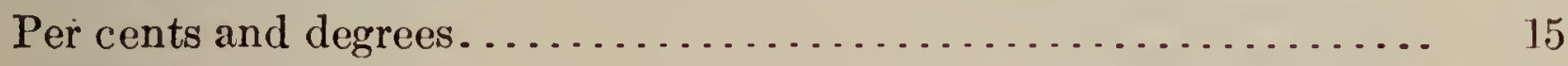

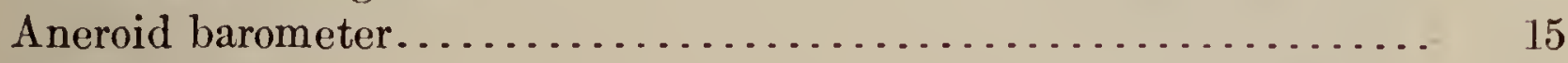

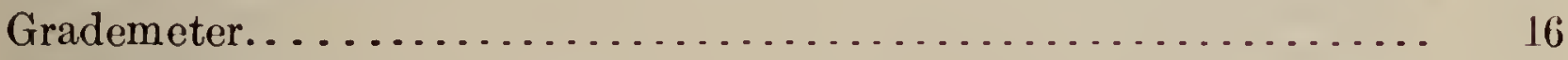

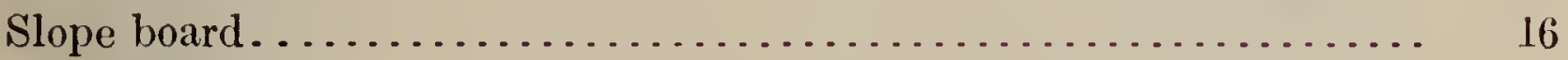

Locke level........................................ 17

Abney level ............................................... 17

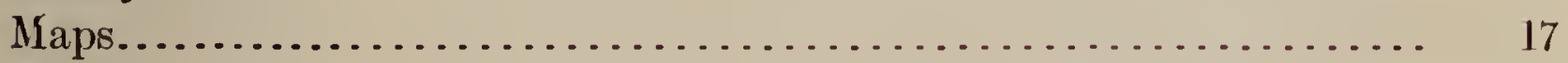

Tools...................................................... 18

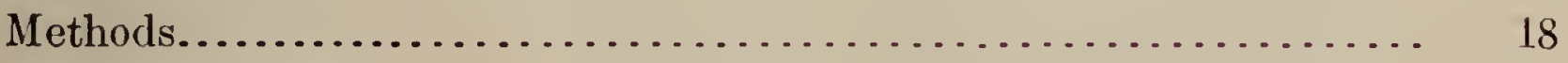

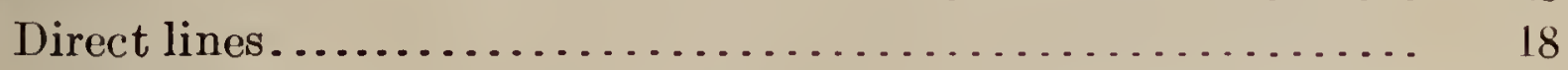

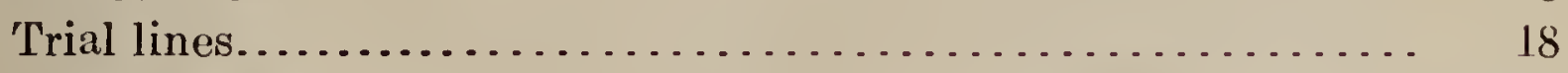

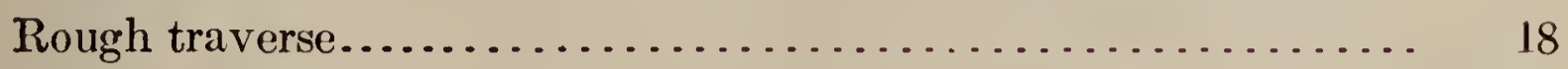

Grade lines...................................... 19

One man method of running grade lines................ 20

Down-hill versus up-hill survey.................... 20

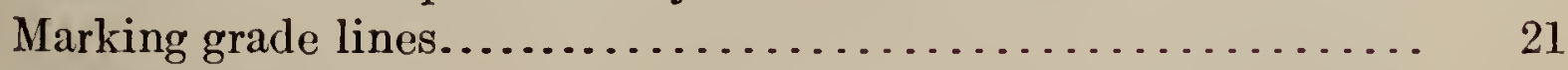

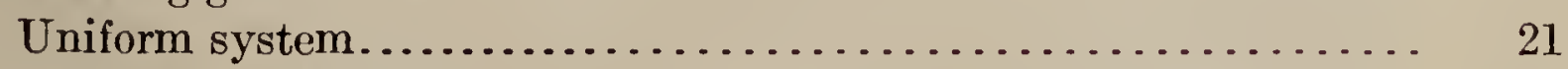

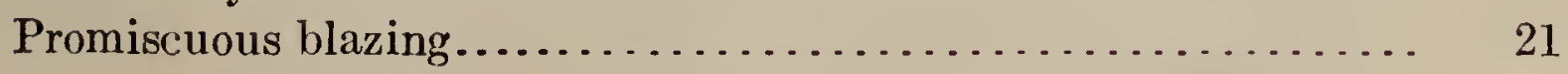

F. S. standard blaze............................... 21 
Page.

Construction....................................... 21

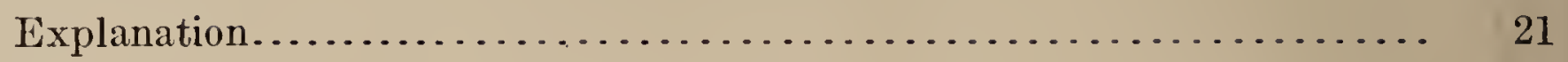

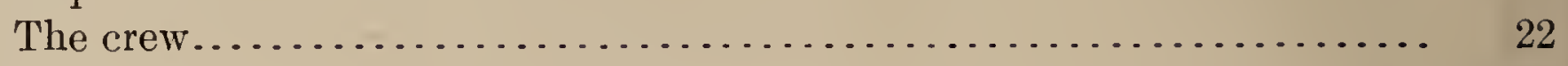

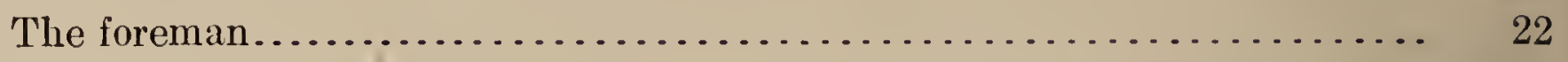

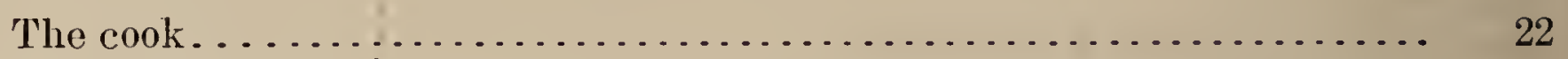

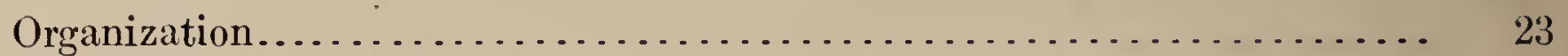

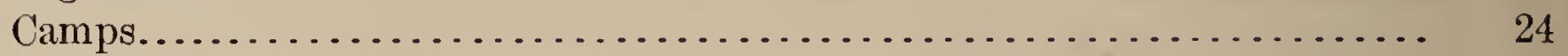

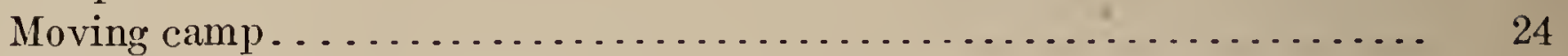

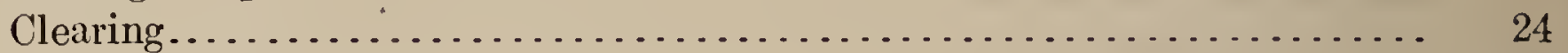

Brush disposal . . . . . . . . . . . . . . . . . . . . . . . . . . . . . . 25

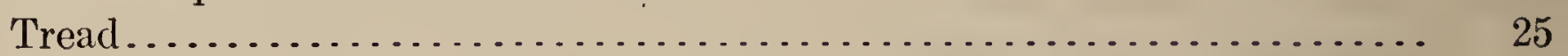

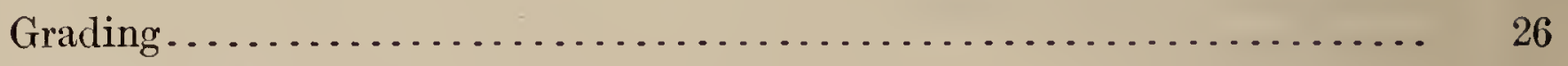

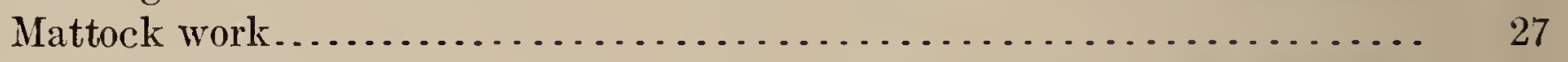

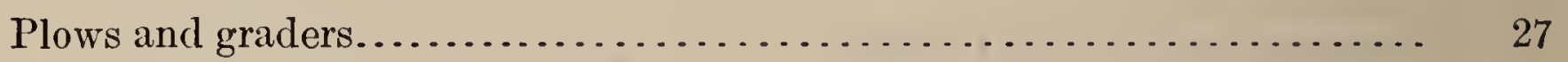

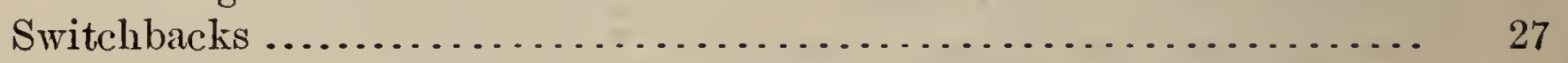

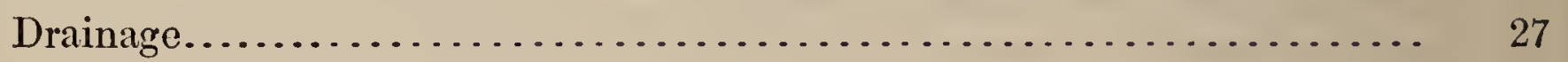

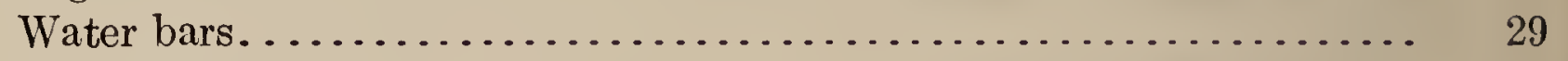

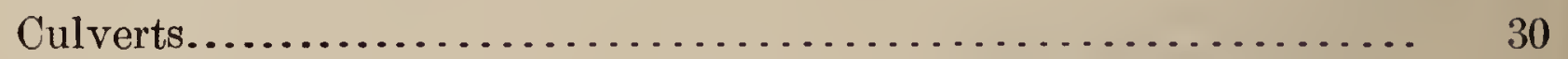

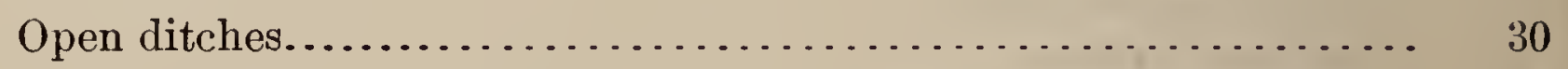

Corduroy...................................... 31

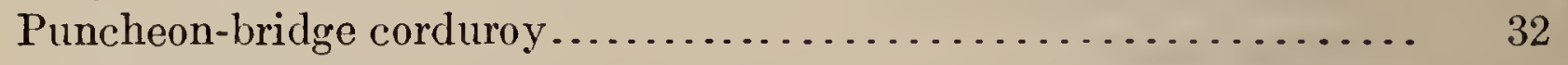

Split-log corduroy ............................. 32

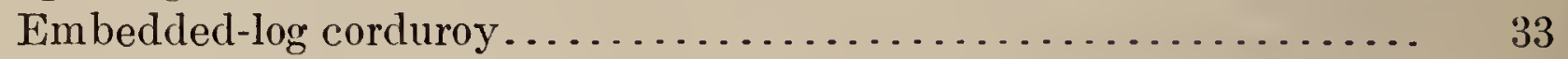

Blazes, guideposts, signposts .............................. 33

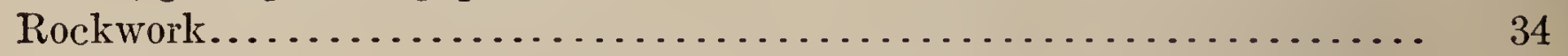

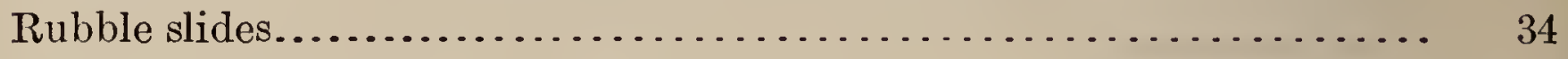

Loose slides. . . . . . . . . . . . . . . . . . . . . . . . . . . . . . . . 35

Retaining walls..................................... 35

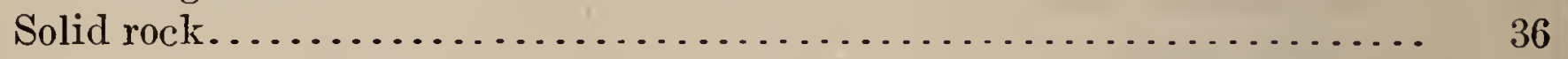

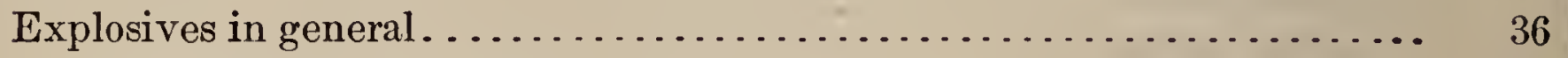

Granular black powders............................ 37

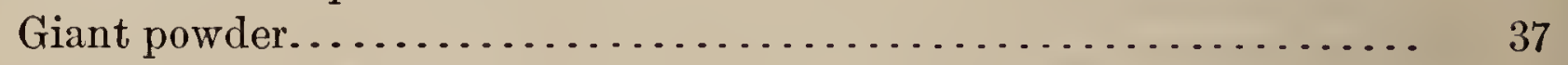

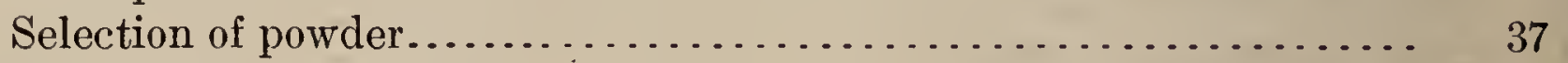

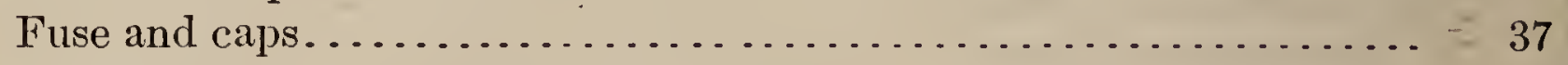

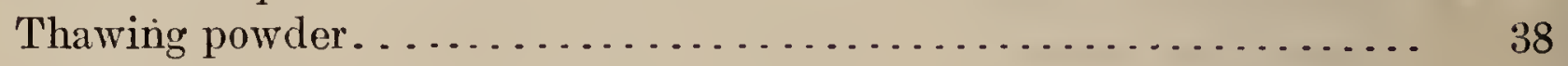

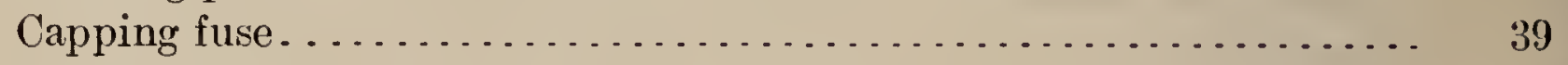

Charging holes.................................... 39

Missed holes..................................... 39

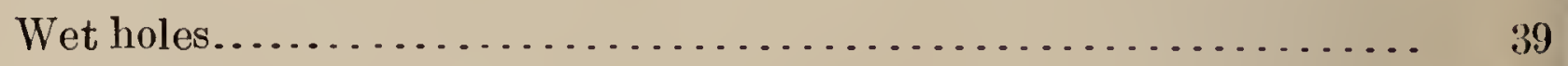

Sharpening steel............................... 40

Bulldozing .................................. 40

Double jacking................................ 40

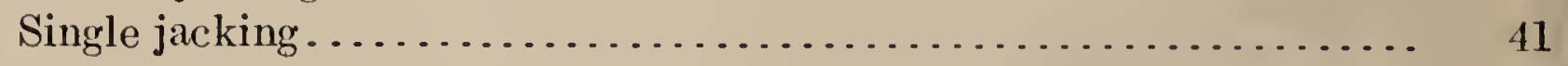

Drilling...................................... 41

Special problems.............................. 41

Bridges. ....................................... 42

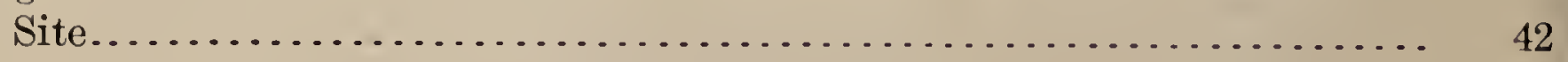

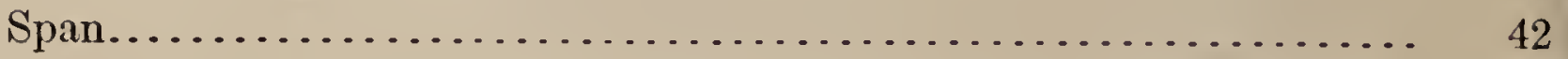

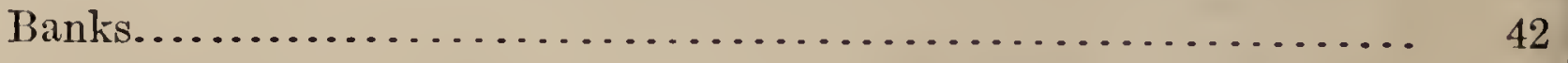

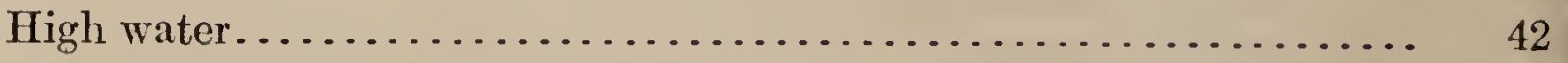

Straight channel................................ 42

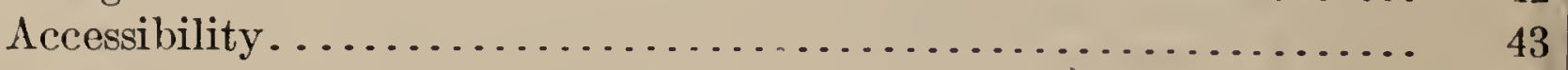

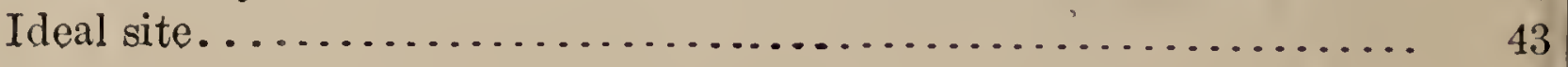


Bridges-Continued.

Preliminary data..................................... 43

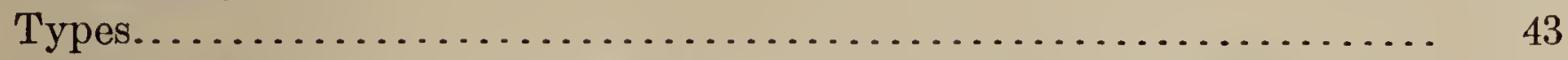

Table 1.-Minimum dimensions for stringers on nontruss bridges ...... 47

Table 2.-Dimensions of principal members for spans 20 to 36 feet, King truss bridge.

Table 3.-Dimensions of principal members for spans 36 to 60 feet, Queen truss bridge

Table 4.- Relative strength of sawed lumber and round timber beams....

Stringer bridge........................................ 48

King truss bridge........................................... 48

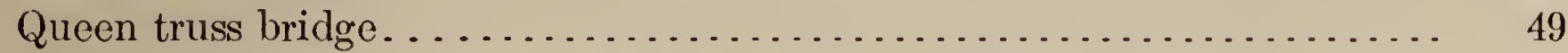

Cable bridges................................................ 49

Trestle bridges............................................ 49

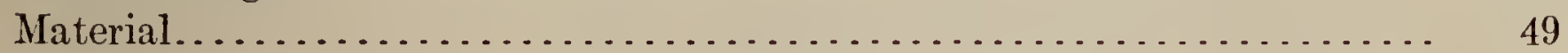

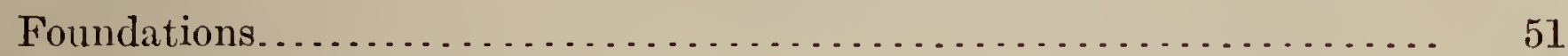

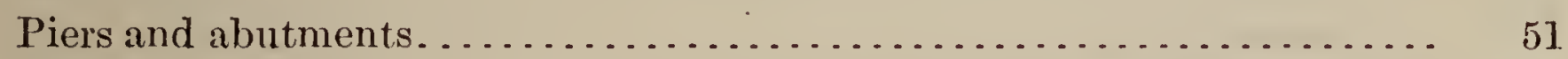

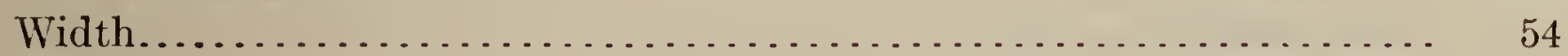

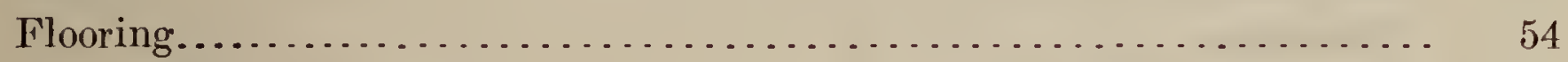

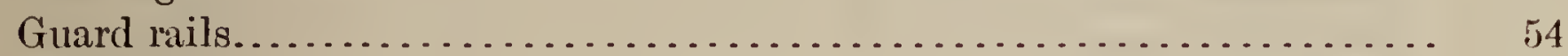

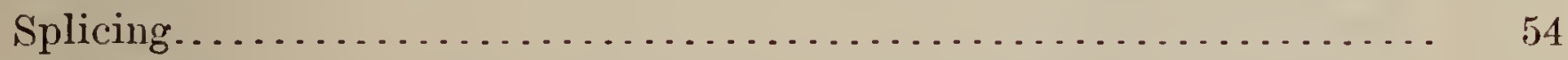

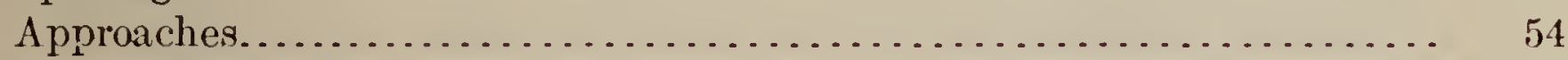

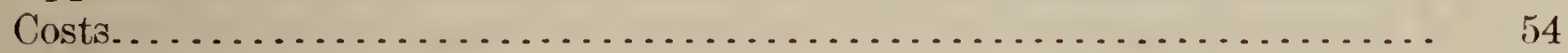

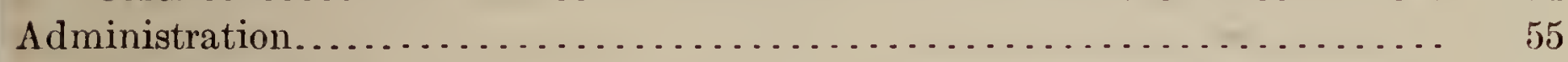

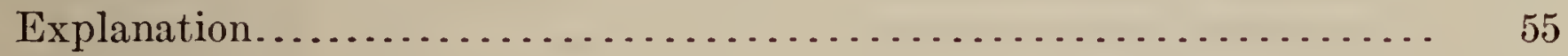

Plans....................................................... 55

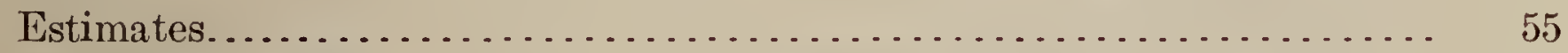

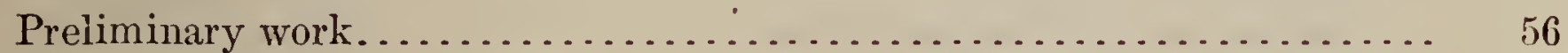

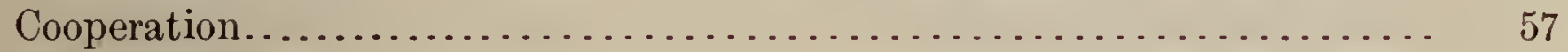

Personnel of crews.......................................... 57

Efficiency........................................... 57

Other classes of important work............................ 58

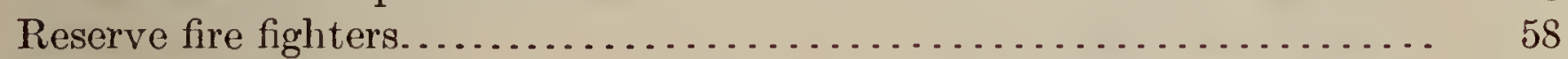

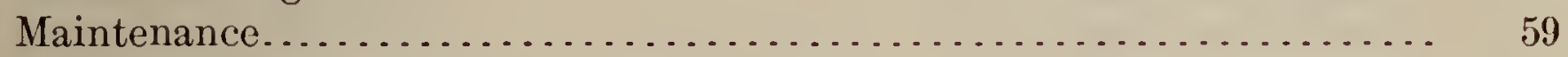

Definition of construction and maintenance................... 60

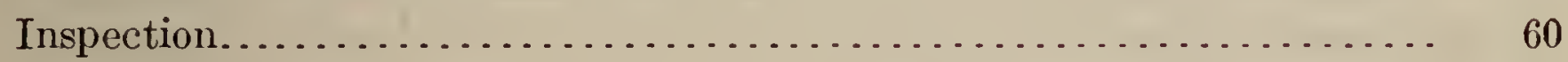

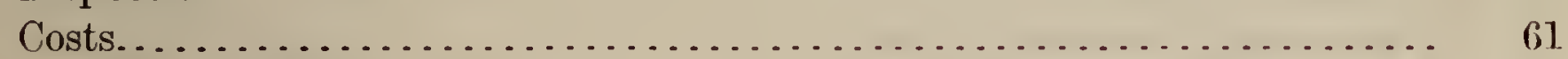

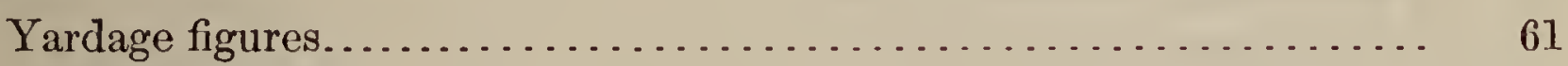

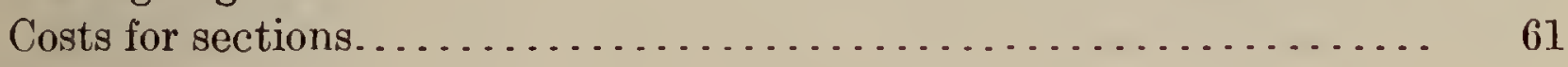

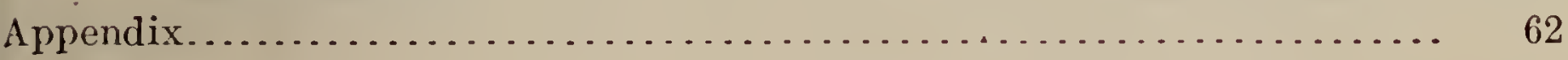




\section{L L U S T R A T I O N S.}

Fia. 1. Slope board ............. 16

2. Trail survey ...................................... 20

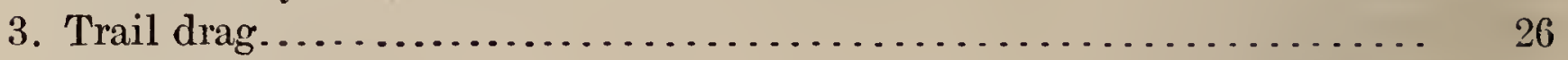

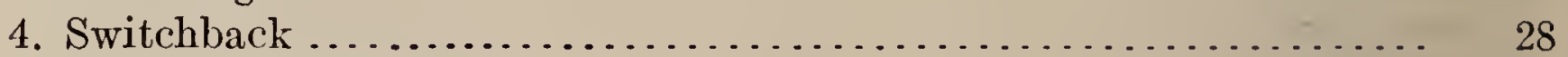

5. Plan of switchback................................. 28

6. Side-hill construction with water bar and diversion ditch......... 29

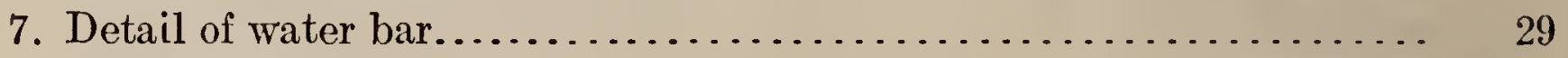

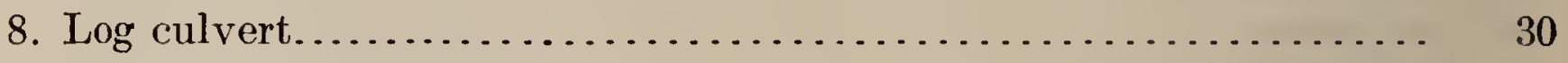

9. Puncheon-bridge corduroy............................... 31

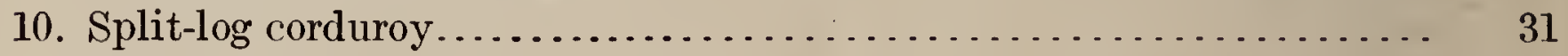

11. Embedded-log corduroy .................................. 31

12. Retaining walls through slide rock....................... 34

13. Crib work through slide rock........................... 35

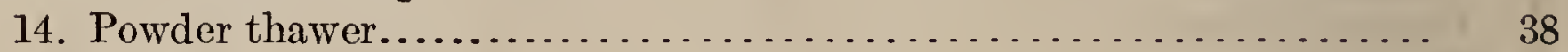

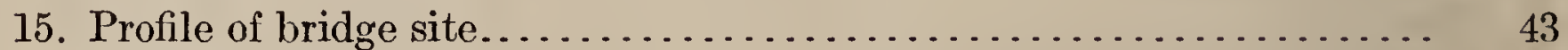

16. Stringer bridge.......................................... 44

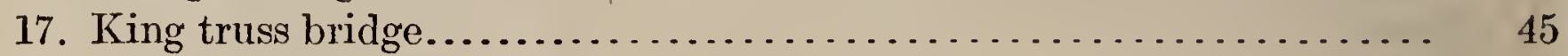

18. Queen truss bridge....................................... 46

19. Suspension bridge................................... 49

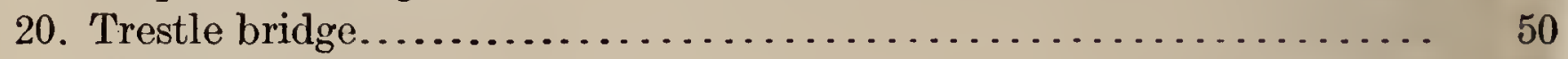

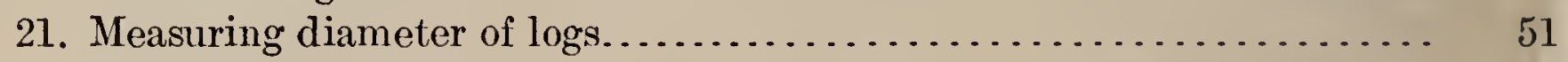

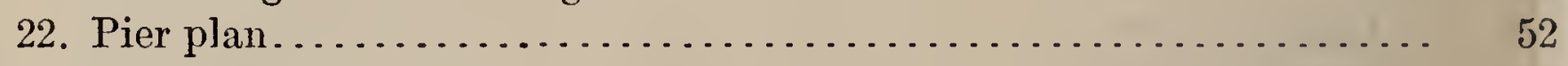

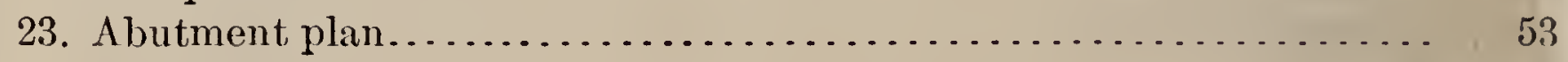




\section{TRAIL CONSTRUCTION ON THE NATIONAL FORESTS.}

\section{PURPOSE.}

The purpose of this handbook is (1) to establish a uniform classification of trails on the National Forests in accordance with their use, (2) to establish standard specifications for each class, (3) to describe approved methods of location, construction, and maintenance, and (4) to furnish reference data useful in preparing estimates and in actual construction work.

Heretofore trails on the National Forests have varied, under very similar conditions, all the way from shotgun trails to bicycle paths, in accordance with the exigencies of the situation or the point of view of the builder. Economically it is as bad to put too much money into a trail as too little. In the pasi, standards have been very largely determined by the money available and the necessity for building the first trails. The number of trails now completed, however, makes this excuse no longer valid. The wrong standard should not be adopted merely because of the lack of funds; it is better to stick to the right one, even if several years are required for final completion of the work.

Methods of location, construction, and maintenance for any particular trail will depend very largely upon the use to which that trail will be put-upon the amount, frequency, and kind of traffic which will pass over it. In the mountains the limit of speed with saddle horses is probably about 4 or 5 miles an hour. Consequently, it would be useless to adopt any standard which would allow a greater speed. On the other hand, the poorest trails should enable a saddle horse to travel with safety at a speed of not less than 2 miles an hour.

The instructions given in this manual should be followed closely. The suggestions are meant merely in the nature of guides. Thorough preliminary work proportionate in amount with the importarice of the project, and the adoption of a standard in advance of construction coinciding with the use of the trail, are imperative.

\section{CLASSIFICATION AND GENERAL SPEGIFICATIONS.}

For convenience in reference a table giving the classification adopted and a summary of the specifications for each class follows this discussion. The details will be found under "Construction." 


\section{DEFINITION OF A TRAIL.}

Mere ways through the forest, whether marked or not, are not regarded as trails; they are matters of woodcraft rather than of permanent forest improvement. A trail is a narrow highway over which a pack animal can travel with safety during the usual period when the need for a highway exists.

\section{IMPORTANCE OF CLASSIFICATION.}

The proper classification of a trail before its construction is important, since that determines the specifications. Usually, but not always, trails following main valleys and streams will be classed as $\mathrm{A}$; and those following ridges or tributary streams will be classed under $\mathrm{B}$ or C. Class A trails may or may not be convertible into wagon roads, depending upon the accepted standards for wagon roads in the locality. Whenever there is assurance that a wagon road will be built in the near future, and that the existence of the trail will assist materially in the construction of the wagon road, then the trail specifications for route and grade should be rigidly held to those suitable for wagon roads.

\section{CLASSIFICA'TION BASED ON USE.}

The classification is based upon the use to which the trail is to be put. Therefore, if the use justifies a class A trail, the specifications for this class should be used. If for any reason it is impossible to conform in every particular to the standard adopted for this class, all other specifications may be disregarded, temporarily, except those for route and grade. If the trail conforms in these two particulars to the class A specifications, it may later be brought up to standard in other particulars. The same, of course, applies to class B trails.

CLASSIFICATION AND GENERAL SPECIFICATIONS. 1

SUMMARY.

\begin{tabular}{|c|c|c|c|}
\hline & $\begin{array}{l}\text { Class A. } \\
\text { (Usually main trails, sometimes con- } \\
\text { vertible into wagon roads with- } \\
\text { out material alteration of route or } \\
\text { grade.) }\end{array}$ & $\begin{array}{l}\text { Class B. } \\
\text { (Usually secondary or } \\
\text { connecting trails sel- } \\
\text { dom used in through } \\
\text { travel.) }\end{array}$ & $\begin{array}{l}\text { Class C. } \\
\text { (Usually branch or } \\
\text { spur trails.) }\end{array}$ \\
\hline Route.. & $\begin{array}{l}\text { Direct as practicable between termini } \\
\text { and intermediate objective points. }\end{array}$ & Same as A............. & Same as $A$. \\
\hline Switchbacks... & $\begin{array}{l}\text { To be avoided whenever possible; } \\
\text { when used each leg to be as long as } \\
\text { nature of ground will permit. }\end{array}$ & $\begin{array}{l}\text { Allowable if material } \\
\text { Saving of expense; } \\
\text { each leg to be as long } \\
\text { as practicable. }\end{array}$ & Wherever desirable. \\
\hline Clearing (net).. & 6 to 10 feet (standard 8 feet) ........... & 6 to 8 feet............. & 4 to 6 feet. \\
\hline Grade. & $\begin{array}{l}0 \text { to } 15 \text { per cent (all grades supported } \\
\text { as evenly as possible; standard } 10 \\
\text { per cent). }\end{array}$ & 0 to 20 per cent......... & $\begin{array}{l}\text { Any grade that a pack } \\
\text { liorse can get over. }\end{array}$ \\
\hline
\end{tabular}

1 Classification is not based on the specifications, but on use of trail.

2 The specifications apply primarily to the larger timber. The undergrow th should be cut for a distance sufficient to prevent blocking of trail by brush and young trees. Overliead clearing should remove all limbs within $S$ feet of the ground. 
SUMM $\Lambda R Y-$ Continued.

\begin{tabular}{|c|c|c|c|}
\hline & $\begin{array}{l}\text { Class } \Lambda \text {. } \\
\text { (Usually main trails, sometimes con- } \\
\text { vertible into wagon roads with- } \\
\text { out material alteration of route or } \\
\text { grade.) }\end{array}$ & $\begin{array}{l}\text { Class B. } \\
\text { (Usually secondary or } \\
\text { connecting trails sel- } \\
\text { dom used in through } \\
\text { travel.) }\end{array}$ & $\begin{array}{l}\text { Class C. } \\
\text { (Usually branch or } \\
\text { spur trails.) }\end{array}$ \\
\hline Tread (net)..... & $\begin{array}{l}15 \text { to } 48 \text { inches (maximum chicfly in } \\
\text { rockwork; never wider than neces- } \\
\text { sary). }\end{array}$ & 12 to 48 inches......... & 12 inches. \\
\hline Drainagc... & For rain and snow water, springs, etc.. & Same as $\Lambda \ldots \ldots$. . & $\begin{array}{l}\text { Only when required } \\
\text { for safety. }\end{array}$ \\
\hline Bridges......... & $\begin{array}{l}\text { For all streams, ctc., not casily crosscd } \\
\text { during all periods of use. }\end{array}$ & Same as $A \ldots . . . .$. & Do. \\
\hline $\begin{array}{l}\text { Corduroy and } \\
\text { culverts. }\end{array}$ & $\begin{array}{l}\text { For all swamps, mudholes, ctc., not } \\
\text { bridged. }\end{array}$ & Samc as $\Lambda \ldots . . . .$. & Do. \\
\hline Blazes.... & $\begin{array}{l}\text { On each side, not more than } 1 \text { cliain } \\
\text { apart if trees aro availablc. Stand- } \\
\text { ard } \mathrm{F} . \mathrm{S} \text {. blazc. }\end{array}$ & Same as $A \ldots$ & Samc as $\Lambda$. \\
\hline Guideposts ..... & $\begin{array}{l}\text { Where trail is not otherwiso plainly } \\
\text { distinguishablc at all seasons. }\end{array}$ & Same as $\Lambda \ldots \ldots$. & Same as $\Lambda$. \\
\hline Signboards ..... & At cach branch and intersection....... & Same as $A \ldots . . . .$. & Same as $\Lambda$. \\
\hline Brush disposal.. & Always piled and burned............. & $\begin{array}{l}\text { Piling and burning } \\
\text { standard practicc; } \\
\text { butmay bescattered } \\
\text { if burning imprac- } \\
\text { ticable. }\end{array}$ & Same as $B$. \\
\hline
\end{tabular}

\section{LOCATION AND PRELIMINARY WORK.}

\section{IMPORTANCE OF PROPER LOCATION.}

The most important work in connection with the building of trails is the preliminary examination to determine the location.' 'Too much emphasis can not be placed upon its importance. Mistakes in location seldom can be corrected after the trail is constructed. Future generations of men and horses inust pay for incompetence or carelessness shown in the preliminary work. At the same time, the work can be overdone. Obviously the least amount of time should be spent in locating a class $\mathrm{C}$ trail, and comparatively much greater time spent in locating a class $\mathrm{A}$ trail. It should be remembered always that it is a trail which is being located - not a railroad grade.

LIMIT OF COST.

The time and money spent should be commensurate with the importance of the project. It is usually a safe guide to hold the cost of location to a figure not exceeding 5 per cent of the probable cost of the trail. 'This guide figure, however, must not be taken literally; most trails should cost less than this, and on some a much higher expenditure is justified. Neither should this figure be applied to each mile of the trail. For example, the probable cost of a trail 10 miles long may be $\$ 100$ per mile, or a total of $\$ 1,000$. The cost of locating correctly the 10 miles should, under average conditions, not exceed $\$ 50$. This means the time of one man for a period of 12 $93418^{\circ}-15-2$ 
to 20 days, or of two men for a period of 6 to 10 days; or for two men, 1 to $1 \frac{1}{2}$ miles per day. Fifty per cent of this time may, however, be spent in locating the most difficult mile or two of the distance, and the balance of the trail located at the rate of 2 or 3 miles per day. It all depends upon the conditions.

\section{a PRaCtical PRoblem.}

Trail locating is a fascinating problem, full of interest and satisfaction to the man who successfully solves it. It is a practical rather than a technical problem, and therefore rarely calls for the servicis of skilled engineers. The essentials are good judgment, experience, and hard work. Every phase of the problem must be investigated. The proper route may be hidden in a mass of almost impenetrable brush and windfalls, or it may be concealed in a rocky bluff which could be worked as cheaply as a higher, steeper route over some open ridge.

\section{COMPETENT MEN FOR TRAIL LOCATING.}

Trail location must be in the hands of competent men. For class $\mathrm{C}$ trails the services of a practical woodsman, working without assistance, is usually sufficient. For the location of trails of classes $A$ and $B$, however, two mon usually are needed, although one wellqualified man can do a great deal of work alone. A third man is desirable when locating the grade line with instruments. The man in charge should be experienced in this class of work and thoroughly acquainted with the country. He must be able to read contour maps, understand the use of instruments, and sketch a sufficiently accurate map of the territory to convince himself and his superior officers that he has chosen the best route, after analyzing all the factors bearing on the problem. The work is usually performed by rangers or others of the regular field force of the Forests. As a rule, the district ranger is the man best qualified for the task, both because of his intimate knowledge of the country and the interest which he will naturally have in the work.

\section{THOROUGH FIELD EXAMINATION IN ADVANCE.}

The establishment of the definite line of location must be preceded by a thorough and complete preliminary field examination covering all of the ground which offers possibilities. A general knowledge of the country is not sufficient. In every case where an important trail project is involved a general reconnaissance of the country should be made with the particular trail project in mind. Even the man who knows "every foot of the country," but who never looked it over for the particular purpose of building a trail through it, will be surprised at the many details previously overlooked. Careful personal investigation is necessary; the opinion of the oldest inhabit- 
ant is often in error. Numerous problems will have to be solved in deciding upon the final location. Consideration of but a single factor without its coordinate relation to others is insufficient. Each factor must be balanced against other factors of possibly greater or less weight.

\section{IMPORTANT POINTS TO CONSIDER.}

(1) A south exposure has less snow, is drier, of ten more open, and has an increased fire hazard.

(2) Ridges afford less expensive trail routes than valleys, but the period of use is correspondingly reduced.

(3) Steep side hills, near the angle of repose, are liable to landslides or snowslides.

(4) Bridges and temporary structures should be avoided as far as possible.

(5) The permanence of a trail depends on the material and its drainage.

\section{GRADE.}

A consideration of the purposes and uses of the proposed trail has determined the class into which it falls; the next problem is to choose the route and locate the grade on the ground. The approximate route once determined, the big problem, and by far the most important, is the determination of the grade. Any other feature of construction may be improved from month to month or from year to year, but if the grade is not properly established the trail must in time be abandoned. Thus not only may time and money be wasted, but the trail while in use will be unsatisfactory.

\section{THREE STANDARD GRADES.}

There are three standard maximum grades for trail construction. These are: Six per cent, 12 per cent, and 18 per cent. 'The actual maximums allowed have already been specified. Being multiples of 6 , these are easy to remember, as are also the reasons for having several maximums. A good grade having a maximum of 6 per cent may later be developed into a first-class road or turnpike. Such a grade might be called, for convenience, a turnpike grade. 'Twelve per cent is about the limit for safe mountain roads, such as are used for freighting, and might properly be called a freight grade. Eighteen per cent may be designated as the maximum efficient trail grade, and is as steep as a loaded pack animal can ascend without violent and exhaustive effort.

LONG, STEEP GRADES.

Long, steep grades should have breaks at frequent intervals where animals may rest and recover. For grades between 15 per cent and 20 per cent these breaks or resting places should be spaced about 
200 to 300 yards; for grades exceeding 20 per cent, about 100 to 150 yards apart. 'The resting places should be about 30 feet in length and should not exceed a 5 per cent grade, preferably level.

EVENLY SUPPORTED GRADES.

The best gradient between any two points is upon a line which would have the same percentage from beginning to end. Often there are "salient points" "along the route, above or below which the grade must run, and the line must be divided into parts, each with its own percentage of rise between these salient points. If an even gradient is also a low gradient, it is unquestionably the proper location for the trail if construction is practicable. The same is true if the gradient is on the most direct and practicable route and is below the maximum. The most frequent error in trail location is the failure to determine in advance (aind to use) the proper uniform gradient between two salient points. For example, trails from one.watershed to another are located along a water grade until near the head of the stream, where a series of switchbacks are built in order to reach the divide. An evenly supported grade from the stream bottom to the divide will avoid the necessity for the switchbacks, make travel much easier, and is usually practicable.

REVERSE GRADES.

An undulatory grade, even though its separate parts are within the grade limits, is wearing on pack animals and tends to impair their efficiency. Reverse grades should be avoided if possible. This means that the trail should never go downhill when the object is to go uphill, as this obviously increases the grade upon the ascending portions of the trail. As a rule some reverse grades are unavoidable on ridge trails, but they are seldom necessary on long climbs from valleys to divides.

\section{DIRECTNESS.}

The desirability of directness is so obvious that little comment is necessary. In some locations, however, it will be found that snow lies on the natural route for so much of the year that it may be desirable to establish the line in a location more exposed to the sun and wind. Often the period of use each year for a trail exposed to sun and wind may be several wecks longer, in spring and fall, than that of one located on a more direct but less favorable route. In most cases it is necessary to sacrifice directness for grade. This sacrifice should not, however, be to the extent of making necessary a series of switchbacks or a long detour when a little steeper grade would materially shorten the distance. This phase of the question should be particularly borne in mind when locating a trail through 
open country where the natural tendency will be to "cut the corners." $A$ class $A$ trail climbing along an open sidehill should be given the maximum grade of 15 per cent, or a class $B$ trail 20 per cent, if necessary to secure the most direct route. Along a timbered sidehill, however, or where a "short cut" is not feasible, the grade should be held down to the standard previously adopted.

INTERMEDIATE OBJECTIVES.

In locating a long trail, consideration must be given to the matter of making intermediate stations and vantage points of various kinds. Ordinarily the trail line should touch station sites or suitable camp grounds at intervals of one day's or one-half day's trip. 'Lookout points, etc., will generally be reached by branch trails.

ROCK.

Rockwork involves the disadvantages of delay and high cost. While usually the matter of slow construction can be tolerated, the question of high cost is a most vital one. If the quality of the trail can be held to a higher class through the doing of a comparatively small amount of rockwork, such work should be done. On the other hand, if the amount of rockwork is likely to be considerable, every effort consistent with the full accomplishment of the purposes for which the trail is built should be made to avoid it.

HIGH VERSUS LOW ROUTES.

It may be necessary to decide between going over or around a hill. If the distance over the hill measured on the ground along a practicable grade is materially less than the distance around, the higher route should be taken. If, however, the lower route is not much longer and can be built with good exposure to wind and sun, and the construction costs are practically equal, the latter should be chosen.

\section{DIFFICULT OBSTACLES.}

So far as a single obstacle, such as a cliff or rock outcropping on sidehills, is concerned, it may be immaterial whether it is passed on the upper side or on the lower. In this and in similar cases the solution lies in the situations into which the respective locations may lead the line. If the next obstacle is approximately at the same elevation and can be passed only on the lower side, the first should be passed on the same side, since otherwise there might be an unnecessary climb followed by a descent within a comparatively short distance. In general, the matter of ascents and descents in the line should receive the most careful consideration. 
CROSSING STREAMS.

It frequently happens that the two banks of a stream along which a trail is being located offer unequal advantages of ground, which suggest numerous crossings to save time and money. Such a route involves many fords and bridges, the objections to which are obvious. The safest general rule is to keep the trail on one side of the stream where that can be done at reasonable cost. If a temporary crossing is made to avoid expensive work, another crossing should be made at the first opportunity to the side of the future permanent location, so that the short spaces may later be connected and the final route thrown on one side of the stream.

\section{MUD HOLES AND SWAMPS.}

Corduroys are often necessary in a trail line. The general rule where swamps and mudholes are only occasionally encountered is to corduroy if the distance is less than the right-angle distance from the tentative line to suitable higher ground. If it is decided to locate around a swamp the point of clearance should be an intermediate objective, and the final line of location should be conducted to it as directly as possible.

\section{ALLUVIAL FLATS.}

Another problem which may occur in oonnection with trail locations along a stream is the availability of comparatively low banks and alluvial flats which show evidence of overflow. If material expense can be saved through the use of such situations it is permissible to locate parts of the line on ground of this character, provided the surface evidences show that the overflows are rare and of brief duration, and that water does not get so deep as to obscure the trail bed, and the current is not too swift or deep for safety. Great care must be taken, however, not to locate a trail through dry water courses subject to sudden flooding. Alluvial flats should always be avoided in localities where there is any danger of quicksand.

\section{BRIDGES VERSUS FORDS.}

When it is evident that the trail must cross a stream, the question arises whether to direct the line to a bridge site or to a ford. If a stream is fordable with difficulty during the usual period of the trail's use, the line should include the best bridge site available. If, on the other hand, the difficulty occurs only at rare intervals, and for brief periods, the line should include the ford. Where there is danger of quicksand forming, a ford must be chosen with great care; a bridge is much safer. In class A trails bridges are always preferable. The cost of maintenance is, however, sometimes a strong argument 
against the building of bridges even on class A trails; for example, in the "back country," where heavy snows and spring freshets form a constant danger and where it is not practicable to watch them.

HEAVY CLEARING.

Ordinarily in class A trails directness must not be sacrificed for the sake of avoiding clearing, yet occasionally there may be a great saving of expense through some concession in this respect. If the direct line closely parallels an open glade or a bit of prairie it is often advisable to select a location to include the open route so far as that can be done without adding materially to the distance. Occasionally there may be a series of open areas extending in the general direction of the proposed trail and separated by comparatively narrow strips of cover. In such cases it is generally advisable to lay out the line so as to pass from one opening to another by the shortest route. In clearing the line through timber, no effort should be made in class $A$ trails to avoid windfalls and heavy standing timber.

\section{FINAL LOCATION A GOMPROMISE.}

While the foregoing outline of the principal considerations in trail location is by no means exhaustive, it serves to indicate their general character and the nature of the problem. The final location will be a matter of compromise, and no effort should be spared to have it the very best compromise possible.

\section{INSTRUMENTS AND METHODS.}

PER CENTS AND DEGREES.

In surveying for railways, roads, or trails, the vertical deflection of the line is always expressed in per cent. Thus a 5 per cent grade means a rise of 5 feet in 100 feet of horizontal distance. The horizontal deflection of the line is always expressed in degrees. Thus, a railway may have a $3^{\circ}$ curve, which is a horizontal deflection of $3^{\circ}$ in 100 feet, from chord to chord, or a road may have a change in direction of $3^{\circ}$ at the junction of two courses. Percentage of grade and degrees of azimuth should never be confused, as very serious errors will result. The terms are never interchangeable.

\section{ANEROID BAROMETER.}

The aneroid barometer is often used to determine the difference in elevation between the ends of the proposed trail, and the approximate distance is determined by pacing. This furnishes a preliminary reconnaissance. A "trial" or "random" line may then be run from one end of the proposed line to the other on the approximate average grade, which has been determined by reconnaissance. This may be done by a grademeter, an Abney level, or a Locke level. A slope board may be used if no better instrument is available. 
GRADEMETER.

The grademeter is a small, compact instrument built on the principle of the plumb bob. It is not readily adapted to running grade lines, but may be used if no better instrument is available. It is intended primarily as a hypsometer or for determining the grade between two given points where no choice of routes can be made. It has a circular pendulum graduated to tangents or per cents. Sights

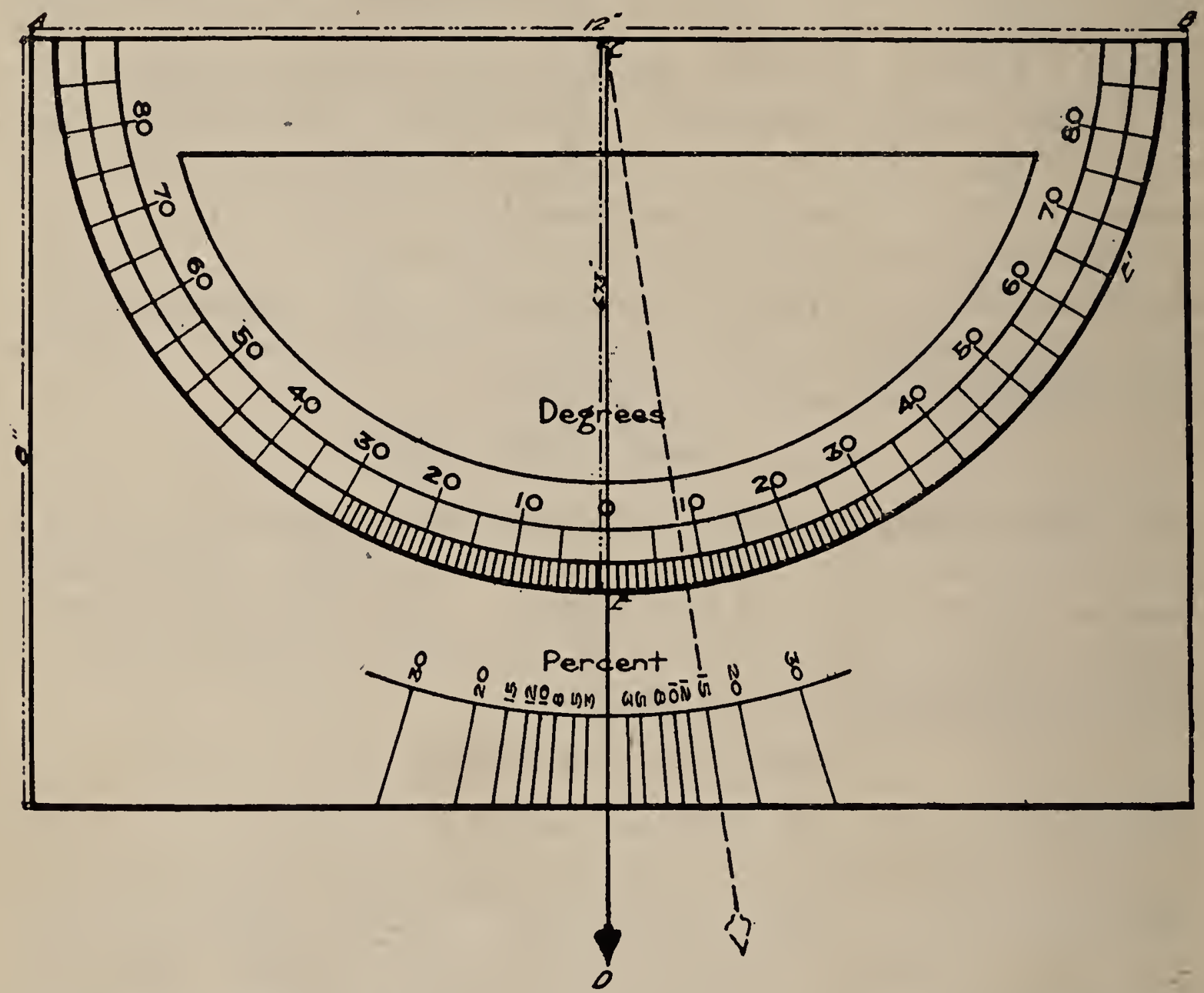

FIG. 1.-Diagram indicating construction of slope board. AB-Sighting edgc; CD-Plumb line. Distance from $\mathrm{E}$ to point on arc of circle $\mathrm{EE}^{\prime}$ measured on the chord equal to 1 degree, found by dividing length of radius CE by 57.3. For 5 degrees, multiply py 5 , etc.

may be taken downhill as well as uphill. No conversion of figures is necessary. If the reading is 10 the grade is 10 per cent.

SIOPE BOARD.

A homemade grademeter may be constructed and used with reasonable accuracy where other instruments are not available. Such an instrument is known as a slope board. It consists of a light board about 8 by 12 inches, forming a true rectangle (fig. 1). From the middle point of the longer edge, a line perpendicular to that side is drawn and a plumb line dropped from the same point. Using any convenient radius, the arc of a circle is drawn, with the same point as a center, and with a protractor degree marks are laid off each way from the perpendicular line. If no protractor is at hand, the spacing for the degree marks can be determined by dividing the length 
of the radius by 57.3. It is convenient to take a radius of 5.73 inches, or 5.75 inches scant, so that the spacing will figure out 0.1 inch; or a radius of $7 \frac{3}{16}$ inches, so that the spacing will be one-eighth inch, depending upon whether or not the scale used is graduated to tenths or eighths. The equivalents of degrees in per cents can be written on the board for convenience. These equivalents may be obtained from a table of tangents or Forest Service Form 126.

The uses and limitations of the slope board are exactly the same as for the grademeter.

\section{LOCKE LEVEL.}

The Locke level is a simple hand level which does not sight either uphill or downhill; it is used by sending an assistant ahead with a pole, upon which sights are taken through the barrel of the level. Allowance must be made for the height of the surveyor's eye above the ground. Thus, if his eye is 5 feet above the ground, he can fix the location of a 5 per cent grade by taking a sight on the ground at a point 100 feet distant, or by sighting at the top of a pole which is 10 feet high and 100 feet distant. In the first case it is a 5 per cent upgrade, and in the second it is a 5 per cent downgrade.

For running different gradients, of course, the height of the surveyor's eye remains the same, and the length of the sight is changed according to the grade. Thus, a sight on the top of a 10 -foot pole, in a distance of 50 feet, would give a 10 per cent downgrade; and a sight on the ground at a distance of 50 feet would give a 10 per cent upgrade still assuming the height of the surveyor's eye to be 5 feet. In the same manner, if the sights were 200 feet, the grade would then be $2 \frac{1}{2}$ per cent.

ABNEY LEVEL.

The Abney level is decidedly the best instrument for running preliminary or final surveys to establish the grade. This instrument contains no swinging pendulum, and can be set to the desired grade before the sight is taken. Some of the Abney levels are graduated to degrees; others to degrees and slopes, in the proportion of $1: 1$ and 1:10; others have graduations for per cent. This has led to some confusion, and some bad construction has resulted. Care should be used to apply only the per cent when this instrument is in use on trails. Abney levels, graduated in per cent only, may now be obtained upon requisition from the supply depot.

MAPS.

All available maps, especially contour maps, should be made use of in the preliminary work. If the maps are reasonably accurate their use will narrow the possibilities for the route to a considerable extent and thus reduce the necessary field work. 
TOOLS.

The tools necessary for marking the lines are comparatively few. A light single-bitted ax is usually sufficient for driving stakes and blazing. A carpenter's lead pencil is excellent for making temporary notations on the stakes and blazes. Trail blazers should not be burdened with more tools than are necessary for efficient work. In many localities the equipment and impedimenta must be reduced to an amount portable without pack horses.

METHODS.

Methods of locating trails vary according to the class of trail projected and the particular obstacles encountered. After the preliminary examination of the general route has been made and the various considerations weighed against each other the next step is to designate and mark the actual line along which the trail will be built. This resolves itself into two principal operations, depending upon the topography and the cover: (a) Running direct lines from point to point; (b) running grade lines.

\section{Direct Lines.}

The simplest method of running a direct line is to fix in view some landmark at or in line beyond the objective point and proceed directly toward it, marking the line by blazes or stakes. This method does not involve the use of instruments, but is necessarily of limited application, since it requires a landmark fortunately situated and constantly in view. In many sections of the forests direct lines can not be followed in locating trails because of rough topography. Deflections from a straight course must be made frequently to avoid steep slopes or bad ground where the reduction of cost more than compensates for loss in directness.

\section{Trial Lines.}

Another method, applicable to short courses, requiring one man with a compass, is the use of trial lines. In this method the locator sets the compass as nearly as possible in the direction of the objective point. He then follows this course until he reaches the vicinity of the objective. The amount of error at the close will indicate approximately the needed change in the compass course, and after a few trials the correct course is easily determined. The line is then blazed and staked.

\section{Rough Traverse.}

It is also possible for one man working alone to find the bearing of the objective point by reference to the total latitude and departure as determined through rough traverse by means of pacing and a compass. In this case the courses should be as few as possible. If 
the traverse involves a comparatively large number of courses or covers a considerable distance, it is desirable that the locator be assisted by two chainmen. Traversing for location is not, however, recommended unless a long, straight course is particularly desired. Direct lines can be used effectively only in relatively smooth regions of light grades.

\section{Grade Lines.}

Where grades are involved it is impossible to consider directness, except as a secondary matter. In any particular trail the starting and terminal points are of course first considered. In addition, the preliminary examination will indicate a number of intermediate objectives, and with the aneroid or level the relative elevation of each objective point is determined. The distance between is approximated or paced, and with this data the per cent of grade is determined between the different objectives.

For example, suppose the location for a Class B trail is being investigated, and the difference in elevation between objective 1 and objective 2 is found to be about 1,250 feet, and the distance approximately $3 \frac{1}{4}$ miles. The approximate grade is therefore $\frac{1,250}{17,160}$, or about 7 per cent. Again, suppose the elevation between objective 2 and objective 3 is 1,250 feet, and the distance as determined by pacing is 2 miles and 3 tallies, or $2 \frac{3}{16}$ miles, equivalent to 11,550 -feet, or a grade of about 11 per cent. Suppose, however, that between these two objectives there are level stretches amounting to one-half mile, so that the actual grade necessary in order to attain the required elevation is $\frac{1,250}{8,910}$, or 14 per cent. Again, assume that the difference in elevation between objective 3 and objective 4 is 900 feet and the paced distance is 14 tallies or 4,620 feet. This calls for a supported grade of $\frac{900}{4,620}$, or about $19 \frac{1}{2}$ per cent; but.it is planned to put in six level stretches 30 feet in length as resting places; this means a grade of $\frac{900}{4,440}$, or about 20 per cent.

After the approximate grade is decided, trial grade lines are run to determine the practicability of an evenly supported grade and the correctness of the grade per cent decided upon. After a few trials the exact line of the trail is chosen. In order to avoid expensive work it is frequently necessary to choose a different gradient between every two objectives with greater or less abrupt changes from one to the other. The class of trail will, of course, determine the extent to which the grade will be evenly supported or broken into two or more gradients. Evenness of grade, clearance of obstacles, and the advantageous use of ground are matters of the greatest moment. In run- 
ning grade lines on curves it is important to remember that the instrument man and the rod man should keep in line along the tangent of the curve, in order to secure a uniform grade (fig. 2).

\section{One-Man Method of Running Grade Lines.}

An experienced man can successfully locate trails working alone. The preliminary survey is made as previously described and the route and approximate grade determined. In running the grade line, the locator blazes or otherwise marks a tree at a point the height of his eye, and takes a trial sight ahead, using an Abney level. He

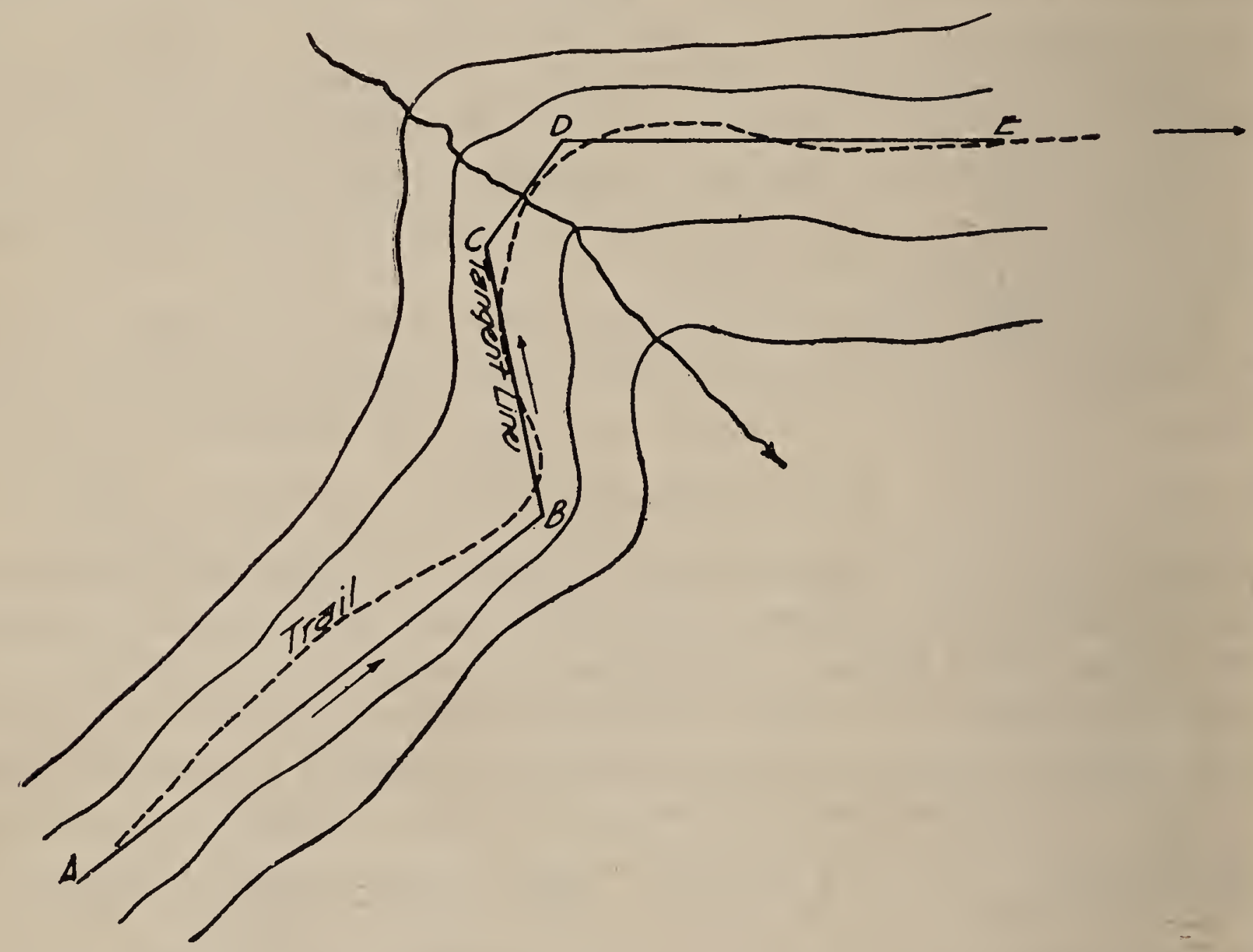

HIG. 2.-Trail survey. Diagram showing positions of instrument man and rodman in running trail grades for final location on curves. Sights should be taken successively from B to C, C to D, and D to E; never from $\mathrm{B}$ to $\mathrm{E}$.

then advances to the point on which the instrument was sighted and takes a back sight at the mark or blaze left at the first station, adjusting his position until the per cent grade set on the instrument strikes the mark at station one. He then marks station two the height of his eye, and proceeds ahead as before. In this way it is possible for one man to establish the grade line without assistance. If desired, he may also set grade stakes as he progresses. Success with the oneman method calls for the use of the Abney level. 'Two men, however, can work to much better advantage.

\section{Downhill versus Uphill Survey.}

In the large majority of cases the grade should be located by a downhill survey. This is always the case when a pass or saddle is the salient high point. When the grade connects two such salient points the location may be run in either direction. 


\section{Marking Grade Line.}

The grade line, as finally determined, should be marked with stakes, or by disturbance of the ground surface, cutting off saplings, or in some other manner. Ordinarily the marks should not be more than 50 feet apart. On broken surfaces there should be a mark at the point of each angle, in order to keep the grade uniform. On trial lines marks should be as few and as inconspicuous as will serve the purpose. Stakes, of course, can be removed from the trial line, but obviously the blazes must remain, and so should not be of a character that may mislead construction crews or trail users.

\section{Uniform System.}

The permanent line, however, should be very plainly marked, so that the trail-building crew will have no difficulty in following it. On the same piece of work definite and uniform practices should be followed in establishing the marks, so that their interpretation will never be in doubt. For instance, in situations where side cutting is to be done, the stake should mark the outside of the tread. If unusual conditions make it necessary to deviate from the regular practice, explanatory notations should be conspicuously placed on the stake. At sharp turns, such as switchbacks, a distinctive mark should be placed on the stake, so that no time will be lost in readily following the line.

\section{Promiscuous Blazing.}

A word of caution against too much blazing will not be out of the way. Promiscuous blazing through the forests is very confusing. There is a tendency among forest officers, particularly new men, to decide without thorough reconnaissance that an ideal trail route has been discovered, and then to blaze it heavily, only to discover afterwards that the route is impracticable. A trail must not be blazed except very lightly until the exact route has been definitely decided upon after thorough examination. Very light chips of the bark are permissible for temporary work, but nothing in the way of blazing which exposes the sapwood to any extent.

\section{F. S. Standard Blaze.}

The Forest Service standard blaze for completed trails is one not less than 8 inches long cut below the sapwood and with a single notch cut just above the blaze.

\section{CONSTRUCTION.}

EXPLANATION.

It is decidedly difficult to prescribe rules or to outline methods of construction which will fit all the varying conditions encountered in e trail work. The methods and type of construction used must be modified to fit conditions as well as the class of trail under construc- 
tion. The instructions given in this chapter should be applied with a degree of judgment and common sense, and should not be followed blindly. Standard methods are outlined which have proved their worth in the great majority of trail projects. It is important to follow the specifications and the methods here presented unless it is clearly apparent that they do not fit the case. The responsibility for poor results, however, must rest squarely upon the forest officer in any case where these instructions are modified.

\section{THE CREW.}

Where improvement work is done by men specially employed for it, the selection of a crew is important. Trail building requires the services of very few skilled workmen. Common laborers as a rule are satisfactory, although where much rock work is expected two or more thoroughly experienced rock men who understand the use of explosives and know how to sharpen tools should be included in the crew. Every man should be physically fit, ready and willing to undertake any line of work assigned.

\section{THE FOREMAN.}

The foreman should have experience in all branches of trail construction, able to "make a hand" in any part of the work, and should know how to handle men. He must be energetic and resourceful, possessed of tact, good judgment, and executive ability. He must be able to subordinate his own ideas to those of his superior officer. He must not vary the location of the trail as blazed and staked out, without the permission of the district ranger or the supervisor. He should have full authority in the field to discharge any man found inefficient or otherwise unsatisfactory. He should be given entire direction of the work, subject only to the supervisory control of the forest officer in charge. He should receive written instructions covering his general duties and defining his authority. On important projects, he should be required to keep an accurate daily record of work done and to submit, on forms furnished for the purpose, reports of progress at stated intervals. One of his important duties is the keeping up of an adequate supply of provisions and equipment, but it is equally important that he cause no unnecessary expense by overstocking. The selection of camp sites at the most advantageous points will require his personal attention. $\mathrm{He}$ should make rules for keeping the camps in sanitary condition and enforce them inflexibly.

\section{THE COOK.}

Next to the foreman, the cook is the most important man in a trail crew. He should be an experienced camp cook, and too great care can not be exercised in making the selection. One essential in 
the cook is absolute cleanliness about the camp. Lacking this, any cook is a failure. He should keep a careful account of supplies and furnish the foreman with a statement showing their condition at stated intervals as required. Economy in the use of supplies must be insisted upon. Wastefulness on the part of the cook runs up the cost of a project amazingly and can not be tolerated. When the crew is engaged more than 1 mile from camp, the cook should prepare dinner and have it delivered to the men on the job.

\section{ORGANIZATION.}

Where improvement work is done by guard labor, incidental to regular patrol duty, the ordinary discipline in the ranger district should be carefully observed, and it is especially important that one officer should have unquestioned authority to control the assignment of men and to direct all operations. Much confusion and friction and loss of efficiency often arise from having numerous officers of the same grade engaged in one undertaking, unless the supervisor designates unmistakably one man as the boss.

The number of men in a crew varies from 2 or 3 to 12 or 15, depending upon the character of the work. Under ordinary conditions requiring side-hill grading and little or no rockwork, a crew consists of 10 men grouped as follows: 1 foreman, 1 cook, 1 packer, 2 swampers, 5 graders. A smaller number will not be adequate for all the needs of the work, and a larger force will necessitate such a scattering of the men as to make good supervision by the foreman difficult. On most large trail projects the entire crew is engaged first on one kind of work, then on another. As a general rule, specialization does not bring the best results.

Where no grading or heavy rockwork is involved, four men make an excellent crew. If the work is comparatively light, two men are sufficient. One man in each of the small crews will be placed in charge, usually with a little extra pay, unless he is a regular forest officer. For crews of less than five men it does not pay to employ a cook. Where no regular cook is employed, the foreman should appoint one man who will divide his time between cooking and working on the trail. This plan has been found to be a time-saver; it also keeps the men in good spirits.

Whether or not the men in small crews are furnished with food supplies or hired with the understanding that they will grub-stake themselves is a matter of individual preference. It is usually better for the ranger or other regularly employed forest officer to pack supplies to such crews, but if not convenient, one man from the crew may be allowed time consumed in this way. 
CAMPS.

Camps should be selected as near the work as possible. Where the nature of the ground will permit camps should be established approximately 1 mile in advance of the front of the job. This will allow operations to be carried on 1 mile each way from the camp, and obviate long walks by the men and carrying of dinners into the field. Pits should be dug in which to bury all kitchen and other refuse. This preparatory work should all be done by men detailed for the purpose before the move is made. Throwing slops on the earth near the kitchen or into near-by streams must not be allowed. Chloride of lime or some other disinfectant should be used in every camp for disinfecting the refuse to prevent disease. A most necessary sanitary precaution is the complete screening of all refuse pits and toilets from flies.

\section{MOVING CAMP.}

The moving machinery must be so organized that breakfast can be prepared at the old camp and the new one established in time to prepare supper for the crew at the regular time. The cook, aided by the packer and one man from the crew, can usually move camp quite easily in one day, each move being for but a short distance. On moving days dinner must be prepared in the morning and taken to the field by the men, who should also, before breakfast, put their impedimenta in shape for cargoing and strike and roll their sleeping tents for packing. Sleeping tents should be pitched in the evening by the men who are to use them after the move is made. Cook and mess tents should be pitched by the cook and his helper.

\section{CLEARING.}

The width of clearing should be sufficient for the easy passage of loaded pack animals. The standard widths appear under the general specifications, but these must be modified at times to meet local conditions. While the line of definite location should be very closely adhered to in clearing, cost which is not fully recompensed by utility should be avoided. For instance, large trees on comparatively level stretches should not be cut merely because they happen to stand on or near the line, for the trail may commonly be curved around them. In most of such cases it will be found that the wearing away of the humus due to the use of the trail will so expose the root swelling that pack animals will veer away from the stump for the sake of better footing, and that the trail is in no way benefited by the removal of the stem. In hillside grading, however, large trees on the line should be taken out, root and branch. On hillsides the lower side of the clearing should be close to the tread line. Where the trail passes over practically level ground the tread line should mark the center line of clearing. 
All logs should be cut out to full standard width of clearing and rolled to one side out of the way, on the lower side of trail if on uneven ground. It is sometimes advisable, if a wagon road is anticipated, to cut the logs to standard width (12 feet) for a wagon tread, since this involves comparatively small additional expense. Decayed logs should be cleared away by grub hoe or mattock to full width of the right of way and the rotten wood scattered. Dead trees and snags standing near the right of way in such a position that they may fall across the trail should be removed at the time of construction. It can be more cheaply done then than later after the tree has fallen. Neglect of this precaution will often materially increase the cost of maintenance. All brush and undergrowth above the tread line should be removed for a distance equal at least to the ordinary height of the mature brush. All brush within the tread should be grubbed out. Seedlings and saplings should be cut off a little below the surface of the ground. Roots crossing the trail on level ground should be grubbed out at least 1 foot on each side of the tread; on hillsides roots should be cut off flush with the bank.

Ordinarily stumps will not be removed. They should be left not more than 1 foot high to avoid rubbing side packs or saddle stirrups. On hillsides, however, every stump touching the lower edge of the tread must be removed; stumps located 12 inches or more below the lower edge and which do not interfere with the maintenance of a smooth tread are useful to help hold the fill or banker logs.

\section{BRUSH DISPOSAL.}

The débris resulting from clearing operations must be disposed of, and the best way to do this is to burn the brush at the time of construction. Where this is impracticable, pile the brush so that it can be readily burned during favorable weather conditions, and save sufficient money to cover the cost of burning later. No unnecessary delay will be tolerated. For class A trails this requirement is absolute; for classes $\mathrm{B}$ and $\mathrm{C}$ trails the piling and burning of brush will be the standard practice.

\section{TREAD.}

Locations extending along hill slopes require more or less side cutting. If the slope of the hillside is 20 per cent or less, side cutting will, in the majority of cases, be unnecessary, except in locations subject to ice glazing during any period of use. Along very steep slopes it is obvious that the width of the tread must be increased in order to permit packs to clear the bank. "Tread," as used in this manual, is the width of the trail on solid foundation and does not include any part of the fill. A maximum tread of 48 inches is sufficient, however, even in rockwork, and in most cases it should be much less. Fifteen inches is the minimum set for class A trails, since this width is more $93418^{\circ}-15-4$ 
than compensated by the increased efficiency of pack animals. Ii no case should the tread be made wider than necessary, since this $i$ one of the most expensive parts of construction. The tread shoul, have a slope toward the hill of about 1 inch per foot.

\section{GRADING.}

The cut bank must be sloped sufficiently to prevent the sliding $\mathrm{i}$ of earth and stone from the upper side. The angle of repose varif according to the character of the ground. The steepest bank (abov $1: 1)$ can be had in stiff clay; next in degree of resistance is eart or earth and stone, and least sand, where $1 \frac{1}{2}: 1$ is found by exper ence to be about the natural slope. A flatter cut bank than usual required in localities where alternate freezing and thawing have tendency to cause slides.

The material excavated in side cutting should be deposited at tr lower side of the tread in such manner that it will be piled up slight?

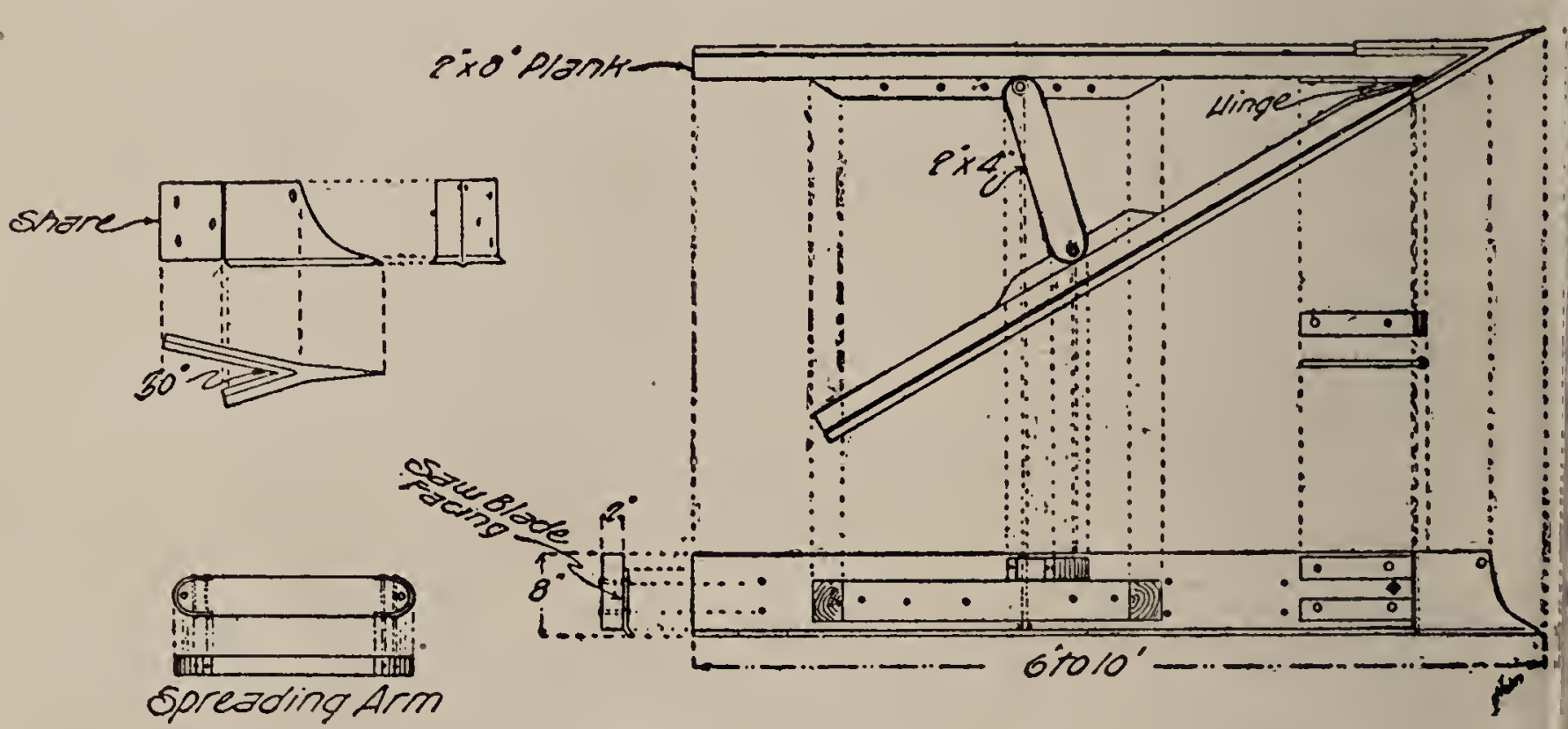

FIG. 3.-Trail drag.

above the surface of the tread when settled. The excavated mater will settle about 10 per cent in volume, and this should be consider when the work is being done. Along this fill at the outer edge of $t$ tread it is well to lay any large stones obtained in the course of $d$ ging to serve as a guard to prevent horses walking along the fill a destroying the edge of the trail. In default of stones, small poles: similar obstructions may be used. The use of supporting logs bankers on hillside grades should be avoided where suitable stone available for retaining or supporting walls, especially in class $A$ tra Where it is impracticable to secure stone, logs may be used. Th should always be peeled to prevent early destruction by insects a so placed as to have as firm a foundation as possible. Whene practicable the upper side of the $\log$ should be close to and a lit above the outer edge of the tread. For placing logs a block and tac is one of the best appliances that can be taken into the field by a tr 
4 nstruction crew. It is absolutely essential in trails of classes $\mathrm{A}$ and and of courso desirable in class $\mathrm{C}$ trails, that the tread be on solid rth or rock, entirely independent of a banker.

\section{MATTOCK WORK.}

Most of the grading work is done with mattocks. To keep the sad uniform, a competent man, in most cases the foreman, should rk ahead and break down the tread, marking the lowest point on e bank to which the crew will excavate. The amount which he ould break down will depend upon the size of the grading crew and e character of the soil. Certain length sections or units, preferably out 50 feet, should be established, and each man of the grading ew assigned to one section. This makes an even distribution of ork, and no discordant features will enter into the crew organition.

\section{PLOWS AND GRADERS.}

Under favorable conditions, effective and cheap hillside grading $\mathrm{n}$ be done by means of a special-ironed reversible hillside plow, trail drag or grader, and a team. The plow is sufficiently light and ong to be used either with one horse or two horses, harnessed abreast tandem. Furrows are plowed and the earth is moved by means of A-shaped drag or grader (fig. 3). The use of such an outfit is, of urse, extremely limited, depending on the slope of the hillside, the mposition of the soil, and the ground cover. The diagram of the drag shows clearly the method of construction. The plow can be irchased through any good implement house.

\section{SWITCHBACKS.}

The chief objection to switchbacks is the sharpness of the turn. sharp turn is objectionable on level ground, and is even more so a sidehill, and is exceedingly wearing on pack animals. If a switchck is found necessary, it should be made so that a horse can walk ound the turn instead of having to "pivot" around. Turns ould be made level and with a minimum radius of 4 feet. (Figs. 4 d 5.) The grade of the trail approaching and leaving the turn ould not exceed 5 per cent for a distance of a few yards. A guard, il should be provided for a short distance along the lower side of the ad, inmediately above the turn, to prevent pack animals from aking crosscuts and injuring the grade. The turn should never made around a tree.

\section{DRAINAGE.}

Neglect of the drainage at the time of construction may mean aclious damage and increased cost of maintenance. What appears a mere damp place in the tread or the cut bank at the time of con- 
struction will eventually develop into a well-defined mudhole when the trail is in use. Structures for drainage scrve two purposes:

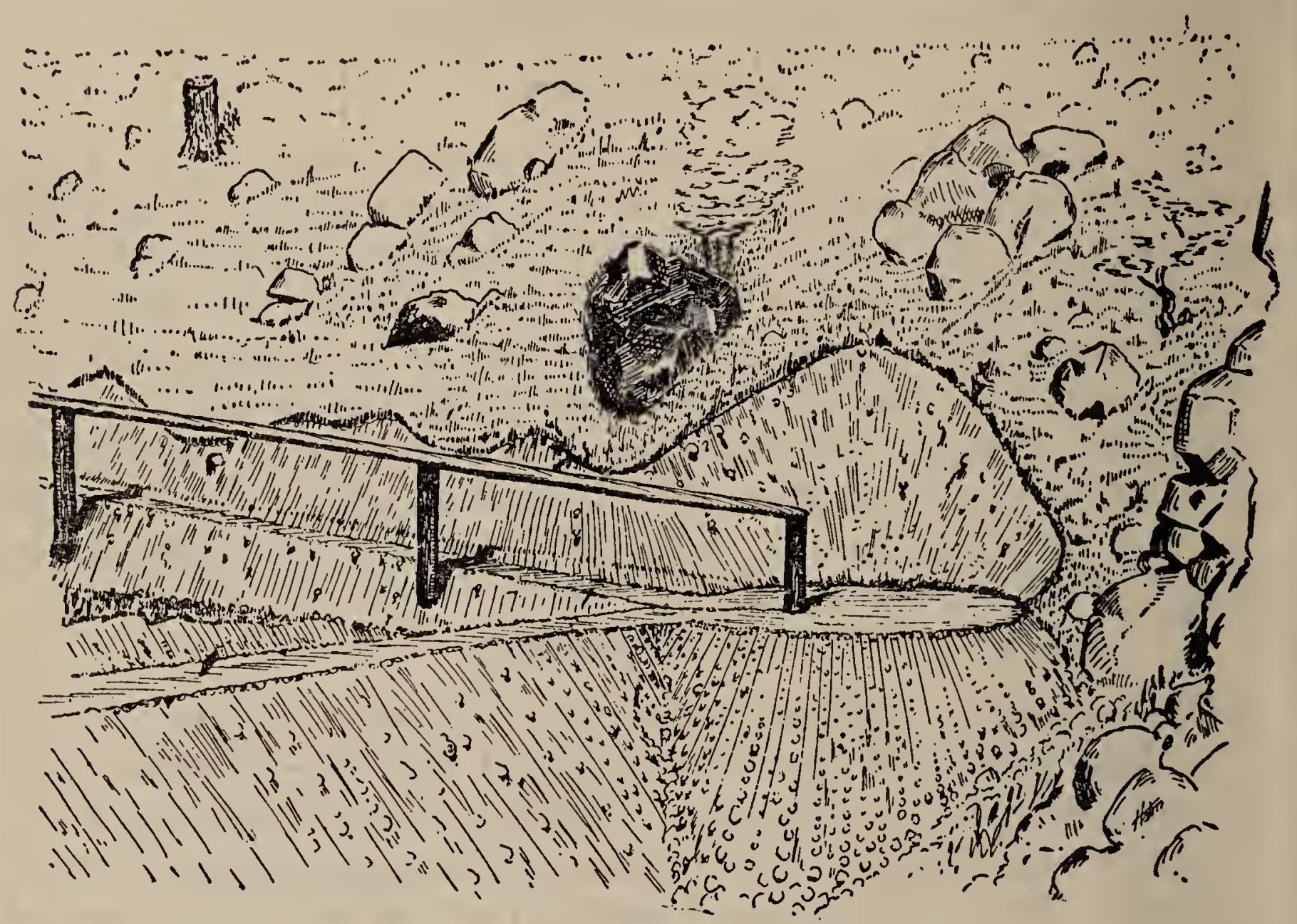

FIG. 4.-Switchback with level turn and guard rail.

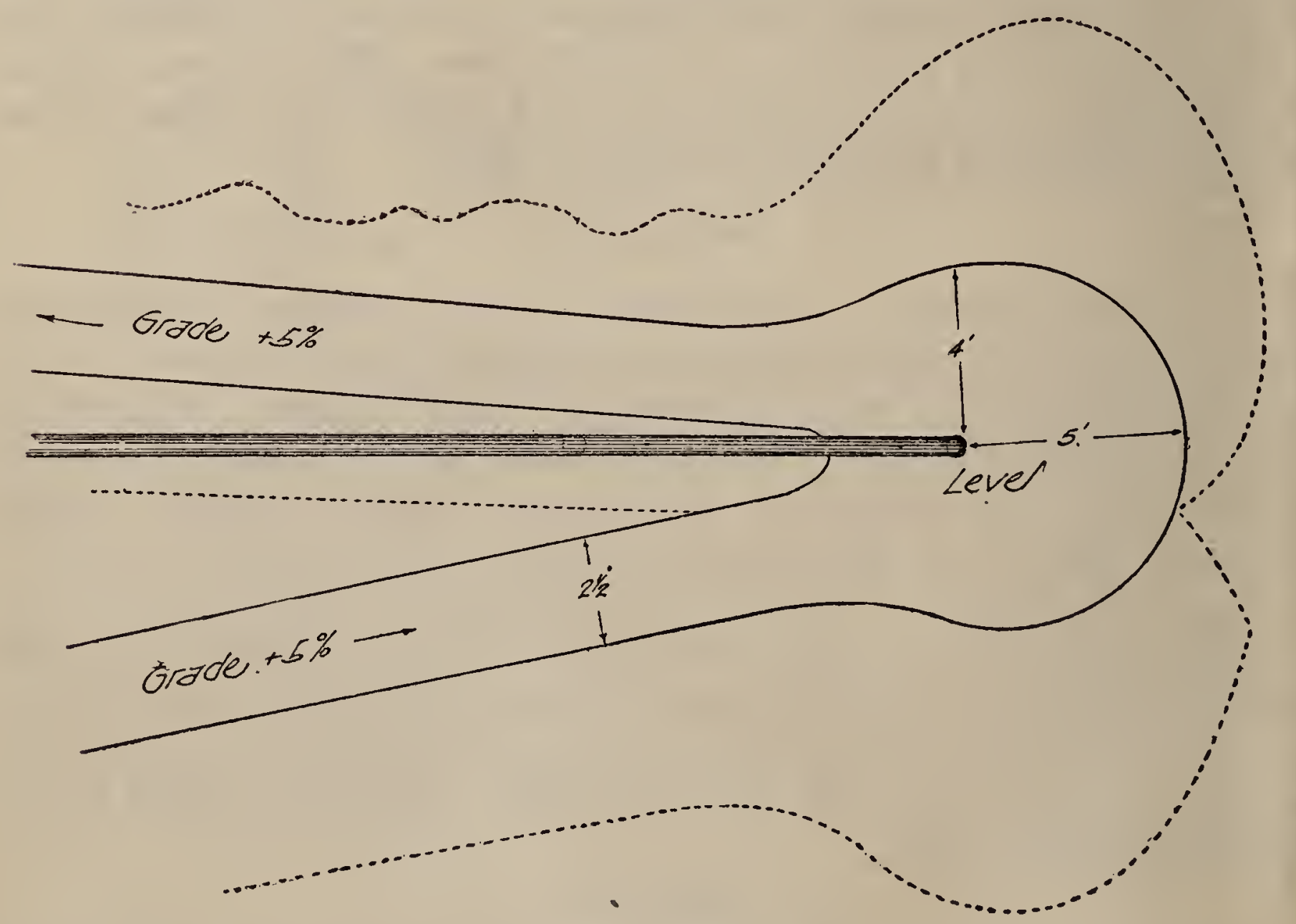

FIG. 5.-Plan of switchback.

(1) To carry off surface water, and (2) to carry water in its natural or forced channel. The first purpose is best served by water bars 
or open conduits, and the second by means of culverts, bridges, and open ditches. Where drainage is not feasible, corduroy must be used. The subject of bridges is treated in a separate chapter.

WATER BARS.

A water bar is a $\log$ from 6 to 10 inches in diameter and from 3 to 5 feet long, laid slanting across the tread. It should extend far enough

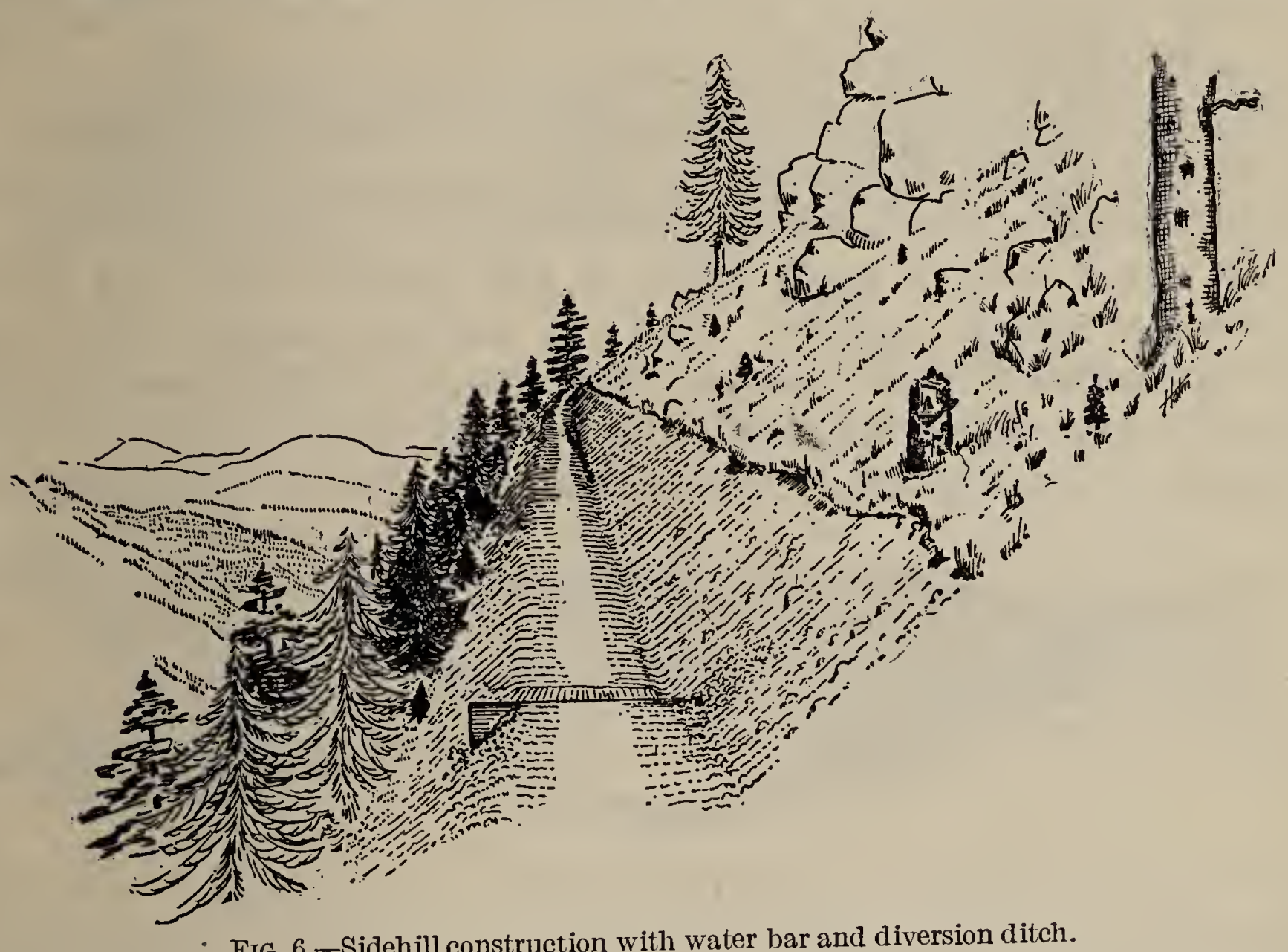

FIG. 6.-Sidehill construction with water bar and diversion ditch.

beyond to prevent the undermining of the trail by the backwash of water. (Figs. 6 and 7.) The earth should always be very firmly
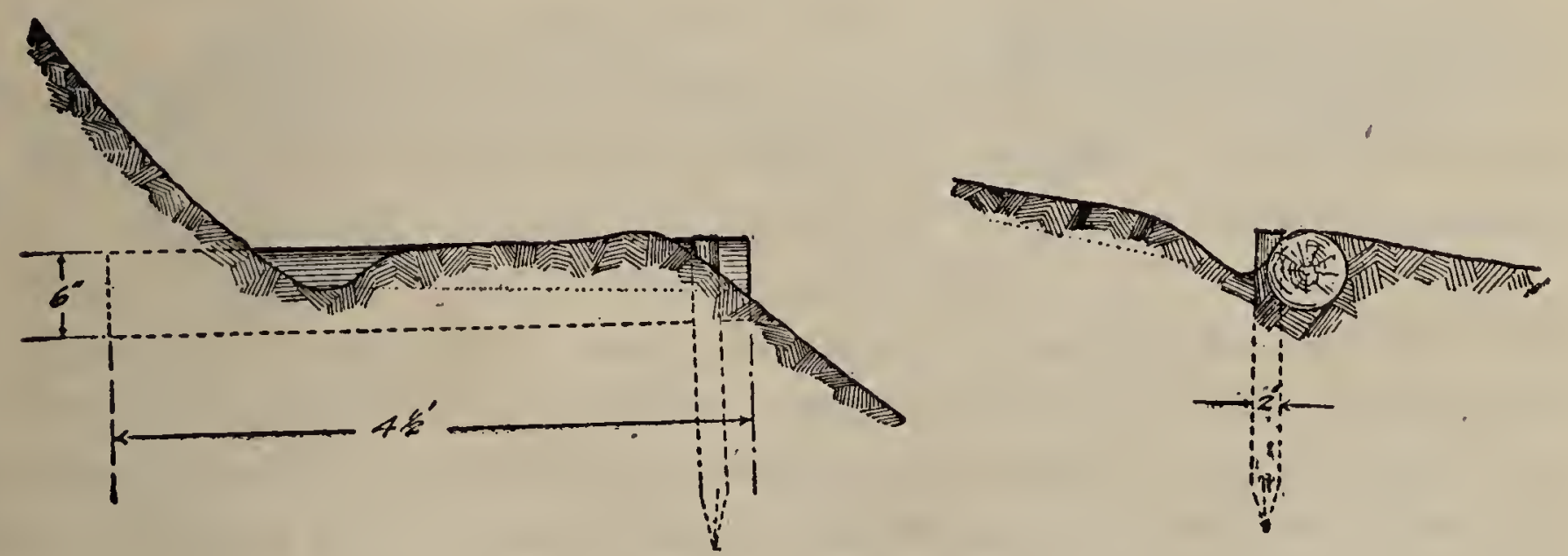

FIG. 7.-Detail of water bar.

tamped around the log. Water bars should be used at every sag and turn in the trail where water would ordinarily run along the tread, and on straight stretches, at the bottom of steep grades, and at points where there is a material change in the per cent of grade. On graded trails along open sidehills water bars should be placed about 100 yards apart to prevent serious washing of the tread. In regions 
subject to sudden and heary rains, bars should be placed close together and should be of relatively large size.

Where trails follow contours in crossing draws, give the trail slight upgrade each way from the watercourse.

CULVERTS.

Culverts are used for carrying more or less permanent water, sucl as small streams, springs, and drains, or for mudholes and swamps In reality a culvert is a small bridge. For convenience, however, $i$ will be defined as a covered passageway for water with a span of no1 more than 4 feet. Structures for spans greater than this will be con. sidered bridges. The ordinary culvert (fig. 8) is usually sufficient for trails. One may be easily made of logs closely fitted and wired. pinned, or spiked together. The wall logs are usually quite large and embedded to about one-half their diameter. The earth or rock about them should be firmly tamped to prevent erosion. The stringers are laid in notches in the wall logs, and are in turn covered

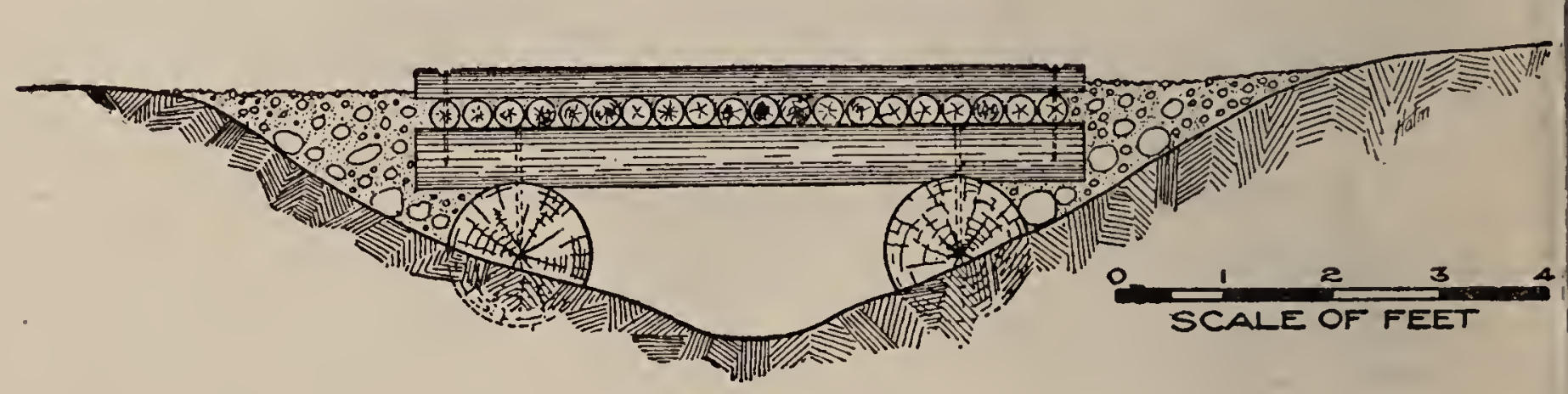

FIG. 8.-Tog culvert.

with poles 4 or 5 feet long, and closely laid at right angles with the line of the trail. The top of the culvert should be level, the bottoin being sloped to give the required fall.

OPEN DITCHES.

It frequently happens that the tread of a trail can be kept in good condition over a section of wet ground requiring corduroy by digging drainage ditches on one or both sides and leading the water to a convenient waste. This alternative should be given careful consideration before undertaking to build corduroy. The use of this method of drainage depends upon the practicability of securing a convenient waste point, and to some extent upon the character of the soil and the proximity of surfacing material. A solid-earth tread is much more permanent and is preferable to any form of corduroy if it can be obtained at reasonable cost.

The depth of the ditches will depend somewhat on the nature of the ground; commonly 18 inches will be adequate. It may sometimes be advantageous to dig these ditches quite deep and fill them with small stone and gravel, thus forming a blind drain. The excavated 


\section{PUNCHEON-BRIDGE CORDUROY.}

Two stringers not less than 8 inches at top end should be laid parallel with the line of trail and 4 or more feet apart on ceinters. They should be as long as convenience of handling will permit, and should be embedded in the ground at least to a depth equal to half their diameter, and given as nearly a uniform bearing as possible. On these stringers flooring of poles not less than $4 \frac{1}{2}$ inches thick and from 6 to 8 feet long should be laid. The practice of laying split poles with the flat and round surfaces alternately uppermost is not to be commended. The unevenness of the pieces is very likely to cause displacement in use, with resulting dangerous holes in the floor. A better way is to size the edges of the pieces so as to make close, clean joints and lay them all with the round side up, assuring a good bearing on the stringers and a relatively uniform surface. On top of the flooring the poles should be pinned or securely wired to the stringers. Where the corduroy requires more than a single length of stringers, reenforcing timbers not less than 10 feet long should be laid close to the stringers, with the middle of the timbers opposite the joints in the stringers, and on the side next to the middle line of the corduroy. Earth should be thrown along the center line of the corduroy to a depth of 2 or 3 inches and also at the ends of the corduroy to make small ramps sloping gradually from the floor of the corduroy to the solid ground. The important factor in the construction of this type of corduroy is the pinning of the parts closely together, to prevent any slipping. 'Two good stakes driven at each end assist in preventing the spreading of the floor poles.

SPLIT-LOG CORDUROY.

Sills not less than 14 inches in diameter and 10 feet long should be placed at right angles to the course of the trail, about 10 feet apart, and firmly embedded in the earth to about one-half their diameter. The flooring should consist of logs laid parallel to the course of the trail, flattened on the upper surface, all of the sapwood removed, and securely notched into the sills. Flooring logs should have a top diameter of not less than 10 inches, and the number used will vary from two to five, depending upon the class of trail. In addition to the hewed or split logs used for the floor, guard logs unhewed, not less than 12 inches in diameter, should be placed on each side of the flooring and securely notched and spiked (wired or pinned will do) into the sills. The flooring should be covered with from 2 to 6 inches of dirt. This type of corduroy if carefully made with large logs will prove very satisfactory. Lengthwise corduroy made of poles is unsatisfactory and dangerous. The use of the split-log corduroy is only limited by the size and character of available timber. Large, straight $\log _{\mathrm{s}}$ are absolutely essential. 
EMBEDDED-LOG CORDUROY.

Two parallel ditches (one may be sufficient in some cases) should be dug on each side of the tread about 8 to 12 feet apart, depending ad upon the width of the proposed corduroy. Their depth will depend alf upon the character of the ground, but 18 inches will ordinarily be sufficient. The excavated dirt should be thrown to the center and the ground leveled. A drainage ditch should then be dug across the tread, leading the water from the side ditches to a waste point below the trail, and a culvert installed. Corduroy timbers, varying in length from 4 to 8 feet and not less than 6 inches in diameter, should then be placed across the tread and firmly embedded in the dirt. No stringers or sills will be needed. After all the timbers are placed in position, two posts or stakes should be driven at each end of the corduroy, to prevent spreading. Poles about 8 inches in diameter, securely wired at the ends should then be laid at each side as in the puncheon-bridge type. Unless the surface of the ground on which the corduroy timber is placed is unusually even, it will be necessary to use comparatively short-length poles in order to secure an even bearing. The practice of merely throwing poles across the mudhole at right angles to the course of the trail should never be permitted.

\section{BLAZES, GUIDEPOSTS, SIGNPOSTS.}

Wherever trees are available, blazes at least 8 inches long should be placed in view of each other on both sides of the trail. At least every 4 rods the standard Forest Service notch should be used. If trees are scarce and the trail is not otherwise easily distinguishable at all seasons, guideposts or stone monuments should be set so that each will be in plain view from the preceding one. This is particularly necessary where the trail crosses open grass land, and it is difficult for those unfamiliar with the route to determine where it reenters the timber. Legible signboards should be placed at each branch and intersection, giving full information of places of importance, distances to the next watering place, cabin, roadhouse, town, or settlement. It is desirable, but not necessarily required, that mile marks showing the distance from each terminus of the trail be established by means of signs or posts. Unpainted wooden signboards should never be used unless the letters are cut or burned into the wood at least one-eighth inch deep. Signboards made of galvanized iron, lettered with black paraffin paint, are more durable, lighter, and more easily packed than those made of wood. They may be made from sheets of galvanized iron 14 by 18 inches. A 2-inch strip on the top side of the sign, bent at right angles to the face of the signboard, $93418^{\circ}-15-5$ 
serves as a ledge to turn water and to keep the face of the sign free from pitch. This leaves a lettering surface 12 by 18 inches, which is sufficiently large for ordinary letters 1 inch high.

ROCKWORK.

The discussion of this subject of rockwork is divided into two general heads, Slide Rock and Solid Rock. The latter, which involves also a discussion of explosives, ${ }^{1}$ will be given the more detailed consideration.

RUBBLE SLIDES.

These are the ordinary rock slides encountered in trail building. Where the trail crosses them (fig. 12), the loose stones should be

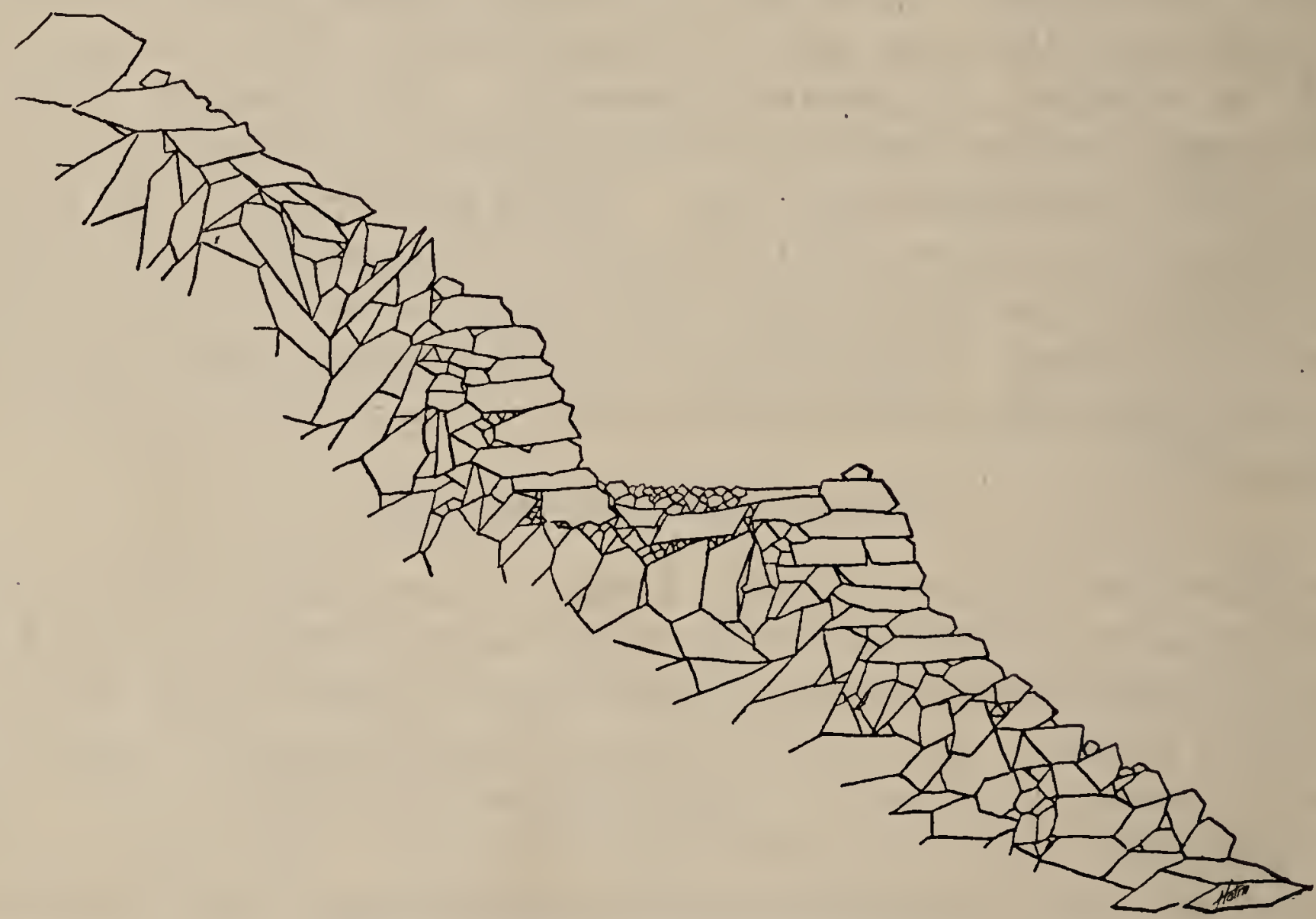

FIG. 12.-Retaining walls through rubble slides.

picked out and thrown below the line. The work should begin a little below the actual grade line on the outer edge of the tread, taking out the larger stones and leaving the smaller ones to form the surface of the tread. As the work progresses back into the slide, finer material will accumulate, and by the time the trail has reached standard width and the bank assumed a natural angle of repose the surface will have become fairly smooth and free from large stones. When duff can be readily obtained it should be used to top-dress the surface. If duff or earth is not available, rotten wood forms a pretty good substitute. Rocks too large for convenient handling can be easily removed with a block and tackle, or with a team, or with both.

\footnotetext{
1 Detailed instructions for the use of particular explosives will be furnished by most of the powder companies from whom purchases are made. Attention is also called to Bulletin 17, Bureau of Mines, Department of the Interior, "A Primer on Explosives for Coal Miners."
} 
Where a slide of rock or gravel is encountered, the surface of which is near the angle of repose, it is sometimes advisable to build a retaining wall along both the foot and back of the trail. Where rocks of suitable dimensions form part of the débris, this can be done by simply moving the larger rock into place (fig. 12). Less work will be involved if the trail is worked only from one side, since this will reduce the danger of slides while the work is in progress and no shifting of grade will be necessary to make a connection. The batter of back walls should be as great as conditions will allow. Where the material (gravel or fine rock) is unfit for the construction of retaining walls, cribwork, though less satisfactory, may be substituted. The

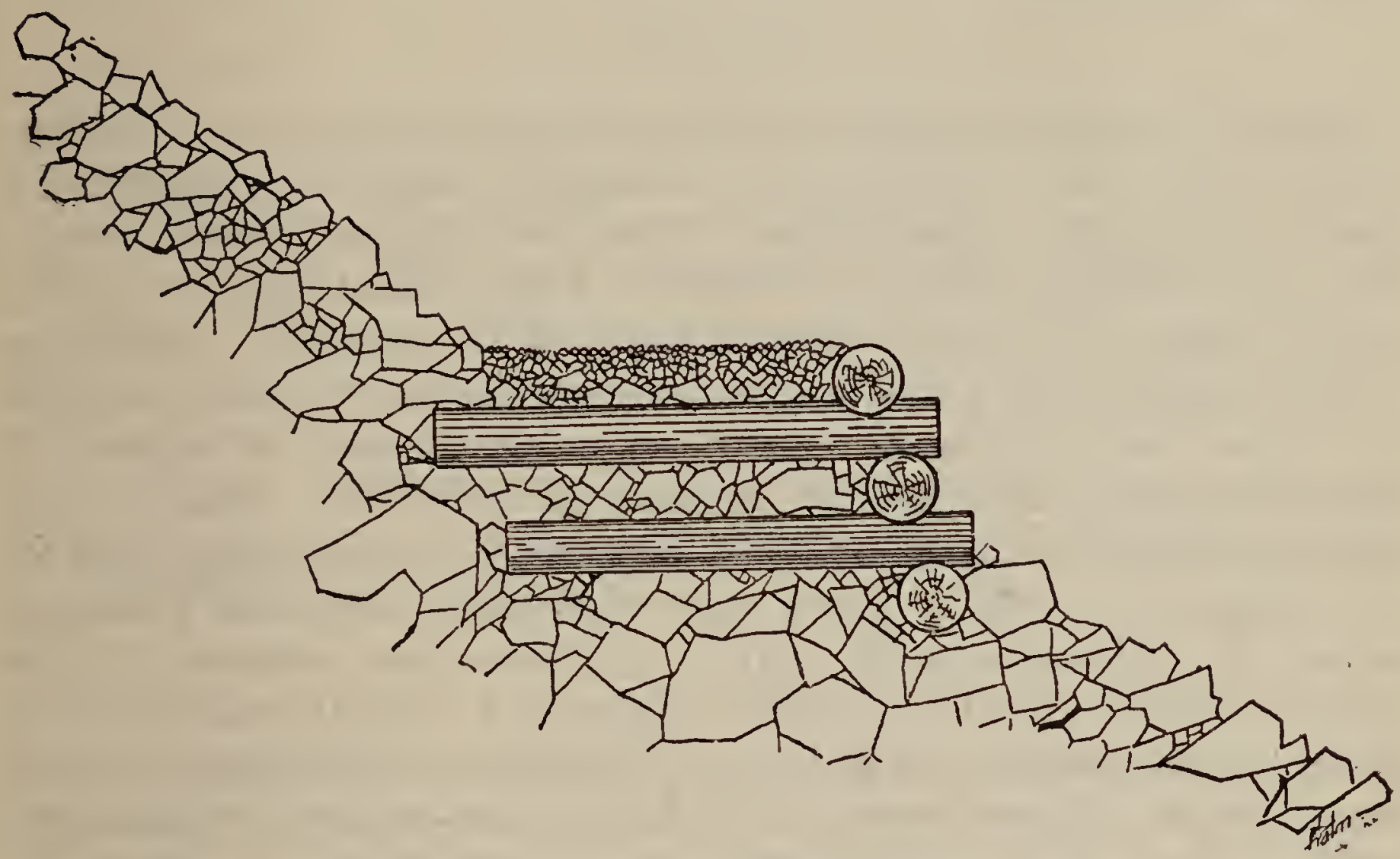

Fig. 13.-Cribwork through rubble slide.

drawing (fig. 13) illustrates the plan of construction. Do not attempt to lay the logs on the slide rock direct. Prepare a trench for the first log; between it and the second $\log$ extend a tie-plate into the hillside, and continue this between each round of logs. In very loose material the tie-plates should extend well into the hill, and must not be more than 10 feet apart. They should be well spiked or pinned to the crib logs. The space between the hill and the crib should be filled with rock, and a cushion laid over the tread. Where the earth must be moved more than a rod in securing top-dressing, a wheelbarrow should be used.

RETAINING WALLS.

It is always preferable, on "account of the danger of fire, to use stone for the supporting and retaining walls, wherever it is available. Special care should be taken to see that the footing or foundation for 
the wall is firm and even. A shallow trench in the hillside, where the base of the wall will rest, commonly serves the purpose if the bottom of the trench is in solid earth not exposed to erosion. Where the wall must rest on stone foundation it is highly important that the foundation slope toward the hill. No mortar or other binding material is needed to hold the stones together. Careful placing, so that the stones (rubble) will bind each other, is sufficient. The footwalls should have a batter of about 2 inches to 1 foot. Often, where blasting is in progress, the charges used may be so regulated that the rock loosened will not be thrown a great distance, but kept close at hand for wall building. This point should receive careful attention from the construction foreman. Close supervision is required with inexperienced labor.

SOLID ROCK.

Where the rockwork involves the use of explosives, real expense begins. Here the necessity for thoroughly competent, experienced men is imperative. Inexperience or lack of judgment means excessive cost and unsatisfactory results. Where blasting is required, special study of the character of the rock is essential. Variations in the hardness of the rock require changes in the tempering of drills and other tools employed, modifications of the size of charges of explosives used, and difference in depth of drill holes. Whether the rock is solid or "seamy," stratified vertically or horizontally, igneous or sedimentary, will in many cases determine how and where to attack it, and indicate the sort of explosive best adapted to the work in hand. It is not possible to give in a manual detailed information or instructions to guide the workman in this branch of trail construction. Every section of rockwork has its own peculiarities, and experience alone can suggest the most effective methods in disposing of it.

\section{EXPLOSIVES IN GENERAL.}

To many persons powder is powder, no matter of what make or composition. For this reason it may be well to discuss briefly the different grades and composition and their use. Black powder is most effective where the rock or earth is homogeneous, and a slow, heavy lift is required. Fine-grained black powder acts more quickly than the large-grained powder. In deciding on the kind of powder to be used, weight should be fully considered. Where doubt exists as to the relative efficiency of black and giant powder for certain work, the latter should be used, since it is several times more powerful than the other, and the difference in price is more than compensated by the relative weight. 
GRANULAR BLACK POWDERS.

Several explosives are manufactured intermediate in strength between ordinary black powder and dynamite. These are granular black powders and contain from 5 to 20 per cent nitroglycerine. For best results they should be closely confined and exploded by using the ordinary cap and part or all of a cartridge of No. 2 dynamite. These black nitro powders are sold in $6 \frac{1}{4}$ and $12 \frac{1}{2}$ pound bags, four and eight bags to the 50-pound case. In wet places it is necessary to use waterproof bags to protect the charge. Care must be exercised in placing the fuse, as these explosives are all highly inflammable and will burn without exploding.

GIANT POWDER.

Giant powder (nitroglycerine explosive, or dynamite) is manufactured in various sizes and qualities, the grade being based on the per cent of nitroglycerine present. The common grades are 20,40, and 60 per cent, but it may also be obtained in 10,15,30, and 35 per cent grades. Sixty and 40 per cent, or No. 1 and No. 2 powder, commonly comes in sticks $\frac{7}{8}$ by 8 inches. Forty per cent, or No. 2 powder, is the best for all around use. For stumps and soft material No. 3 (20 per cent) is by far the best.

The 40 and 60 per cent grades are the ones most commonly used. Eighty per cent powder is quite sensitive, and accidents in packing and handling it are likely to occur.

\section{SELECTION OF POWDER.}

The character of the rock to be worked largely influences the selection of the grade and kind of explosive best suited to the job. Generally speaking, the harder and solider the rock, the "quicker" should be the powder, such as 60 or even 80 per cent giant. Loose or porous rock, like much of the basaltic material found in many places, is most effectively handled with deep holes and slow powder, nothing quicker than 40 per cent giant, or frequently 20 per cent giant, or common black blasting powder. Where the holes are deep, it is well to use quite small charges, one-half a stick or so, of quick powder to "spring" the hole, that is, shatter or pulverize the rock at the bottom of the hole, and so make room for a large charge of slower powder for the main work.

FUSE AND CAPS.

It is always desirable to use three-ply waterproof fuse, since this is not injured by dampness and the powder train in it is not apt to become broken when the fuse is bent. No grade of caps lower than 
XXXXX should be used to detonate high explosives, and with some powders XXXXXX or XXXXXXX must be used to get complete lifting power. Low-grade primers are often responsible for poor results. The black nitro powders especially require high-grade caps. In general, the fuse and caps recommended by the manufacturer for use with an explosive will give best results and should be used unless others are known to be more satisfactory.

THAWING POWDER.

In cold weather giant powder must be warmed or thawed before use. It freezes at $45^{\circ} \mathrm{F}$. (certain brands will stand a temperature of $35^{\circ}$ ). If heated too much it is likely to ignite and burn up, or under certain conditions to explode prematurely. One way to thaw frozen powder is to place it in a metal vessel which can be suspended

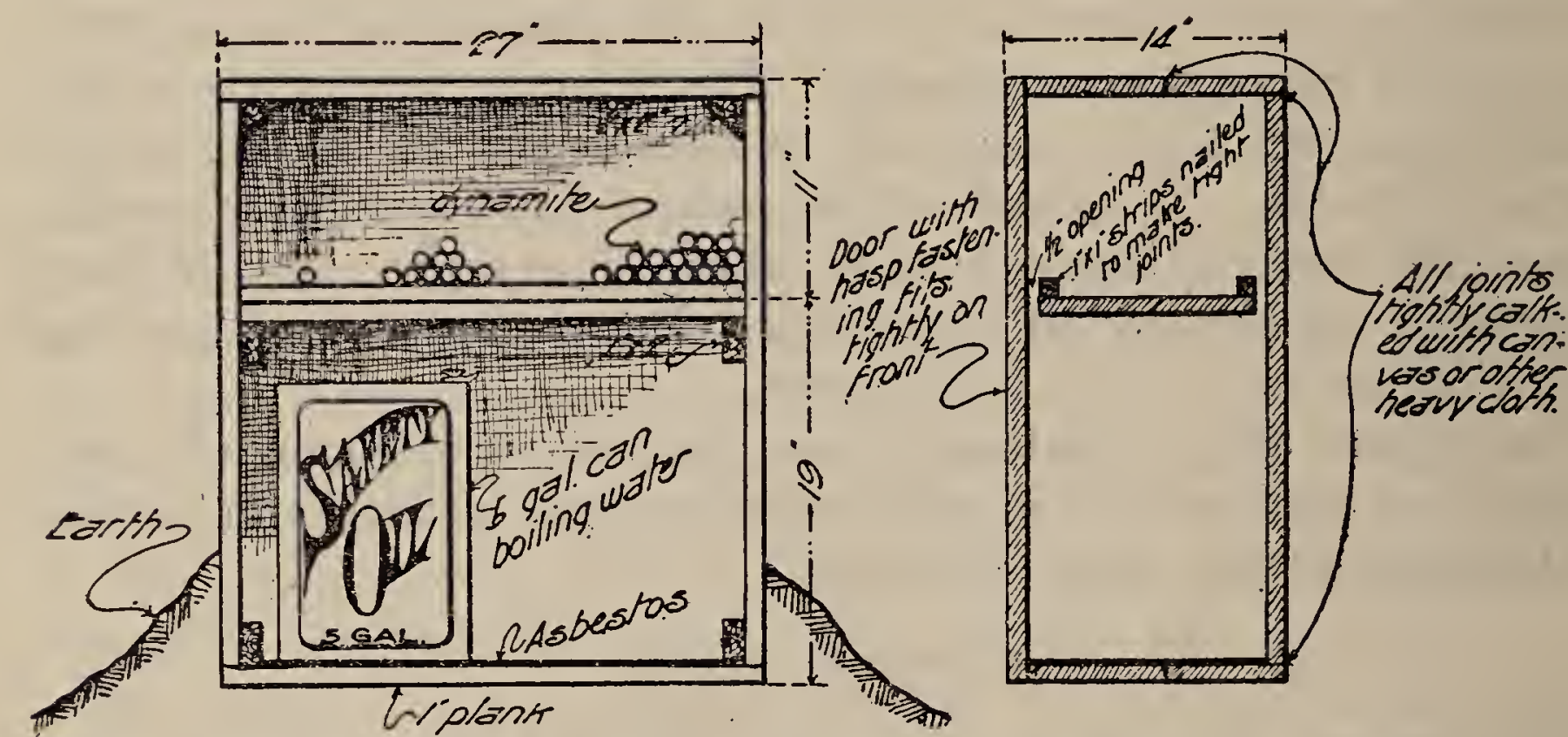

FIG. 14.-Plan of powder thawer. Sufficient size for 100 pounds of porrder and two 5-gallon water cans. By use of several cans successively heated over fire, powder can maintain high temperature in powder chamber with perfect safety.

in a larger one containing warm water. The temperature should not be greater than can be endured without discomfort by the bare hand. Never attempt to use frozen powder until it has been exposed to heat long enough to make it soft throughout.

Figure 14 illustrates a cheaply constructed and convenient receptacle for thawing dynamite in cold weather. It consists of a box of 1-inch lumber built in two compartments, with a hinged front. In the upper compartment sufficient space is provided for about 100 pounds of dynamite. The lower space is large enough to contain two 5 -gallon oil cans. All joints are tightly calked with cloth. Earth is banked around the bottom of the box, except in front. The oil cans filled with water are heated over an open fire and set inside the box. The heat radiated is amply sufficient to thaw the powder. Usually several oil cans are used, so that some may be heated while the others are in use. A strip of asbestos or other noninflammable mate- 
rial is usually placed upon the bottom of the box to prevent its ignition by the sparks adhering to the cans. The box is easily made, and on small jobs is as good as the more expensive apparatus offered for sale.

CAPPING FUSE.

The fuse should exactly fit the cap; if it is too large, pare it down, and if too small, wrap it with paper. Press the fresh-cut end of the fuse gently into the cap until the powder train comes in contact with the detonator, then with the crimpers tighten the cap sufficiently to prevent slipping. Be careful not to crimp tight enough to cut off the powder train and thus prevent the fire from reaching the fulminate.

CHARGING HOLES.

Cut the sticks in half, split the paper, and let powder slip into the hole, using the paper as a guide. Tamp each half stick firmly, always using a wooden tamper. Cut the last stick of the charge in two, open the paper at one end, and make a hole in the powder about $2 \frac{1}{2}$ inches deep with a stick sharpened like a pencil and slightly larger in diameter than the cap. Put the capped fuse in this hole and press paper around it. Make a few cuts through the paper and slip all into the hole; press down snugly with tamper. Split the paper on the remaining half stick, place in hole, and tamp lightly. Put about an inch of fine dirt or clay on powder and tamp. This will be sufficient; the old method of tamping the hole full to the collar has been generally abandoned.

MISSED HOLES.

Should a hole misfire, no tamping need be cleaned out; a new hole is not necessary. Prepare another cap and fuse and half stick of powder, as above, insert on tamping, and fire. It is advisable to tear up the mop rags and place a portion tightly in the top of each hole to prevent chips and dirt from falling into missed holes. The rags also prevent fire from the fuse falling into the holes and igniting such portions of the powder as may have adhered to the sides in loading.

WET HOLES.

In preparing fuses for wet holes slip the cap on the fuse, mark the place with finger nail, draw the cap off, smear the fuse between mark and end with axle grease, soap, or other heavy oil, push cap back over grease, and crimp tightly. This makes a waterproof joint that will protect the fulminate. Care should be exercised in the use of crimpers to avoid crimping too tightly, which is likely to cut off the train and prevent the explosion. 
SHARPENING STEEL.

The personnel for extensive trail projects should include a man who knows how to sharpen steel. However, it may be necessary sometimes to sharpen steel when it would be impossible to secure the services of an experienced tool fitter. Steel should not be heated more than 3 or 4 inches back from the bit. The steel, when emerging from the fire, should be cherry red to light straw color. This color should be retained until the point is inserted in water. Do not drop the entire steel into the water at once, but lower the point just below the surface, swing back and forth at that depth until the steel turns dark all over, then lower to the bottom of the vessel. By this method only the point will be chilled.

When sharpening steel for deep drilling, care should be taken to have the bits the same width or to have the shorter steel slightly wider than the long steel.

Where blacksmith's coal is not available, charcoal makes a fair substitute. Dry red-fir bark, when broken into small bits and used with a strong air blast, will also give good results. Neither is as satisfactory as a good grade of forge coal.

BULLDOZING.

There are many situations where great masses of rock may be effectively and economically moved without the slow process of drilling and blasting. This method, commonly called "bulldozing," simply requires the placing of the explosive in some crevice or seam behind or under the mass to be moved, and by force of the discharge lifting and throwing the rock out of the way with little or no shattering of it. What at first appears to be a solid body of rock may, upon close inspection, show a small crack or seam extending to a considerable depth and in such direction as to afford an excellent opportunity for "bulldozing." Frequently an hour spent in searching for such a point of attack will save days of drilling and slow piece by piece removal of the rock. In this sort of work relatively large charges are needed, and it is false economy to try to save powder at the expense of time. Better use a pound or two of explosive in excess of what might be absolutely necessary than use too little and not accomplish the desired result. Always use a slow powder for work of this character.

DOUBLE JACKING.

Where drilling is required, two men ordinarily form the drill crew, one striking and one holding the drill. Drills should be made of seven-eighths inch octagonal drill steel of the best quality. A few cents per pound difference in price will obviate much trouble and delay due to drill points chipping and breaking. Enough drills 
should be provided so that a sufficient number will always be available for use, even while some are being sharpened. When no blacksmith is regularly employed, the number of drills should be greatest. In such case, tool sharpening should be done but once a day, either the first thing in the morning or the last thing at night, by the drill crew. When the crew do their own sharpening, it is advisable to give the sharpener 50 cents or a dollar a day above the ordinary wage and arrange with him to do this work on his own time. Much depends on the proper tempering of drill steel. Too hard a temper invites breaking of the drill bit; too soft results in the bits blunting quickly.

SINGLE JACKING.

It often happens that points of solid rock intrude into the tread of a trail, or the location line sometimes crosses a bare face of rock having but a slight slope, where a tread may be made by cutting a shallow ledge along the face. In such cases the best method of drilling is by "single jacking"; that is, by having one man both hold the drill and do the striking. Where there is much rock work the "single jacking" should be deferred until the heavier work is finished, when both members of the drill squad can be put at it and their full time employed to best advantage.

DRILLING.

In drilling, too much emphasis can not be laid on the importance of properly "placing" the hole and determining, in advance, its depth. Advantage should be taken of the character of the rock as respects cleavage, so that when the explosion takes place the rock may be broken at the proper angle and in the right place. This is a trick of the trade acquired by experience and counts for more than any other single factor where the work is difficult.

Occasionally, though rarely, a hole more than 4 or $4 \frac{1}{2}$ feet deep is desirable. Where this is so the ordinary drills are discarded and churn drills employed. The use of this tool is so uncommon in trail work that a description of it and the method of using it seems unnecessary.

SPECIAI, PROBIEMS.

Along the line of a trail in rough regions large slabs of rock, often weighing several tons, are not uncommon. These obstructions may, as a rule, be easily removed in the following way: If the rock rests solidly upon another rock or other firm substance a few sticks of dynamite placed on top of the rock immediately above the point of rest and covered with a shovelful of earth, firmly packed, will shatter the rock, or at least break it into pieces small enough to be moved away by hand. If the rock is not resting upon a firm support, or if 
there is an opening under it, the dynamite, a good, big charge, should be placed beneath it and well packed with earth. The explosive will then almost certainly bulldoze the obstruction clear out of the way. These methods save much time that would be taken up in drilling into the rock and are usually more effective.

\section{BRIDGES.}

SITE.

The factors affecting the selection of a bridge site are, in order of their importance:

1. Shortness of span.

2. Favorable banks.

3. Minimum range of high water.

4. Straight and unobstructed chamnel above and below.

5. Accessibility.

SPAN.

The most important consideration is length of span. However, other conditions being equal, the construction cost of a bridge with a center pier, where conditions are favorable for it, is usually less than for a single-span bridge somewhat shorter than the total length of the pier bridge but longer than either span.

BANKS.

'The banks of the stream at a suitable site should be of approximately the same elevation, high above water level, and of such material that a solid footing will be offered for the abutments. Solid rock is preferable if the bridge may be fitted to it without excessive trimming. Locations requiring the building of abutments and piers on ground affording insecure and easily washed-out foundations must be carefully avoided. The placing of a pier or abutment in a channel of ten so changes the current that apparently solid gravel, sand, and bowlder banks will be easily washed out.

HIGH WATER.

In the preliminary examination of the site the determination of the high-water mark is very important. Obstruction in the stream bed above or below the site may greatly increase the flood level at this particular point. The bridge must be given several feet clearance above the highest apparent flood mark. This can usually be determined from marks on rocks, presence of driftwood, etc., adjacent to the site.

STRAIGHT CHANNEL.

A straight and unobstructed channel above and below the site practically insures a normal flood level. With these conditions driftwood will not accumulate and the channel will carry the flood waters with the least chance of damage. 
ACCESSIBILITY.

A safe and permanent trail leading to the bridge site is an important consideration. The cost of a trail across bog, marshland, or high-water channel is often the deciding factor in choosing the site.

IDEAL SITE.

The ideal site is one where the stream is narrow, the banks high and of solid material, and the stream straight and affording free and unobstructed flow, even at flood stage.

\section{PRELIMINARY DATA.}

The report of preliminary examinations of sites should give the various dimensions and outline the factors influencing the final choice. For small bridges such data will be used in checking the type and style of bridge recommended. For larger bridges the report will provide the data necessary for the preparation of plans by

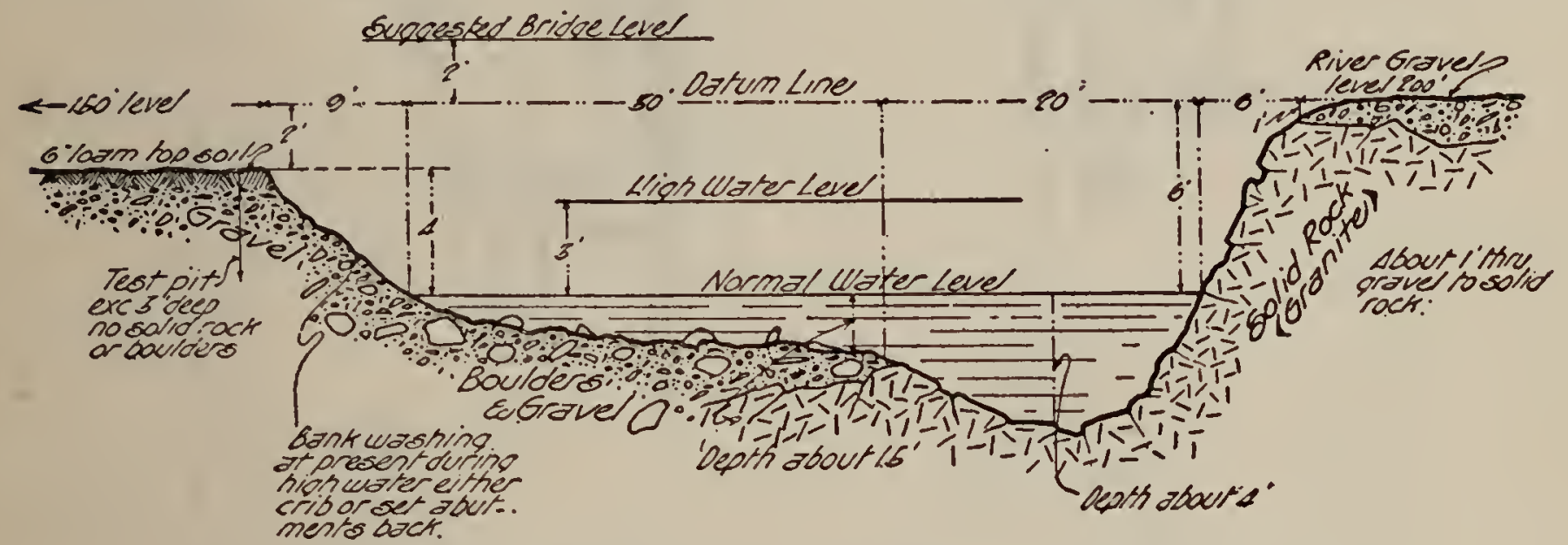

Fig. 15.-Specimen profile of bridge site, showing data needed for proper design.

a competent engineer. The report can be most clearly illustrated by means of a profile or cross-section (fig. 15). The measurements on the ground required for the preparation of such a diagram can be easily obtained with a tape and Abney or Locke level.

TYPES.

Bridges constructed in connection with forest trail work will ordinarily be for short spans and to provide for traffic loads comparatively light. The bridges will generally be of simple and inexpensive design, with wood as the principal structural material. The type of bridge most suitable to the site is largely dependent upon the span. In most cases, however, it will follow closely the design of one of the three following types:

1. Simple non truss stringer.

2. King truss.

3. Queen truss. .

Figures 16, 17, and 18 illustrate specimen designs for these three types. Dimensions of members for other spans may be obtained directly from Tables 1, 2, and 3 . 

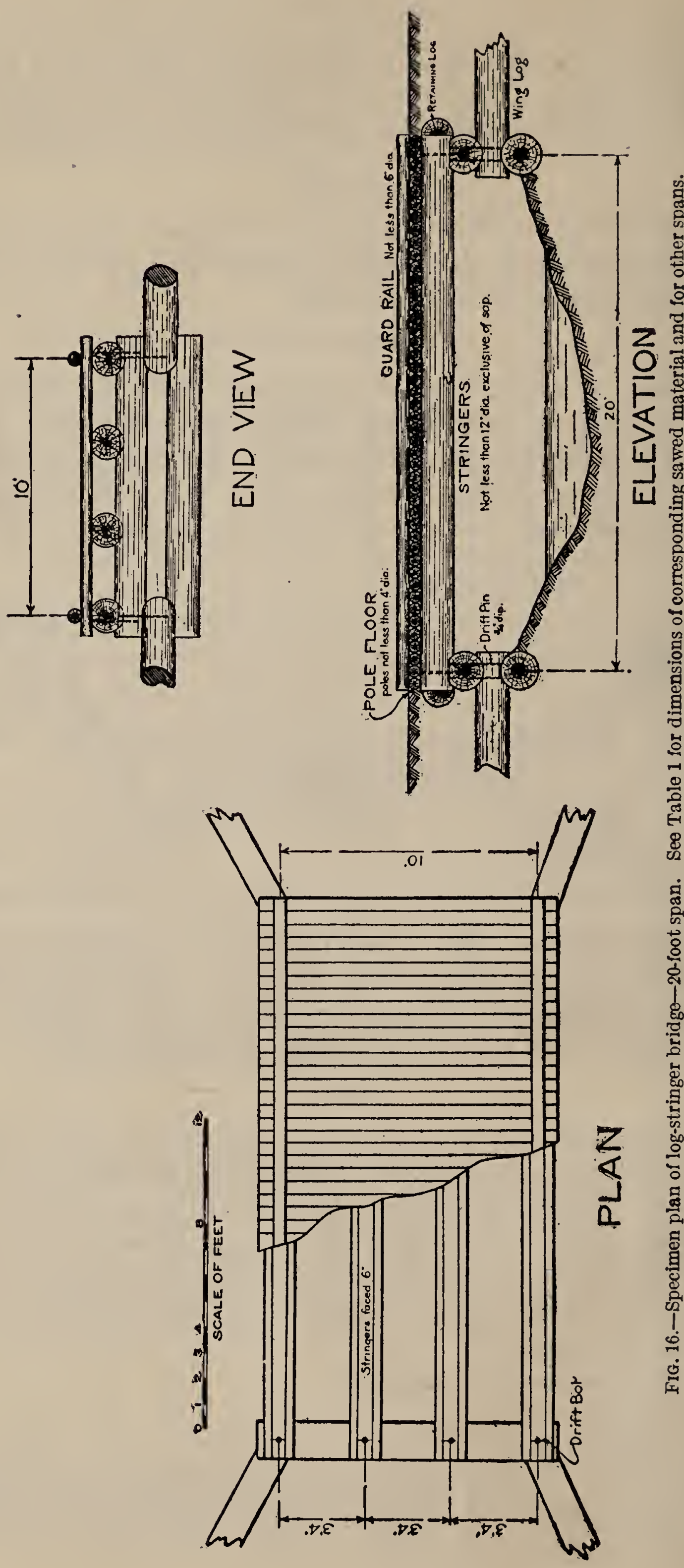
TRAIL CONSTRUCTION ON THE NATIONAL FORESTS.

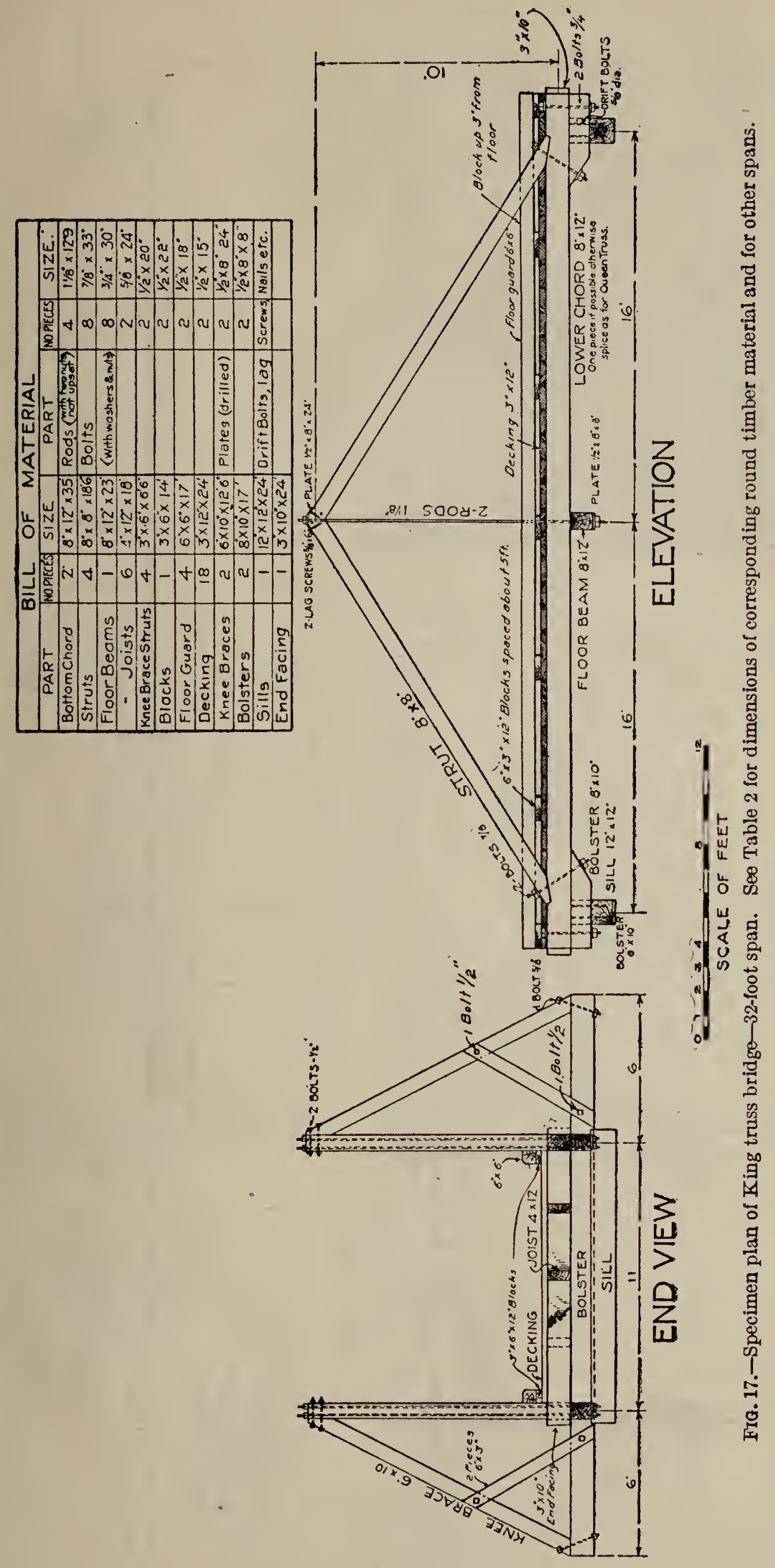




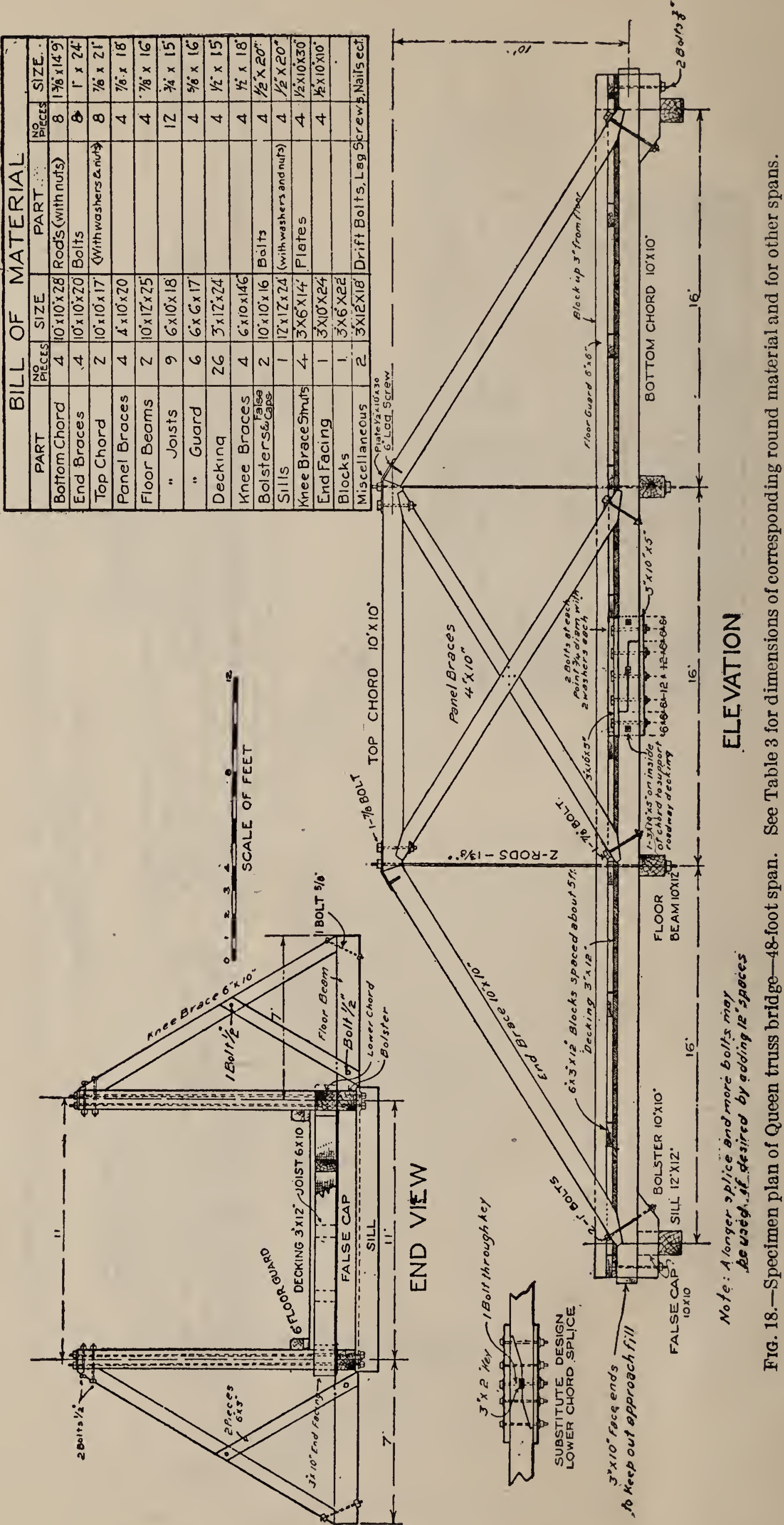


TRAIL CONSTRUCTION ON THE NATIONAL FORESTS.

TABLE 1.-Minimum dimensions for stringers on nontruss bridges.

\begin{tabular}{|c|c|c|c|c|c|c|}
\hline \multirow{2}{*}{ Span in feet. } & \multicolumn{2}{|c|}{$\begin{array}{l}\text { 3-stringer bridge, } \\
8 \text { foet wide. }\end{array}$} & \multicolumn{2}{|c|}{$\begin{array}{l}\text { 4-stringer bridge, } \\
8 \text { feot wide. }\end{array}$} & \multicolumn{2}{|c|}{$\begin{array}{l}\text { 4-stringer bridge, } \\
10 \text { foet wide. }\end{array}$} \\
\hline & $\begin{array}{l}\text { Sawed } \\
\text { lumber } \\
(\mathrm{b} \times \mathrm{d}) \text {. }\end{array}$ & $\begin{array}{c}\text { Round } \\
\text { timber, } \\
\text { diameter. }\end{array}$ & $\begin{array}{l}\text { Sawed } \\
\text { lumber } \\
(b \times d) \text {. }\end{array}$ & $\begin{array}{l}\text { Round } \\
\text { timber, } \\
\text { diameter. }\end{array}$ & $\begin{array}{c}\text { Sawed } \\
\text { lumber } \\
(\mathrm{b} \times \mathrm{d}) \text {. }\end{array}$ & $\begin{array}{l}\text { Round } \\
\text { timber. } \\
\text { diameter. }\end{array}$ \\
\hline 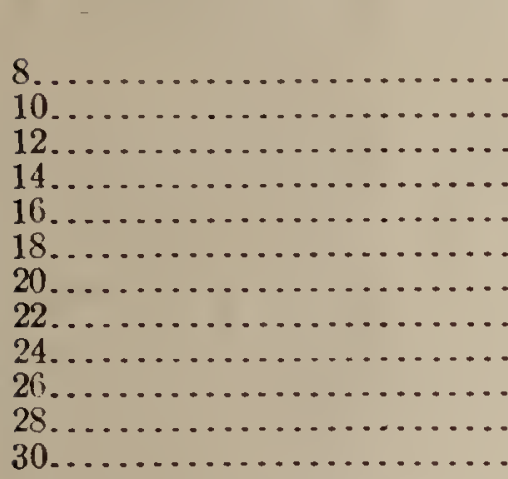 & $\begin{array}{r}\text { Inches. } \\
3 \times 8 \\
3 \times 10 \\
3 \times 12 \\
4 \times 12 \\
6 \times 12 \\
8 \times 12 \\
10 \times 12 \\
10 \times 12 \\
12 \times 12 \\
12 \times 14 \\
12 \times 14 \\
14 \times 14\end{array}$ & $\begin{array}{r}\text { Inches. } \\
7 \\
8 \\
9 \\
10 \\
11 \\
11 \\
12 \\
13 \\
14 \\
15 \\
15 \\
16\end{array}$ & $\begin{array}{r}\text { Inches. } \\
3 \times 8 \\
3 \times 10 \\
3 \times 12 \\
4 \times 12 \\
4 \times 12 \\
6 \times 12 \\
8 \times 12 \\
8 \times 12 \\
10 \times 12 \\
12 \times 12 \\
12 \times 12 \\
12 \times 14\end{array}$ & $\begin{array}{r}\text { Inches. } \\
6 \\
7 \\
8 \\
9 \\
10 \\
10 \\
11 \\
12 \\
12 \\
13 \\
14 \\
15\end{array}$ & $\begin{array}{r}\text { Inches. } \\
3 \times 8 \\
3 \times 10 \\
3 \times 12 \\
4 \times 12 \\
6 \times 12 \\
8 \times 12 \\
10 \times 12 \\
10 \times 12 \\
12 \times 12 \\
12 \times 14 \\
12 \times 14 \\
14 \times 14\end{array}$ & Inches. \\
\hline
\end{tabular}

NотE.--Round timber diameters should be measured as indicated in figure 21. A 3-stringer bridge 6 feet wide should have material of the same dimensions as given above for a 4 -stringer bridge 8 feet wide.

TABLE 2.-King truss bridge-Dimensions of principal members for spans 20 to 36 feet.

\begin{tabular}{|c|c|c|c|c|c|c|c|c|c|c|c|c|c|c|}
\hline \multirow{3}{*}{ Span. } & \multicolumn{2}{|c|}{ Lower chord. } & \multicolumn{2}{|c|}{ Strut. } & \multicolumn{2}{|c|}{ Rod. } & \multicolumn{4}{|c|}{ Floor joists. } & \multicolumn{2}{|c|}{ Floor beams. } & \multicolumn{2}{|c|}{ Ínee brace. } \\
\hline & \multirow{2}{*}{ 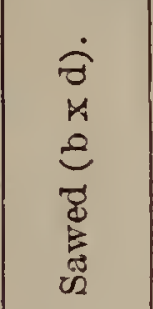 } & \multirow{2}{*}{ 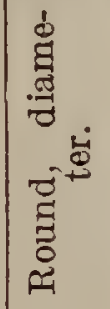 } & \multirow{2}{*}{ 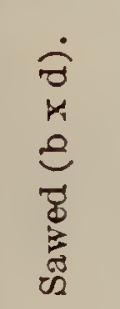 } & \multirow{2}{*}{ 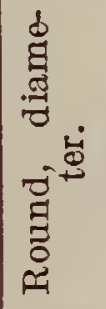 } & \multirow[b]{2}{*}{ 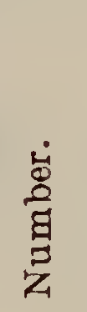 } & \multirow[b]{2}{*}{ 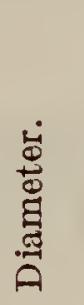 } & \multicolumn{2}{|c|}{ Sawed. } & \multicolumn{2}{|c|}{ Round. } & \multirow{2}{*}{ 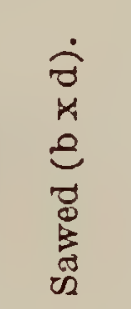 } & \multirow{2}{*}{ 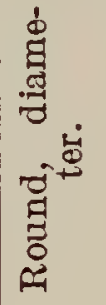 } & \multirow{2}{*}{ 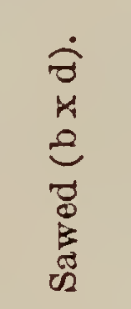 } & \multirow{2}{*}{ 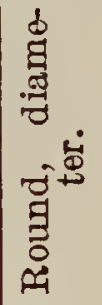 } \\
\hline & & & & & & & 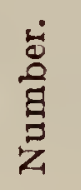 & 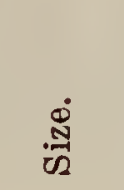 & 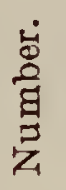 & 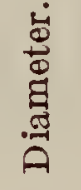 & & & & \\
\hline Feet. & In. & In. & In. & In & & In. & & & & In. & In. & In. & In. & In. \\
\hline $\begin{array}{l}20 \\
22\end{array}$ & $\begin{array}{llr}6 & \times 8 \\
6 \times & 10\end{array}$ & $\begin{array}{r}8 \\
10\end{array}$ & $\begin{array}{ll}6 \mathrm{x} & 6 \\
6 \mathrm{x} & 6\end{array}$ & $\begin{array}{l}7 \\
7\end{array}$ & $\begin{array}{l}1 \\
1\end{array}$ & $\begin{array}{l}1 \frac{1}{4} \\
1 \frac{1}{4}\end{array}$ & $\begin{array}{l}3 \\
3\end{array}$ & $\begin{array}{l}4 \times 8 \\
3 \times 10\end{array}$ & $\begin{array}{l}2 \\
2\end{array}$ & $\begin{array}{r}8 \\
10\end{array}$ & $\begin{array}{ll}6 \times 8 & 8 \\
6 \times 10\end{array}$ & $\begin{array}{r}8 \\
10\end{array}$ & $\begin{array}{ll}6 \mathrm{x} & 6 \\
6 \mathrm{x} & 6\end{array}$ & $\begin{array}{l}7 \\
7\end{array}$ \\
\hline 24 & & 10 & $6 \times 6$ & 7 & 1 & $1 \frac{2}{8}$ & 3 & & 2 & 10 & & 10 & $6 \times 6$ & \\
\hline 26 & 10 & 10 & $7 \times 7$ & 8 & 1 & $1 \frac{8}{8}$ & 3 & $4 \times 10$ & 2 & 10 & $7 \times 10$ & 10 & $6 \times 8$ & 8 \\
\hline 28 & & 10 & $7 \times 7$ & 8 & 2 & $1^{\circ}$ & 3 & & 2 & 10 & & 10 & $6 \times 8$ & 8 \\
\hline 30 & & 11 & $7 \times 7$ & 8 & 2 & $1 \frac{1}{8}$ & 3 & & 2 & 12 & & 11 & $6 \mathrm{x}$ & 8 \\
\hline 32 & & 13 & $8 \times 8$ & 9 & 2 & $1 \frac{8}{8}$ & 3 & $4 \times 12$ & 2 & 12 & $8 x$ & 13 & $6 \mathrm{x}$ & 10 \\
\hline 34 & & 13 & $8 \times 8$ & 9 & 2 & $1 \frac{8}{8}$ & 3 & $6 \times 12$ & 2 & $\hat{1}$ & $8 \times 1$ & 13 & $6 \times 10$ & 10 \\
\hline 36 & $8 \times 12$ & 13 & $8 \times 10$ & 10 & 2 & $1 \frac{9}{4}$ & 3 & $6 \times 12$ & 2 & 12 & $8 \times 12$ & 13 & $6 \times 10$ & 10 \\
\hline
\end{tabular}

Width:

Clear, 10 feet.
Over all, 11 feet, center to center. Load, 125 pounds per square foot. Factor safety, 6 .
Floor, 3-inch decking or 4-inch poles.

Floor guard, 6 inches by 6 inches.

Bolts, nuts, washers, etc., as on specimen plan (fig. 17). 
TABle 3.-Queen truss bridge-Dimensions of principal members for spans 36 to 60 feet.

\begin{tabular}{|c|c|c|c|c|c|c|c|c|c|c|c|c|c|c|c|c|}
\hline \multirow[b]{2}{*}{ 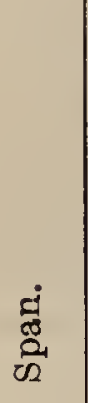 } & \multirow[b]{2}{*}{ 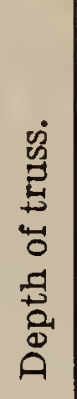 } & \multirow[b]{2}{*}{ 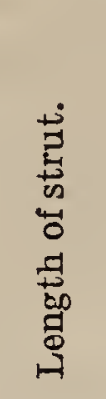 } & \multicolumn{2}{|c|}{ End brace. } & \multicolumn{2}{|c|}{ Top chord. } & \multicolumn{2}{|c|}{$\begin{array}{l}\text { Bottom } \\
\text { chord. }\end{array}$} & \multicolumn{2}{|c|}{$\begin{array}{c}\text { Floor } \\
\text { beams. }\end{array}$} & \multicolumn{2}{|c|}{ Joists. } & \multicolumn{2}{|c|}{$\begin{array}{l}\text { Panel } \\
\text { brace. }\end{array}$} & \multirow[b]{2}{*}{ 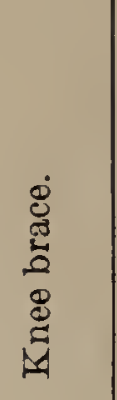 } & \multirow{2}{*}{ 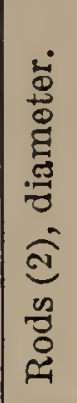 } \\
\hline & & & 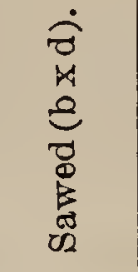 & 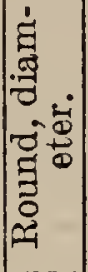 & 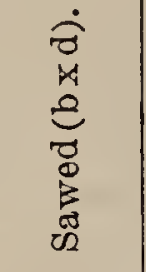 & 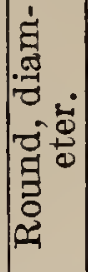 & 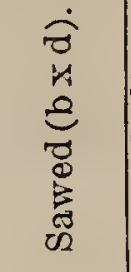 & 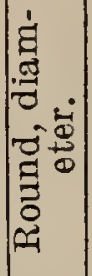 & 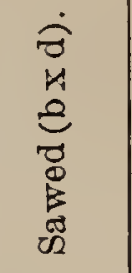 & 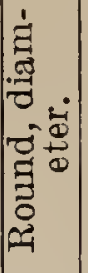 & 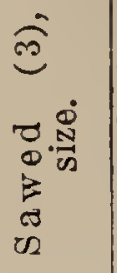 & 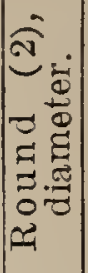 & 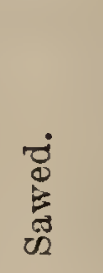 & 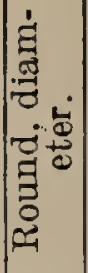 & & \\
\hline$F t$. & Ft. & $F t$ & In. & $I n$. & In. & In. & In & In & In & In & In & In. & In. & In & In. & In. \\
\hline 36 & 9 & 15.00 & $8 x$ & 9 & $8 \times 8$ & & $8 \times 10$ & 10 & $8 \times 10$ & 10 & $4 \times 10$ & 10 & $4 \times$ & 7 & 5 & $1 \frac{1}{8}$ \\
\hline 38 & 9 & 15.54 & $8 \times 8$ & 9 & $8 \times 8$ & 9 & $8 \times 10$ & 10 & $8 \times 10$ & 10 & $4 \times 10$ & 10 & $4 \mathrm{x}$ & 7 & $6 \mathrm{x}$ & $1 \frac{1}{8}$ \\
\hline 40 & 9 & 16.0 & $8 \times 8$ & 9 & $8 \times 8$ & 9 & $8 x$ & 10 & $8 x$ & 11 & $4 \mathrm{x}$ & 10 & $4 x$ & 7 & $6 \times 6$ & $1 \frac{1}{4}$ \\
\hline 42 & 9 & & $8 \times 10$ & 10 & $8 \times 8$ & 10 & & 10 & $10 x$ & 11 & & 10 & & & $6 \times 6$ & $1 \frac{1}{4}$ \\
\hline 44 & 10 & 17.75 & $8 \times 10$ & 10 & $8 \times 8$ & 10 & $8 x$ & 11 & $10 x$ & 12 & $4 x$ & 11) & 43 & 8 & $6 \mathrm{x}$ & 17 \\
\hline 46 & 10 & 18. & $10 x$ & & $10 \times 10$ & 10 & $10 x$ & 12 & & 12 & & 11 & 4 & 9 & $\mathrm{x}$ & $1 \frac{3}{8}$ \\
\hline 48 & 10 & & & 11 & & 10 & & 12 & & 13 & & 12 & & 9 & & 13 \\
\hline 50 & 10 & & & 11 & 10 & 11 & & 13 & & 14 & $6 x$ & $1:$ & & 9 & $\begin{array}{ll}x & 8\end{array}$ & $1 \frac{3}{8}$ \\
\hline 52 & 12 & 21.0 & & 12 & $10 \times 10$ & 11 & & 14 & & 14. & $6 x$ & 14 & & 9 & $\times 10$ & $1 \frac{\mathrm{s}}{\mathrm{g}}$ \\
\hline 54 & 12 & 21.6 & $10 x$ & 12 & $10 \times 10$ & 11 & & 14 & $10 x$ & 14 & $6 x$ & 14 & & 9 & $\times 10$ & $1 \frac{1}{2}$ \\
\hline 56 & 12 & 22.1 & $10 x$ & 14 & & 11 & & 14 & & 14 & $6 \mathrm{x}$ & 1 & & 10 & & \\
\hline 58 & 12 & 22.76 & $10 \times$ & 14 & $10 \times 10$ & 11 & & 14 & $12 \mathrm{x}$ & 14 & $8 \times 1$ & 14 & & 10 & $6 \times 10$ & 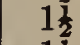 \\
\hline 60 & 12 & 23.32 & $10 \times 12$ & 14 & $10 \times 10$ & 11 & $12 \times 12$ & 15 & $12 \times 12$ & 14 & $8 \times 12$ & 15 & $4 \times 12$ & 10 & $6 \times 10$ & $1 \frac{3}{2}$ \\
\hline
\end{tabular}

Width:

Clear, 10 feet.

Over all, 11 feet center to center.

Load, 125 pounds per square foot.
Factor safety, 6 .

Floor, 3 -inch decking or 4-inch poles.

Floor guard, 6 by 6 inches.

Bolts, nuts, washers, etc., as on plan (fig. 18).

TABLE 4.-Relative strengths of sawed lumber and round-timber beams.

\begin{tabular}{|c|c|c|c|c|c|}
\hline $\begin{array}{l}\text { Sawed } \\
\text { lumber } \\
(b \times d) \text {. }\end{array}$ & $\begin{array}{c}\text { Square } \\
\text { lumber } \\
\text { corres- } \\
\text { ponding. }\end{array}$ & $\begin{array}{c}\text { Round } \\
\text { timber } \\
\text { corres- } \\
\text { ponding, } \\
\text { diameter. }\end{array}$ & $\begin{array}{l}\text { Sawed } \\
\text { lumber } \\
(\mathrm{b} \times \mathrm{d}) \text {. }\end{array}$ & $\begin{array}{c}\text { Square } \\
\text { lumber } \\
\text { corres- } \\
\text { ponding. }\end{array}$ & $\begin{array}{l}\text { Round } \\
\text { timber } \\
\text { corres- } \\
\text { ponding, } \\
\text { diameter. }\end{array}$ \\
\hline $\begin{array}{l}\text { Inches. } \\
3 \times 88 \\
3 \times 10 \\
3 \times 12 \\
4 \times 6 \\
4 \times 8 \\
4 \times 10 \\
4 \times 12 \\
6 \times 126 \\
6 \times 8 \\
6 \times 10 \\
6 \times 12\end{array}$ & $\begin{array}{r}\text { Inches. } \\
6 \\
7 \\
8 \\
6 \\
7 \\
8 \\
9 \\
6 \\
7 \\
9 \\
10\end{array}$ & $\begin{array}{r}\text { Inches. } \\
7 \\
8 \\
9 \\
7 \\
8 \\
9 \\
10 \\
7 \\
8 \\
10 \\
11\end{array}$ & $\begin{array}{r}\text { Inches. } \\
7 \times 7 \\
7 \times 10 \\
7 \times 12 \\
8 \times 8 \\
8 \times 10 \\
8 \times 12 \\
10 \times 10 \\
10 \times 12 \\
12 \times 12 \\
12 \times 14 \\
14 \times 14\end{array}$ & $\begin{array}{r}\text { Inches. } \\
7 \\
9 \\
10 \\
8 \\
9 \\
11 \\
10 \\
12 \\
12 \\
13 \\
14\end{array}$ & $\begin{array}{r}\text { Inches. } \\
8 \\
10 \\
11 \\
9 \\
10 \\
13 \\
11 \\
74 \\
14 \\
15 \\
16\end{array}$ \\
\hline
\end{tabular}

STRINGER BRIDGE.

For spans less than 20 feet, a stringer bridge will adequately meet the needs. For spans between 20 and 36 feet the King truss design will ordinarily be most suitable, although where large-size timber is available and the probable loads light, nontruss stringer bridges will often be found about as satisfactory and more economical.

\section{KING TRUSS BRIDGE.}

Truss bridges should, however, always be adopted in regions of heary snow. In such localities the accumulation of heary snow in the winter creates loads far in excess of any traffic loads that the bridge will be called upon to bear. The continued application of such a load for several months creates such a strain that a strong nontrussed bridge will be left with a permanent sag. 


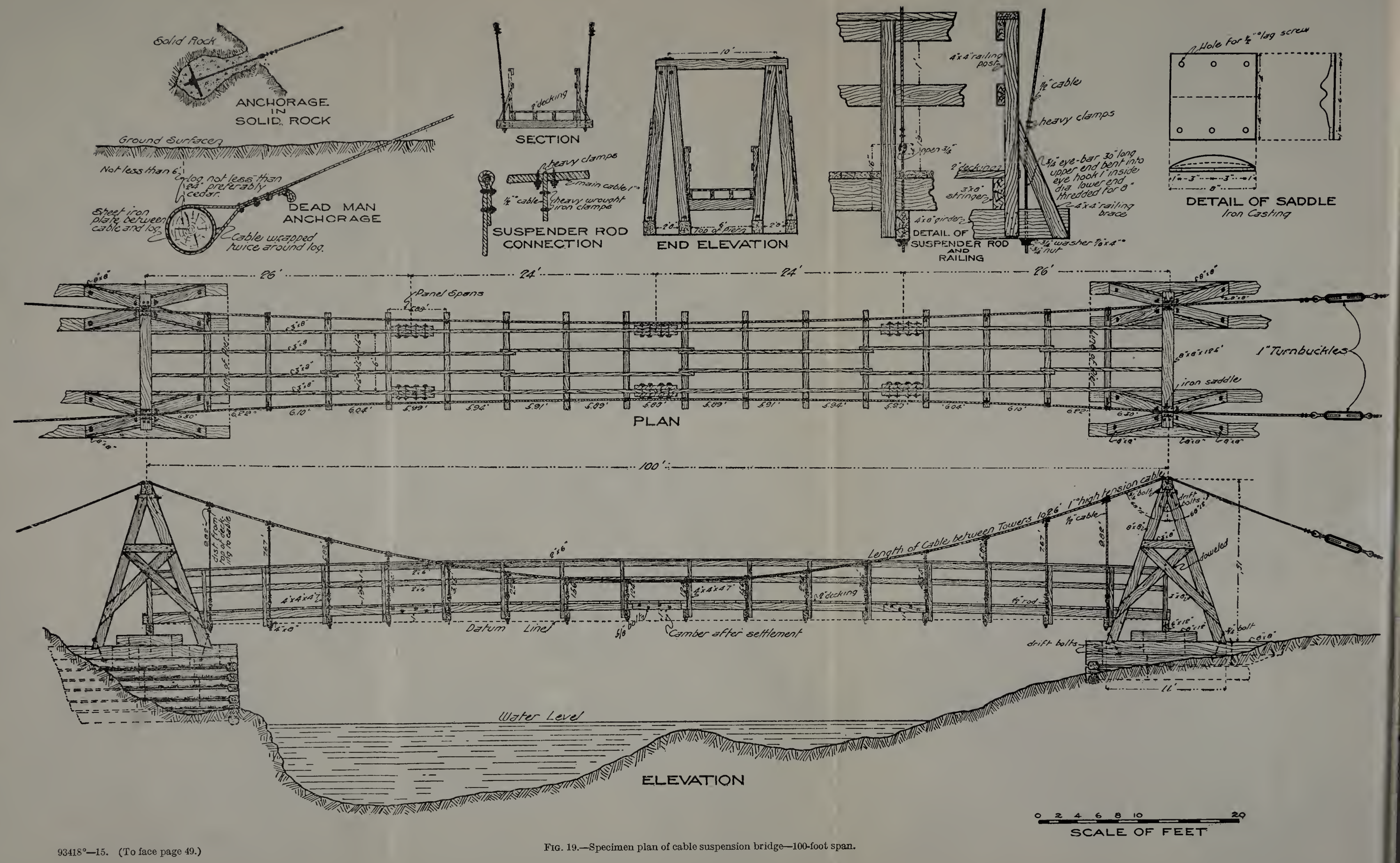
TRAIL CONSTRUCTION ON THE NATIONAL FORESTS.

\section{QUEEN TRUSS BRIDGE.}

The Queen truss style is the most suitable for spans between 36 and 60 feet. It may even be used for spans longer than 60 feet under certain conditions. Plans for bridges of spans 60 feet and over will be prepared by the engineering organization of the district office.

CABLE BRIDGES.

Such designs will consist of more complicated wooden trusses or cable suspension bridges. The latter is finding increasing favor for trails because of its special applicability to spans from 75 to 200 feet where present traffic is light and the chances for future vehicle travel are remote. An illustration of a bridge of this character is given in figure 19. No great detail is shown on this design. Plans for each bridge of such a type will be prepared by a competent engineer. One - great advantage of this type, in addition to its light weight and comparatively low cost, is the fact that if properly designed it may be constructed without false work of any kind. This advantage is of great importance where the stream to be bridged lies in a deep canyon or is particularly swift and deep.

\section{TRESTLE BRIDGES.}

Trestle bridges are seldom needed on trails. The use of a bridge of this type is to cross deep draws or canyons with a small stream flow. Usually in such a case the cheaper expedient of dropping the trail to the creek bottom is adopted. A bridge of this type is applicable, however, to some situations, and a specimen plan is illustrated by figure 20 .

\section{MATERIAL.}

On account of the variability in the strength of green timber, bridges of such material are commonly built with a large factor of safety. This is particularly true with round material, first because of the uncertainty of the strength due to the amount of sapwood and other defects, and secondly, because of the negligible difference in cost. Under existing conditions of trail work on the Forests, stringers less than 12 inches diameter are not generally used in spans 8 feet and over. - In Tables 1, 2, and 3 are computed the minimum safe dimensions. Smaller sizes than those indicated should nover be used. The snow loads on Forest bridges in the great majority of cases exceed any live loads to which such structures may be subjected, and therefore in planning the bridge only the former is usually considered. This, of course, would not apply to localities where a depth of snow exceeding 3 or 4 feet is uncommon.

The bridge plans shown in this handbook are designed for a total load, live and dead, of 125 pounds to the square foot, and when good 


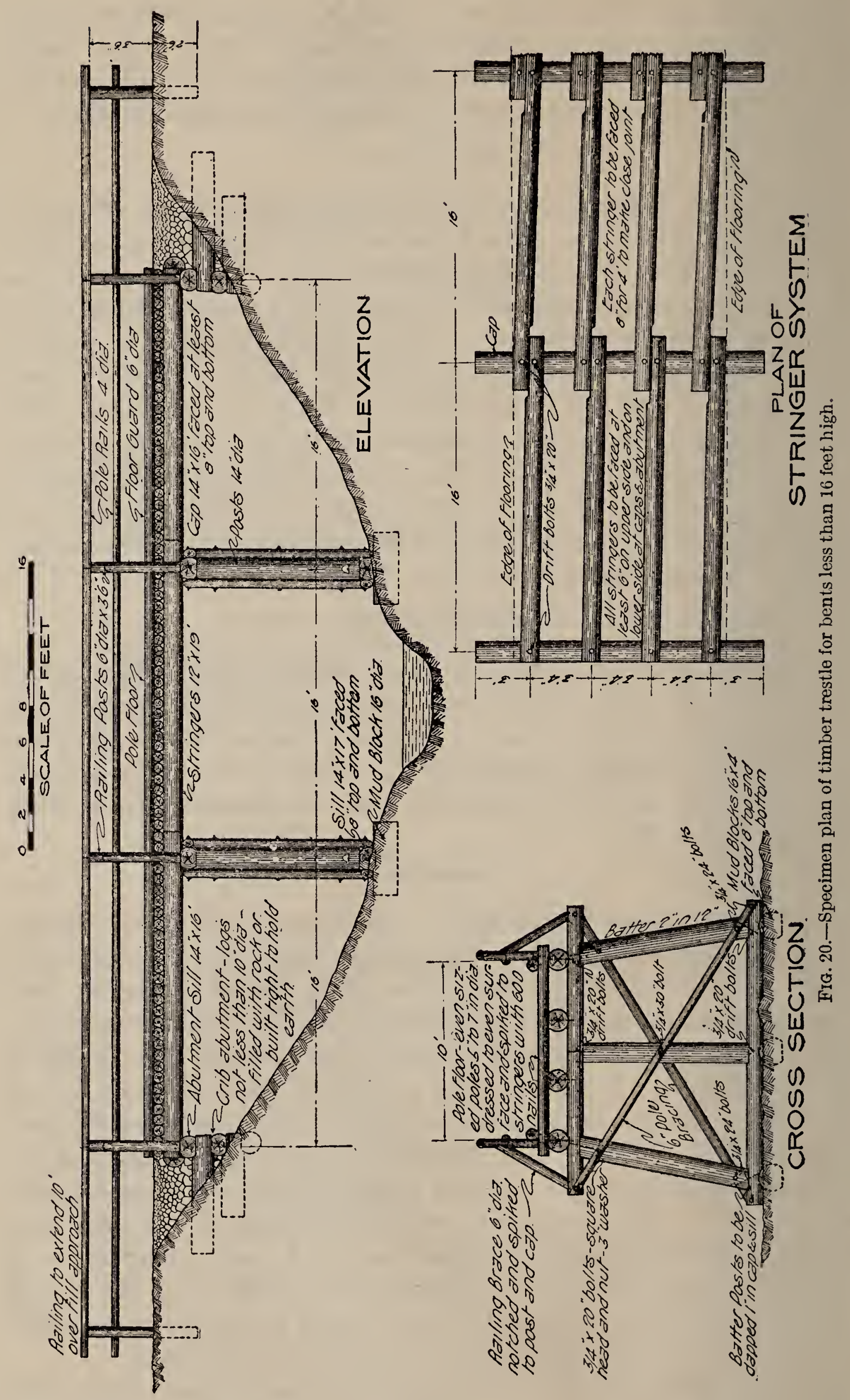


structural timber is used afford a factor of safety of 6 . Fir timber (Pseudotsuga taxifotia) is probably superior to any other western species for structural purposes. Western larch and yellow pine are fairly satisfactory; white pine, spruce, and lodgepole pine are inferior. The life of timber bridges, at best, hardly exceeds 12 years, and therefore the most durable woods available should be used, even though the cost of securing them is somewhat greater than for the less durable kinds. The first cost will be more than offset by the decreased maintenance cost and longer life of the bridge. The sapwood of a $\log$ has much less strength, and is more subject to decay than the heartwood; therefore diameters should be measured by the method indicated in figure 21 .

Logs used in the bridges should be straight and sound, trimmed, and peeled. Sawed lumber is much more satisfactory, but the cost is usually prohibitive; it will be used rarely in bridges of simple design.

\section{FOUNDATIONS.}

It is of fundamental importance that the foundation of the bridge, the abutments, and piers, rest upon firm and solid

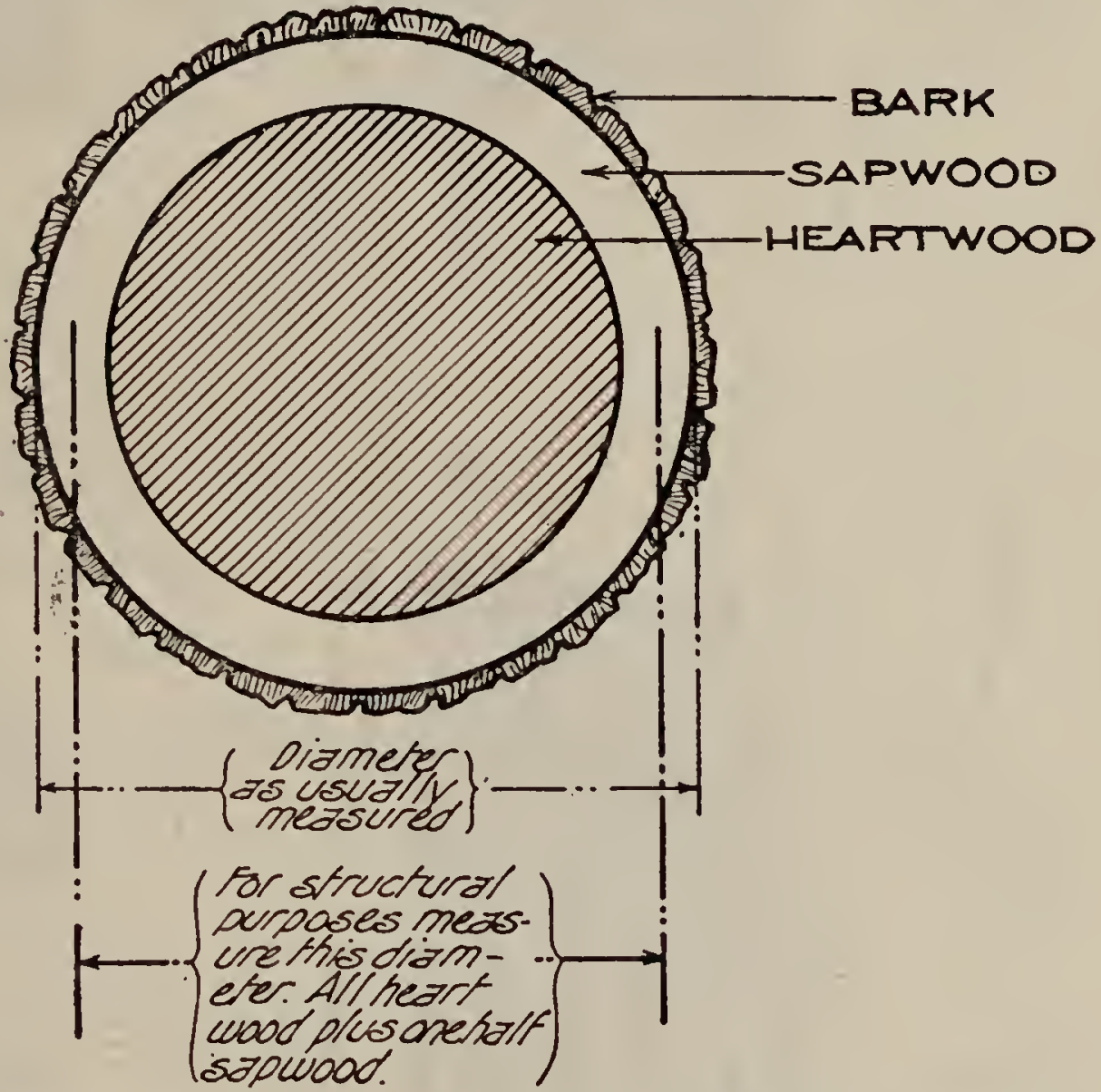

Fig. 21.-Method of measuring diameter of logs for structural purposes.

The sapwood has less strength than the heartwood and is also more subject to decay; therefore in using the tables diameter of logs should be measured at small end, as above, in order to discount one-half of sapwood.

ground. If the top material will not bear up under the load, or is subject to washing by the currents created by the construction of the pier or abutment, the excavation should be carried below the surface until a stable footing is secured. Riprap should be used freely to protect the foundation structures from undermining. Too often abutments of a bridge are crowded closely to the edge of an unstable stream bank, when a few feet added to the span would eliminate the danger of undermining.

\section{PIERS AND ABUTMENTS.}

Most foundation structures will be of log cribbing, similar to that illustrated by figures 22 and 23 . Logs 10 to 12 inches in diameter are most suitable. They should be built tight if earth is to be 
used for filling or ballast. If rock, which is far preferable, is available for this purpose, spaces between logs may be left. The crib should be thoroughly fastened with drift bolts, and all projecting

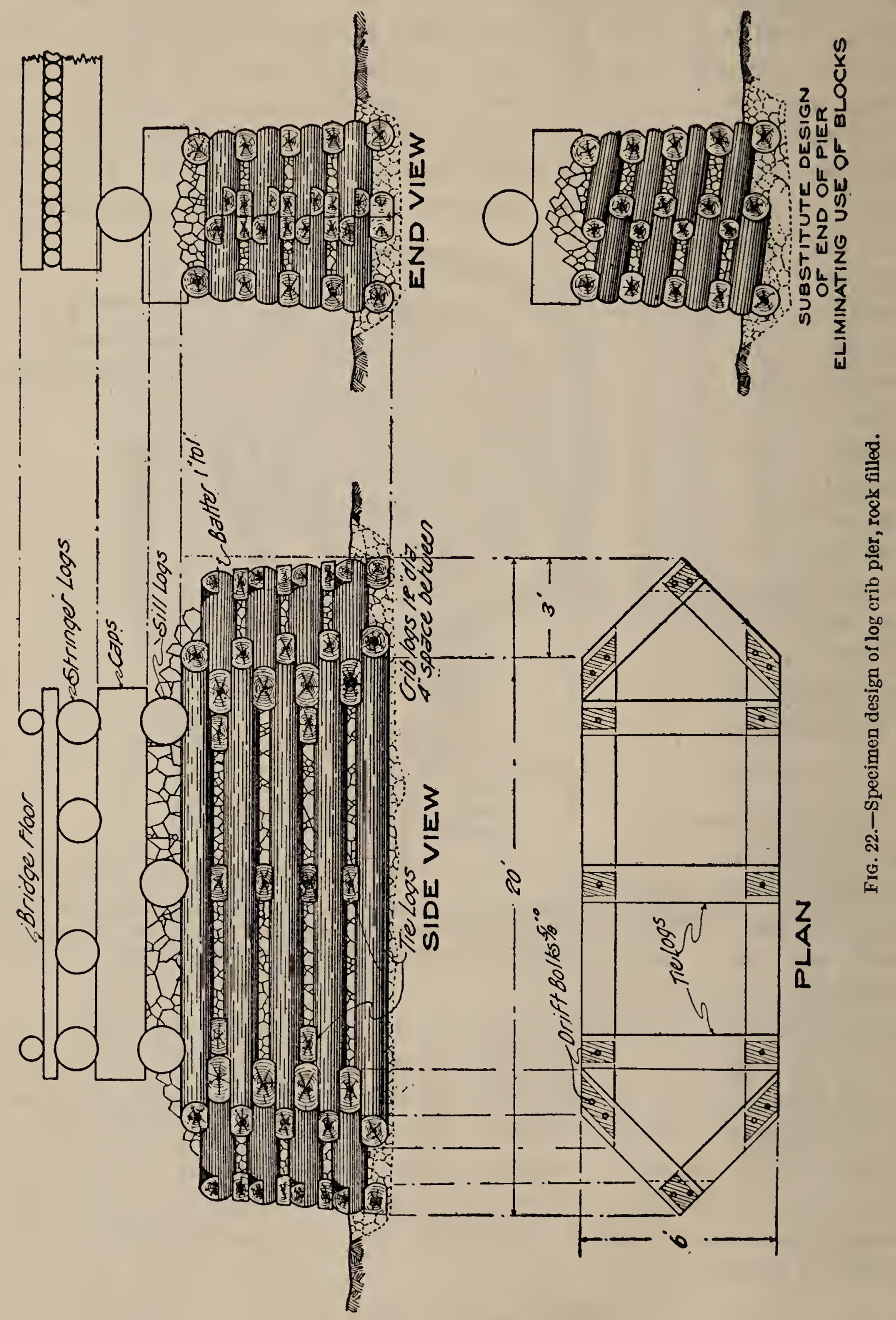

ends trimmed off. Abutments and piers in the stream bed should be so constructed that both the up and down stream sides will present an angle of $45^{\circ}$ with the current. Tie logs, in the case of three- 


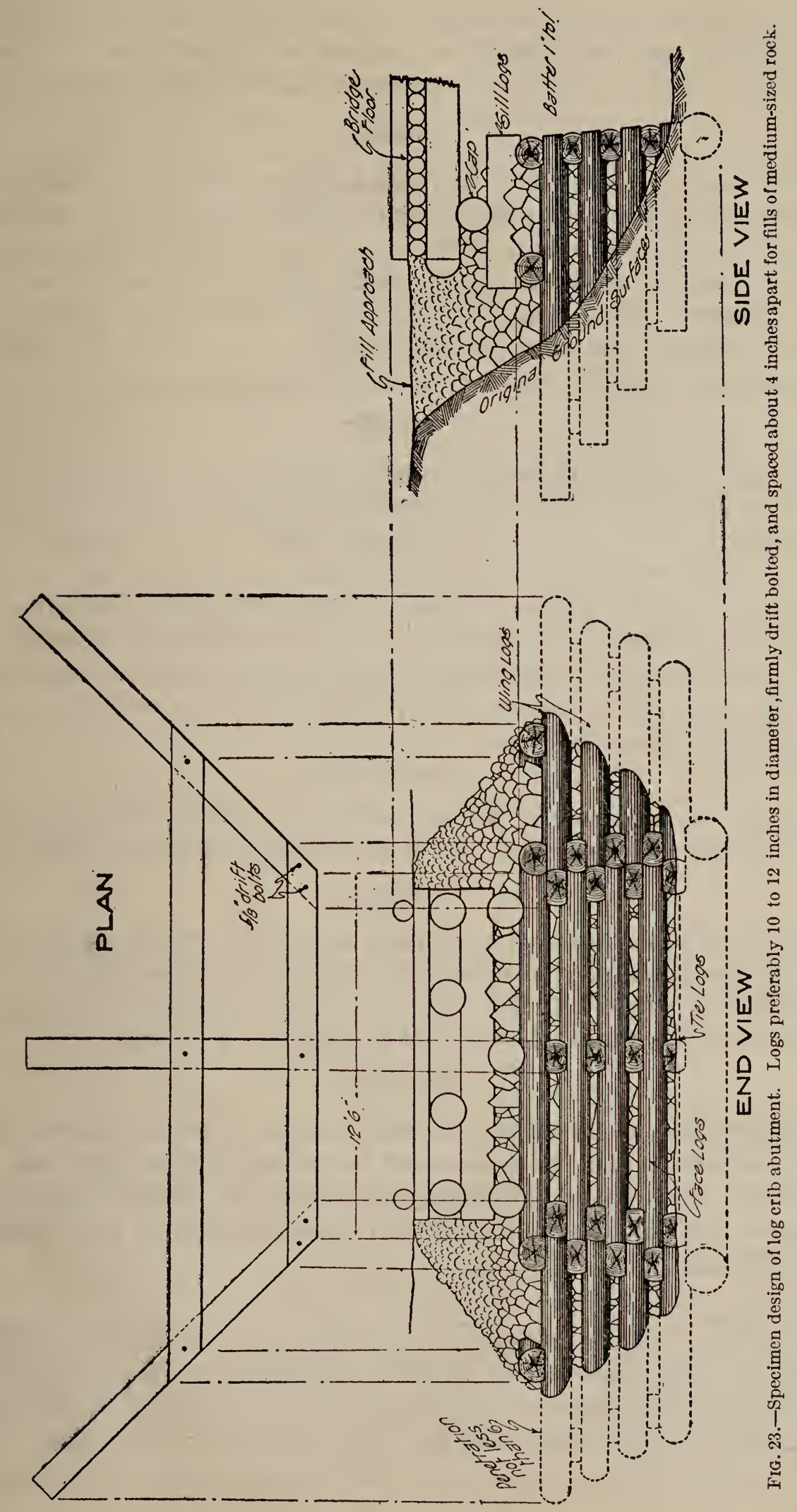


sided abutments, should extend not less than 6 feet into the bank. Numerous crossties should be inserted on closed piers. A batter of 1 inch to the foot is usually given the faces of piers and abutments.

\section{WIDTH.}

On class A trails where there is a prospect that the trail will be converted into a wagon road within the life of the bridge, the width should be not less than 10 feet in the clear. Under other conditions and on trails of classes $\mathrm{B}$ and $\mathrm{C}$, a width of $5 \frac{1}{2}$ to 6 or sometimes 8 feet is sufficient. Special reasons may exist in some cases, however, for greater widths (for example, along stock driveways). The width in such cases should be sufficient to meet the requirements.

\section{FLOORING.}

A pole floor should be well constructed by securing straight poles of even diameter. Floor poles need not be peeled. Each pole should be spiked with at least three 60-penny spikes to the stringers. The top surface is greatly improved by dressing with an adz and the expense is very small. Puncheon makes a suitable floor if small, even-sized poles are not available. The pieces should be sized to give an even bearing and the edges trimmed down to afford close joints. Three-inch plank of course offers the best floor material, but is comparatively expensive.

\section{GUARD RAILS.}

Guard railing made of peeled poles adds greatly to the appearance of a bridge and should be put on all the more important bridges.

\section{SPLICING.}

Splicing of the lower chord of King and Queen trusses, as illustrated on the accompanying specimen plan of the latter type, should only be resorted to where actually necessary; chords made of one piece are much stronger unless the splice is particularly well made.

\section{APPROACHES.}

Approaches at the ends of a bridge should be on solid earth or fill, if practicable, and on grades not exceeding 10 per cent. On low ground they should be amply protected by loose riprap. Fill approaches should be built high to provide for settling and should be of stable material.

\section{costs.}

Many controlling factors enter into the cost of small timber bridges; cost data must therefore be used with judgment and discretion. From actual practice, however, it is found that the average cost of stringer bridges over 8-feet span and less than 30 feet of 10 -foot clear width cost about $\$ 2.50$ per linear foot. King truss bridges cost about $\$ 3$ 
per foot, and Queen truss äbout $\$ 3.50$. Trestle bridges of height less than 15 feet can be constructed for about $\$ 2.50$ per foot. Cable suspension bridges of spans between 75 and 125 feet about $\$ 8$ per foot; bridges of any other type for similar spans will cost a great deal more per foot. Sawed-lumber bridges, figuring lumber at $\$ 15$ per thousand at the site, cost on the average about $\$ 35$ per thousand feet in the structure. All of the above costs are exclusive of abutments, piers, and approaches.

\section{ADMINISTRATION.}

EXPLANATION.

Since this is primarily a construction handbook, not an administrative treatise, only those points are included under administration which may be considered as directly affecting the construction work. The need for improvement working plans and the details to be included in each do not properly come into this field

PLANS.

It is, however, highly important in the construction of trails that they be properly planned. On each Forest the trails in existence, as well as those contemplated, should be classified in accordance with the principles previously outlined. For convenience of record, the trail system should be divided into units according to class, and each trail unit named or numbered. An inventory of the trails of each class and definite plans for bringing every trail up to the standard required and for providing the means for proper maintenance should be made.

\section{ESTIMATES.}

The importance of securing accurate estimates in advance, not only for the construction of new trails but for the completion and annual maintenance of existing trails, becomes greater with the increased volume of work. No intelligent improvement plan can be made without them; neither can the funds be distributed so as to accomplish the greatest good. Too often have important trail projects been carried out with indifferent results because the money allotted has been insufficient to complete them properly. Sacrifice of route and grade are the most common results as well as the most serious. More careful estimates in advance will largely obviate this difficulty.

The varying conditions as to topography, density of cover, percentage of rockwork, etc., make it difficult in advance to determine exactly the cost of construction, but general average costs for different kinds of work may be used to advantage in making estimates. In the Appendix will be found tables giving approximate figures. 


\section{PRELIMINARY WORK.}

Careful planning of the trail system and the selection of the route and grade one or more years in advance of construction will eliminate one of the big sources of error and one of the big losses in money and efficiency. If the machinery for trail building can be built up, so also can the machinery for properly planning and locating them. This work is primarily the job of the district ranger and should form a part of his regular duties. It is far better to postpone actual construction for a year or more in order to accomplish the preliminary field work than to put through a "half-baked" project. Neither is it necessary or advisable to be assured of the needed funds to build the trail before undertaking the reconnaissance. The preliminary work once accomplished and a definite record made of it, the construction work may proceed without delay at any time special trail money is available or spare time of patrolmen or other forest officers may be utilized. Furthermore, if a trail has been marked during the year previous to construction, opportunity is given for a spring inspection. This, if done while the snow is thawing or when much of it has disappeared, may show the desirability of occasional changes in alignment to avoid places where the snow lies until late in the spring. The funds expended in laying out a trail which may not be built for several years should not be considered as nonproductive, since the knowledge gained becomes immediately valuable in influencing the work of rangers and guards in tributary areas. In many instances ill-advised expenditures may be prevented if a definite route for a future trail has been laid out.

In case of fire a trail can be quickly built with a large force of men if the route has been previously chosen and is well blazed. If the route is not blazed the building of the trail necessarily proceeds slowly and seriously delays control operations on the fire.

In a country where there is dense brush and undergrowth preliminary trail reconnaissance can be very advantageously carried out during the winter on deep snow. This is especially true where topographic maps are not available. Winter work will not, of course, take the place of the usual reconnaissance when the snow is gone, but it will so narrow the possibilities for the route that the cost of the succeeding field work will be greatly reduced.

It is expected that a great part of the preliminary work will be performed by the regular Forest force incidental to their other duties, the correlation of the several lines of work here, as elsewhere, being conducive to economical administration. If, however, the work can not be performed in this manner, a special allotment should be obtained in the same manner as for construction work. 


\section{COOPERATION.}

The Service benefits greatly by cooperating with local public authorities, companies, associations, and individuals in the elaboration and execution of trail plans. Very frequently material assistance can be obtained in this way, which is decidedly important in view of the limited funds usually available for improvement work. Since trails are always open to use by the public without limitations, there is every reason to solicit cooperation from any likely source, so long as there is no obligation upon the part of the Service other than free use of the trail when completed. The conditions governing cooperation on trail projects are decidedly different in this respect from those affecting cooperative telephone lines.

\section{PERSONNEL OF CREWS.}

The services of settler's and others resident in or near the Forest should, wherever possible, be secured for construction work. Such people are commonly reliable, willing, efficient workers, and, to a greater or less extent, personally interested in trail development. They soon form a regular force of trained workmen, familiar with the problems of trail building, and available year after year. At the same time the value of the training, both on location and on construction work, for prospective forest officers should not be overlooked. Experience as a member of the crew is decidedly valuable to a forest officer later called upon to assume responsibility for the work. It is well to include a small percentage of this class of men in some at least of the crews, even if entirely inexperienced and at the cost of the highest efficiency. This includes students of forestry as well as other likely material. The development of an efficient, well-trained personnel is one of the big problems of the Service, and should be kept in mind in all classes of work.

\section{EFFICIENCY.}

Every trail crew should be selected with a view to fitness for successive projects of the same or similar nature, and should be given to understand at the time of employment that the character of the work is likely to change at any time. No trail crew will be effective if composed entirely of specialists. The majority, at least, of the crew must be good all-round men, if the best results are expected. Upon the completion of one project, some other may conveniently be reached. Supervisors and district rangers should look closely to this feature. The sending of numerous crews into the field for relatively short periods, when one crew employed for the entire season can do the work, is expensive, and also tends to remove the incentive to good service which a long job inspires. Such a practice also creates lost motion in going to and returning from the field. The plan of 
working successive projects, beginning in the spring at the low altitudes as soon as the snow disappears, and reversing the program for summer and autumn work, is to be commended.

\section{OTHER CLASSES OF IMPORTANT WORK.}

An opportunity is often presented for correlating the work of trail building with that of telephone construction. The question of whether or not the same crew should build both projects is largely one to be decided for each particular case. The plan has the advantage, however, of always insuring work for the crew for which money is provided, in case the material for the telephone line is for any reason delayed. There is no reason why the same crew could not ordinarily do both classes of work, since the employment of professional telephone linemen is not advocated. One very important point to consider in building every trail is the probability of later building a telephone line along the same route. The work of clearing will be modified to some extent if a tree telephone line is planned to follow the trail. The supporting trees for the line should be picked out and left standing, and the swamping carried on so that an effective telephone as well as a trail right of way is obtained. Whenever possible telephone and trail lines should be parallel rather than intersecting. Slack telephone wires crossing a trail are of ten a serious interference to rapid travel. It will rarely be advisable, in deciding on the route for a trail, to give any consideration to the requirements for telephone construction, yet occasionally some concession in this respect may considerably reduce the cost of telephone work without materially increasing the cost or usefulness of the trail. For example, the trail may be located either through scattered timber or along a brushy, open hillside. Clearly the route selected, from the telephone point of view, should be through the timber, and might also be the trail route, other things being equal.

Cabins, fences, lookout towers, and the like can ordinarily be constructed by the crew handling the trail work in the vicinity, if the work is properly planned in advance and the necessary equipment furnished.

\section{RESERVE FIRE FIGHTERS.}

There are two principal factors to take into consideration in planning the size and distribution of trail crews-efficiency in the trail work, and the use of men as reserve fire fighters. Except for unusually large projects, the best distribution of the trail crews in connection with fire fighting can usually be accomplished without loss of efficiency. The problem is one of choosing the projects or parts of projects which will insure the most effective distribution of men. This should be the controlling factor in the allotment of improvement funds. The completion, or even the starting, of a 
particular project is entirely secondary to the fitting of the crew into the protective organization. The presence of a reconnaissance crew or a force of men on a timber sale may cause the shifting of the trail projects undertaken in any particular season; or it may influence the character of work on a class A trail so as to make it conform to specifications only as regards route and grade.

The men employed on trail crews must be ready and willing to go on short notice and even on short rations in case of a fire emergency. Their equipment for trail work is ample for almost any possible employment in the Forest where hard work is to be done. It may be advisable, however, in some localities to equip them with particular reference to fire fighting-furnishing any special tools needed, and arranging for the rapid transportation of tools, food supplies, and camp paraphernalia. Wherever practicable, the camp should be in communication by telephone with the district ranger's headquarters. Portable phone and emergency wire may be used for this purpose.

\section{MAINTENANCE.}

Maintenance is primarily a problem of general Forest administration, and its discussion here need be very brief. Trail maintenance is not radically different from the problem of maintenance of other Forest improvements. As the volume of the work increases, more and more of the regular improvement allotment must be diverted into maintenance and less into construction. Improvement plans must provide adequate machinery for this phase of the work. The cost will be largely affected by the character of the original construction work. The more thoroughly the work is done in the beginning the lighter will be the subsequent cost of maintenance. Especially is this true as respects the damage due to defective or insufficient drainage. The work may usually be accomplished with good results in the early part of the patrol season, by adding very slightly to the number of temporary men commonly assigned for patrol duty. Trails, and telephone lines as well, may be put in good repair under the direct supervision of rangers and experienced guards. This applies where the trails are chiefly valuable for protective and administrative purposes during the patrol season. Where the trails are in use for other purposes throughout the greater part of the year, there should be a force specially detailed to attend to the maintenance of trails and telephones. It is uniformly best to correlate this work with other similar lines, making each an important feature and having no one paramount, except where in special cases the ranger in charge directs attention to a particular matter. 'This correlation reduces the cost of maintenance in the Forest as a whole by keeping men employed all the time and reducing lost motion to a minimum. The cost of actual construction of a trail may be deter- 
mined with reasonable accuracy, but that of preliminary location and maintenance must of necessity be subject to a variable that will preclude exactness, if location and maintenance be correlated with other work. To attempt to figure the precise cost of any piece of ordinary trail maintenance would involve undue niceties of calculation and loss of valuable time. The best that can be done in this respect is for each man to approximate the amount of time spent each day on different kinds of work in hours and report results to the district ranger, and he can figure money totals for each project and forward an intelligible summary to the supervisor.

Three men make an excellent crew in ordinary work of cleaning and repairing trails. By this arrangement two men can be working while the third man is moving camp, getting supplies, and wrangling horses. This is necessary, since frequent moving is usually required. All repairs should be made in the same manner and with the same grade of workmanship as first construction. All trails should be repaired every year.

DEFINITION OF CONSTRUCTION AND MAINTENANCE.

The following distinction, which applies not only to trails but to all classes of improvement work, has been made between the terms "construction" and "maintenance."

Construction includes all work incident to the completion of a project in accordance with the specifications under which the work was undertaken. As soon as the specifications are complied with, the supervisor will certify that the project has been completed. If at any time later the specifications are changed, then any work necessary to satisfy the new specifications will be considered as construction.

Maintenance includes all work of repairs and replacement incident to maintaining the standard for the project as outlined by the specifications.

INSPECTION.

Nothing in any branch of administrative work conduces more surely to efficiency than frequent and thorough inspection. The work must, however, be done in a spirit of absolute fairness and with due regard to circumstances and conditions. Frank criticism is most beneficial, while hypercriticism too often defeats the very purposes of judicious inspection.

After the preliminary reconnaissance and location of a trail line is made, the supervisor or deputy supervisor should, if practicable, carefully inspect the proposed line not only to determine the feasibility of construction under general specifications and in accordance with established standards, but also to check up estimated costs. Neglect of these precautionary steps will of ten cause disappointment in final results. 
As soon as construction begins careful inspections should start and be made as often as circumstances will permit. Every project of any consequence should be examined closely by the supervisor or deputy supervisor at least once while work is going on and again after completion. The ranger in charge of the district should keep in touch with the situation at all times.

\section{costs.}

Standard forms for cost keeping will be adopted for trail work; they should be thoroughly understood by all forest officers. It is important to compare the cost and results on different trail projects in order to properly rate the factors which control construction costs, as well as to check the efficiency of the work as it progresses.

A daily record of the number of men employed, rates of pay, and distribution of work is essential. The labor record must be supplemented with a record of other expenditures (food, equipment, powder, freight, express, hauling, etc.), and the total expenditures for the project distributed to the classes of work. The classes of work upon which unit-cost figures are ordinarily desired are as follows: Clearing per mile, grading per rod, rockwork per cubic yard, bridges, culverts, corduroy per rod.

\section{YARDAGE FIGURES.}

It is hardly feasible to attempt to keep yardage figures on trail work for any work other than for solid rock. The cost of ordinary grading in earth is more largely influenced by the vegetation, the character of the soil, and the finishing work than by the volume of earth moved. To secure cost figures which will take in to consideration the widely varying factors means a more complicated system than is justified by the value of the results. For this reason a cost figure for grading work per linear rod will be considered standard.

\section{COSTS FOR SECTIONS.}

On most projects conditions will vary to such an extent that a division into sections will be necessary; each section will contain as nearly as practicable uniform conditions. The cost data will be supplemented by a carefully written description of conditions in each section, covering such items as the character, type, and stand of timber, windfalls, undergrowth, character of soil, per cent of slopes, outcrop, rock points, etc.

Where only one or two men are employed, and especially where little supervision can be given, the men should mark by stakes the progress of each day's work. Fairly good cost figures can be obtained later by measuring the distance and roughly proportioning the classes of work. 


\section{APPENDIX.}

\section{TOOLS.}

The trail crew should be provided with all the tools likely to be needed on any part of the job. Some of the tools may not be used, but it is better to have them on hand when and if required than to lose valuable time securing them or trying to improvise substitutes.

\section{TOOLS NEEDED FOR A CREW OF 10 MEN, INCLUDING FOREMAN AND COOK.}

FOR EARTH WORK.

2 crosscut saws with handles (2-man).

6 D. B. axes.

$6 \mathrm{~L}$. H. shovels.

4 mattocks with handles.

2 picks, miners', with handles.

4 brush hooks, with handles.

2 peavies (stocked).

1 carborundum grinder.

6 carborundum whetstones, 4 -inch.

12 10-inch flat files.

12 8-inch flat files.
2 12-inch wood rasps.

3 D. B. axe handles.

1 miners' pick handle.

4 mattock handles.

12 -inch auger.

1 double-pulley steel block, $\frac{1}{2}$-inch sheave. 1 single-pulley steel block, $\frac{1}{2}$-inch sheave. 100 feet $\frac{3}{8}$-inch flexible wire rope.

Approximate total weight, 300 pounds.

Approximate total cost, $\$ 50$.

FOR ROCK WORK.

Number of tools, based upon assignment of four men to rock work, two men in each drill crew:

4 sets drills-112 feet of $\frac{7}{8}$-inch drill steel, to make 4 sets each comprising one 12-inch, two 18-inch, two 24-inch, two 30 -inch, two 36-inch, one 48-inch, one 60-inch.

2 striking hammers, single jack, 3 pounds.

2 striking hammers, double jack, 8 pounds.
Number of tools, etc.-Continued.

2 rock hammers, 12 pounds.

2 crowbars, 16 pounds.

4 drill spoons-two 30 -inch, two 60 inch.

8 gads, 6 feet $\frac{7}{8}$-inch drill steel, to make two 6-inch, two 8-inch, two 10-inch, two 12-inch.

2 California crimpers.

4 striking-hammer handles.

\section{BLACKSMITH OUTFIT.}

1 short-legged square portable forge.

1 vise, small, similar to Monarch No. 231.

1 anvil, 50 pounds, cast, with hardie.

3 pairstongs, blacksmith's-1 bolt, 1 pick, 1 plain.

1 hot chisel.
2 hammers, blacksmith's. 100 pounds blacksmith's coal. 5 pounds welding compound.

Approximate total weight, 580 pounds.

Total cost, $\$ 70$. 
SPECIAL TOOLS FOR BRIDGE WORK.

1 carpenter's square.

$1 \mathrm{adz}$.

1 carpenter's level.

1 heavy wrench to tighten rods.

1 monkey wrench, large size.
If team is available-

1 pair spreaders, heavy.

10 feet $\frac{1}{4}$-inch chain fitted with round hook at one end and grab hook at the other.

Approximate weight, 25 pounds. Approximate cost, $\$ 10$.

TENTAGE

(Crew of 10 men, including foreman and cook).

112 by 14 foot wall tent with fly (cook tent).

112 by 14 foot wall tent with fly (mess tent).
37 by 9 foot wall tents (sleeping quarters).

\section{PROVISION LIST.}

(Ten men for 10 days; 100 rations.)

Flour, 100 pounds.

Cured meats, ${ }^{1} 75$ pounds.

Potatoes, 100 pounds

Beans, 20 pounds.

Sugar, ${ }^{2} 40$ pounds.

Lard, ${ }^{3}$ in 5 -pound pails, 10 pounds.

Butter, creamery, 1-pound cartons, 10 pounds.

Dried fruits, 20 pounds.

Rice, 5 pounds.

Coffee, good grade, ground, 1-pound sealed tins, 10 pounds.

Tea, 1 pound.

Cocoa, $\frac{1}{2}$-pound cans, 2 pounds.

Cheese, 5 pounds.

Macaroni, 2 pounds.

Milk, Carnation grade, 48 cans.

Corn beef, 2 pounds, 5 cans.

Tomatoes, $2 \frac{1}{2}$ pounds solid pack, 8 cans.

Peas, 2 pounds solid pack, 5 cans.

Corn, 1-pound solid pack, 10 cans.

Sauer kraut, 3-pound, 4 cans.

Rolled oats, 10 pounds.

Onions, 10 pounds.

Corn meal, 5 pounds.
Graham flour, 5 pounds.

Pancake flour, 5 pounds.

Salt, 3 pounds.

Baking powder, 3 pounds.

Soda, 1 pound.

Yeast cake, 1 packet.

Eggs, 10 dozen.

Catsup, 2 bottles.

Pickles, sour, 1 kit or 2 gallons.

Mustard, ground, 4-ounce can.

Pepper, ground, 8-ounce call.

Cinnamon, ground, 4-ounce can.

Allspice, ground, 4-ounce can.

Lemon extract, 4-ounce bottle.

Vanilla extract, 4-ounce bottle.

Vinegar, 1-quart bottle.

Soap, laundry, 5 pounds.

Matches, 5-cent packages, 3.

Candles, 2 pounds.

Coal oil, 1-quart bottles, 4 .

Chloride of lime, 1 pound.

Approximate total weight, 550 pounds.

Approximate total cost, $\$ 65$.

1 If fresh meat is available, use 50 pounds cured, 25 pounds fresh.

2 If sirup is preferred, reduce sugar accordingly.

3 If fresh meat is used, increase lard to 15 pounds. 


\section{KITCHEN OUTFIT.}

(Crew of 10 men, including foreman and cook.)

1 lantern.

$2 \mathrm{~S}$. B. axes.

1 sheet-steel cook stove No. 8 , with 6 joints of pipe.

4 fry pans, assorted sizes.

2 granite kettles, 12-quart, with covers. 4 granite kettles, 6 -quart, with covers.

2 granite stew kettles, 6-quart, with covers.

1 granite coffee pot, 8-quart.

1 granite tea pot, 3-quart.

2 dishpans, 14-quart.

1 granite rice boiler, 6 -inch.

2 dripping pans to fit oven of stove.

1 can opener.

1 rolling pin.

4 tin wash basins.

4 tin water pails, 10-quart.

3 tin dippers, 1-quart.

$1 \frac{1}{2}$ dozen retinned plates.

$1 \frac{1}{2}$ dozen retinned cups and saucers.

$\frac{1}{2}$ dozen retinned dish-up basins, 2-quart.

$\frac{1}{2}$ dozen retinned dish-up basins, 1-quart.

1 dozen mush bowls.

1. retinned sirup pitcher, 1 quart.
1 retinned cream pitcher, 1 quart.

2 butcher knives-one 10-inch, one 12inch.

1 butcher steel.

1 meat fork.

2 retinned stirring spoons.

1 meat saw.

4 tin milk pans, 6-quart.

$1 \frac{1}{2}$ dozen wood-handled steel knives and forks.

$1 \frac{1}{2}$ dozen teaspoons.

$1 \frac{1}{2}$ dozen tablespoons.

15 -gallon slop can, galvanized iron.

5 yards 12 -ounce duck or light canvas, ${ }^{1}$ 36 inches wide.

$\frac{1}{2}$ pound 10 -ounce tacks.

10 pounds assorted nails.

1 carpenter's hammer.

1 carpenter's hand saw.

1 alarm clock.

10 yards crash toweling.

10 yards unbleached muslin.

Approximate total weight, 325 pounds.

Approximate total cost, $\$ 62$.

PACK TRANSPORTATION.

On basis of 50 miles packing from supply point to field: · Pounds.

Tools for clearing and earthwork . . . . . . . . . . . . . . . . . . 300

Tools for rockwork..................................... 580

Kitchen outfit..................................... 350

Provisions 10 men 10 days.............................. 550

Tentage and impedimenta........................... 900

Total............................................... 680

With an average load of 149 pounds this will require 18 pack horses to move the crew and equipment to the field the first trip. After the first camp is established 6 pack horses will be required for moving camp, and this number should be kept by the trail crew for use whenever needed. The remaining 12 horses should be kept on the road bringing in fresh supplies and doing whatever else the train is ordinarily used for.

\section{Class A. Standard Trail-Approximate.}

COST OF LABOR.

(Experience figures for northern Idaho.)

Clearing right of way, per mile. $\$ 10$ to $\$ 50$

\footnotetext{
1 This item is intended to be used for tops for table frames built of light poles. Narrow strips of wood, like laths, 36 inches long, should be tacked to the canvas one-half inch apart. The cover thus made can be kept clean quite easily and may be rolled up into a compact bundle and readily packed from one camp to another. Two covers are provided-for mess table 9 foet long and for cook's tablo 6 foet long.
} 
PICK, SHOVEL, AND MATTOCK WORK. ${ }^{1}$

Hillside grade:

Earth, per cubic yard.

20 cents.

Earth and stone, per cubic yard..................... 25 cents.

Earth and clay, per cubic yard ..................... 30 cents.

Where line is obstructed by trees or stumps that must be removed, add 15 per cent to above figures.

Loose slide rock, 45 per cent slope, per rod..................... 50 cents.

Loose slide rock, 70 per cent slope, per rod.............. . . . . . . 75 cents.

Solid-rock blasting work, cubic yard..................... $\$ 1$ to $\$ 1.50$.

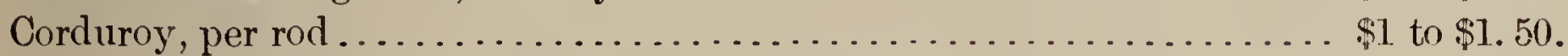

Cost depends on availability of timber.

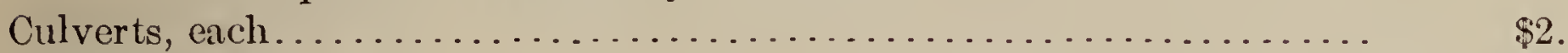

Drain boxes, $\log$, each................................. 50 cents.

SUPPLIES AND EQUIPMENT FOR TRAII-IOCATION WORK.

[Two men three days; man packs.]

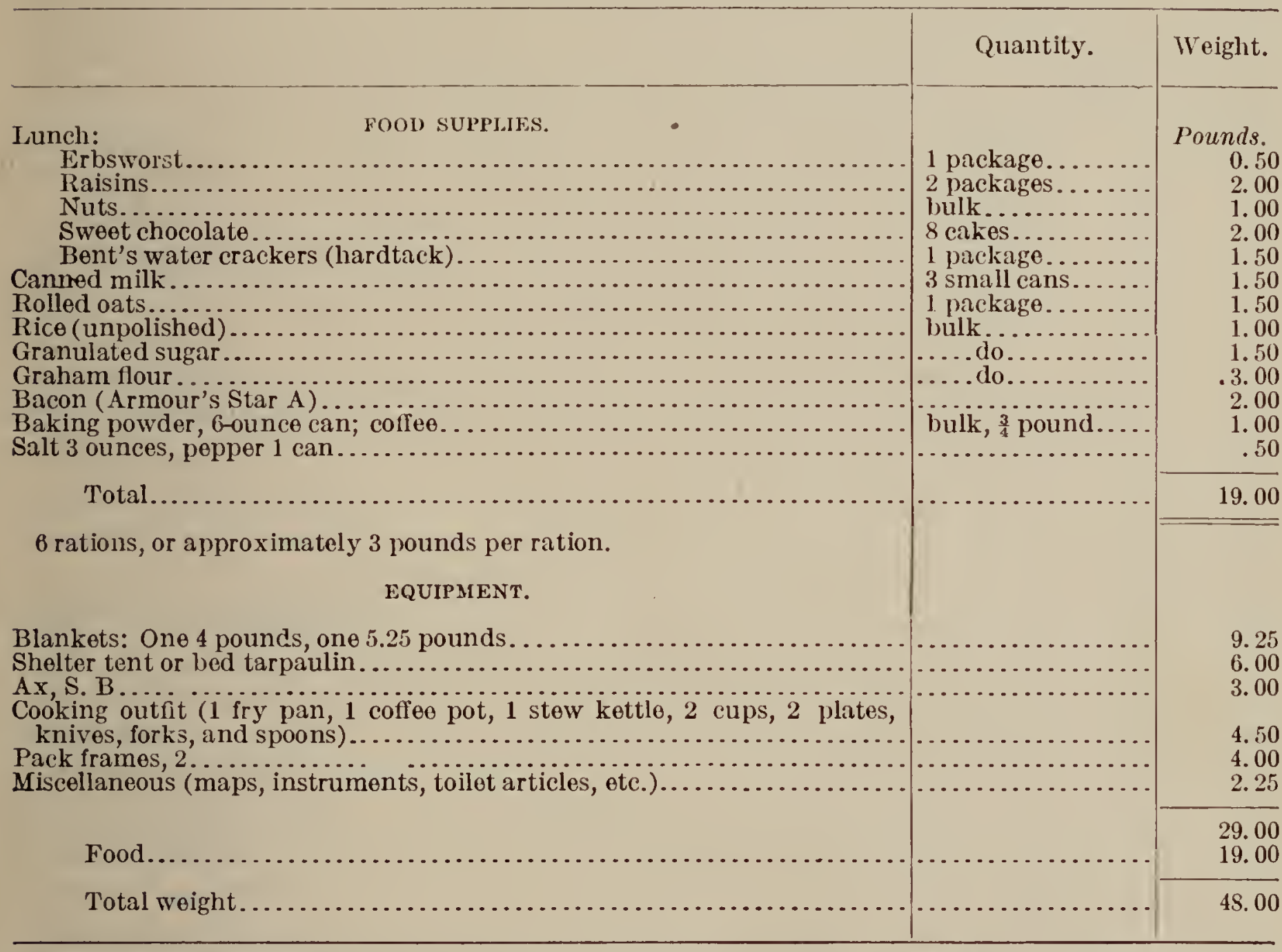

1 Rarely is the character of the ground such that a plow can be used to advantage. Wherever it is practicable a "Iillside" reversible, 12-inch plow is best. In case a plow can be used the forage for team must beincluded in estimates, and the team and plow made a part of the equipment, additional to what is listed. Approximate weight of plow, complete, 85 pounds; approximate cost, $\$ 13$. 



\section{N D E X.}

Page.

Abney level.................................... 15, 17,43

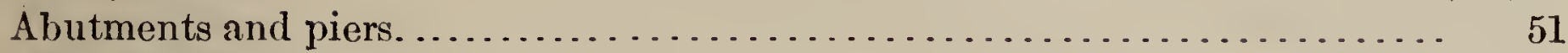

Accessibility of bridge site. . . . . . . . . . . . . . . . . . . . . . . 43

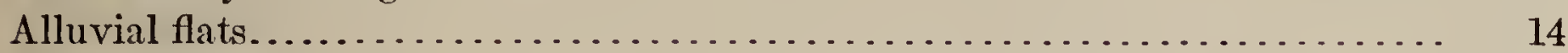

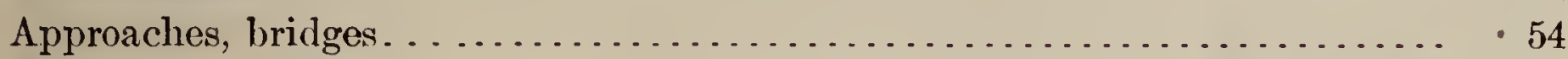

Bankers.......................................... 26

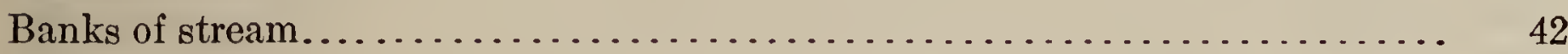

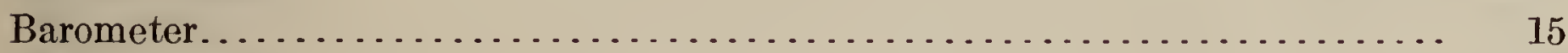

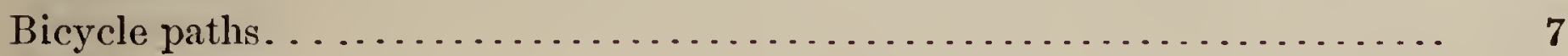

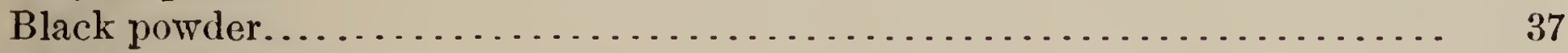

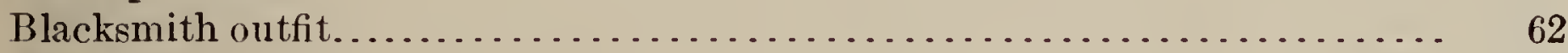

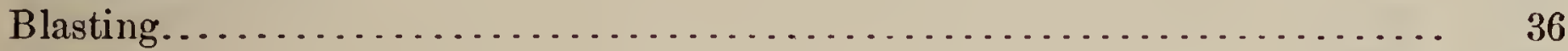

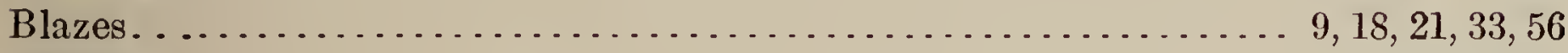

Bridges. ................................... 9, 14, 29,42-55

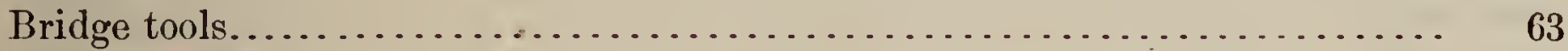

Brush disposal. . . . . . . . . . . . . . . . . . . . . . . . . . . . 9,25

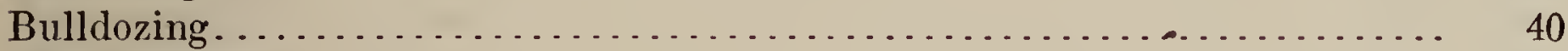

Cable bridges. ..................................... 49

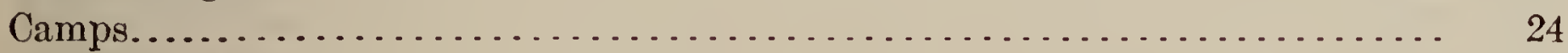

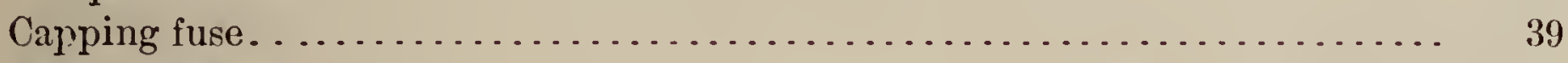

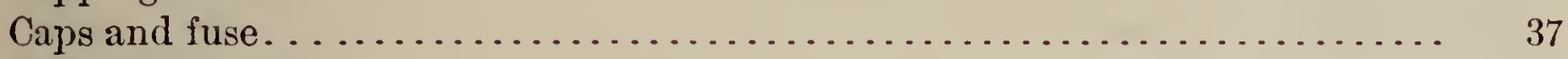

Channel, straight. ...................................... 42

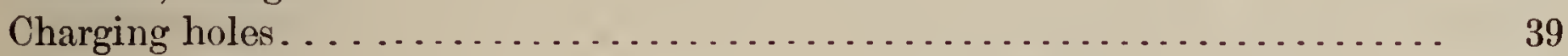

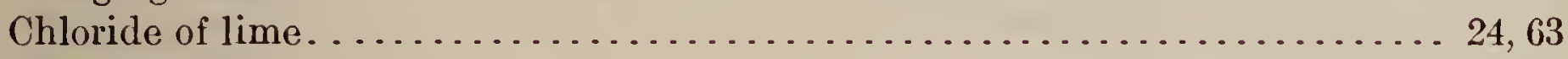

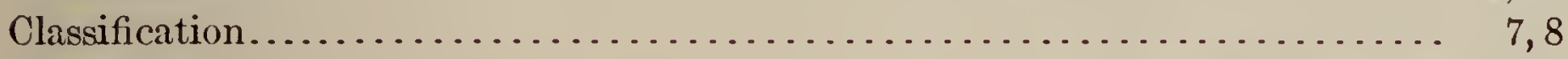

Clearing........................................ . $8,15,24-25$

Construction, definition. . . . . . . . . . . . . . . . . . . . . . . 60

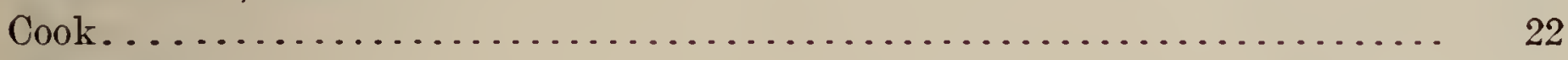

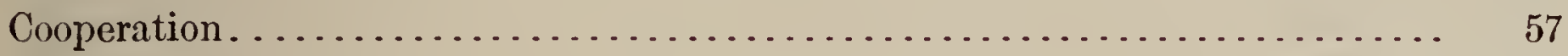

Corduroy ........................................ 9, 14, 29-33

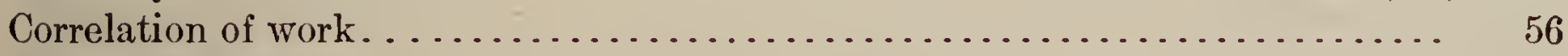

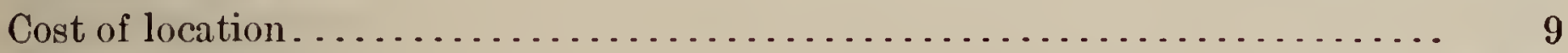

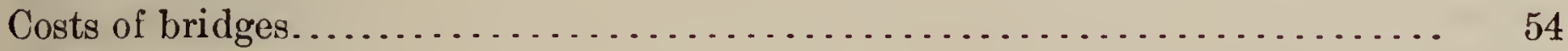

Costs of construction......................... 54-55,60,61,64-65

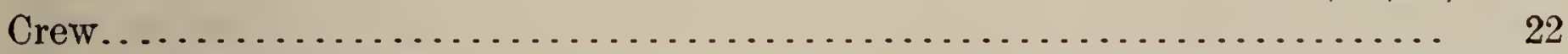

Crew for trail maintenance............................. $59-60$

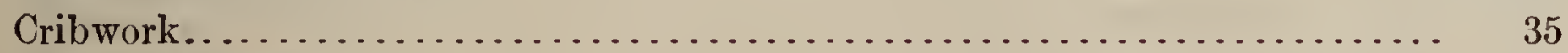

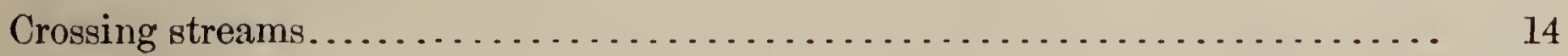

Culverts. ..................................... 9,29-30

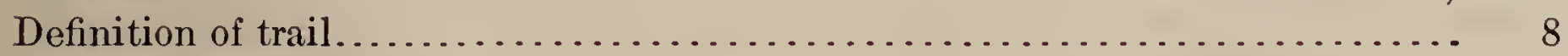

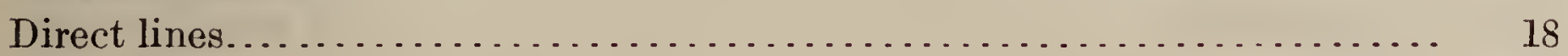

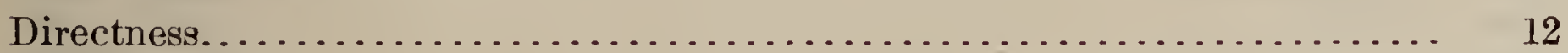

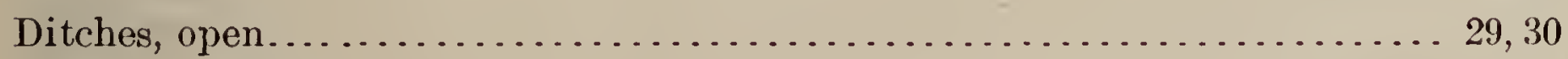

Double jacking. . . . . . . . . . . . . . . . . . . . . . . . . . . . . . 40

Drainage......................................... 9, 27-29

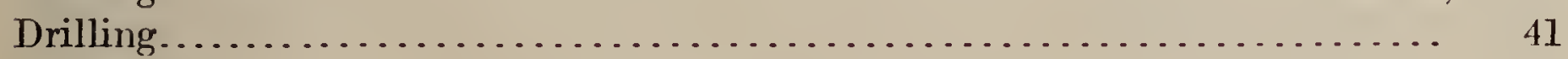

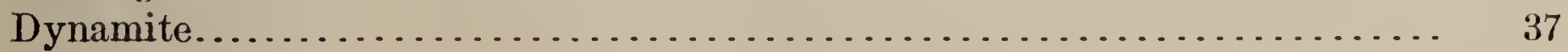


Page.
.

Efficiency............................................... 57

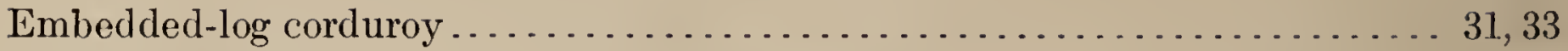

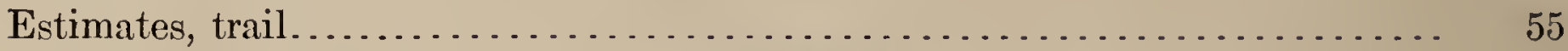

Example running grade lines.................................... 19

Explosives.................................................... 36

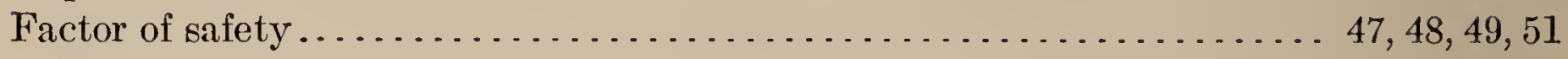

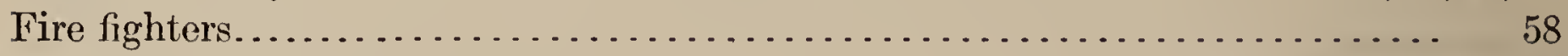

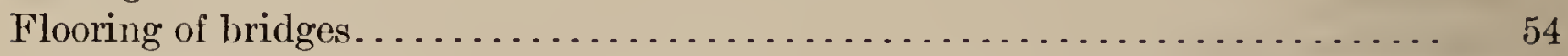

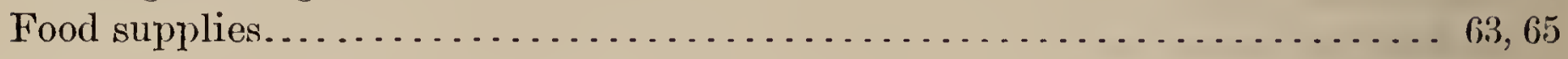

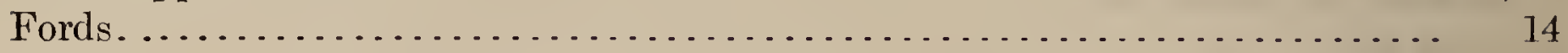

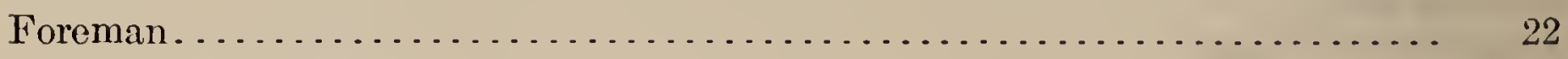

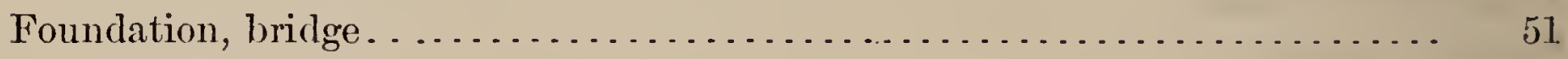

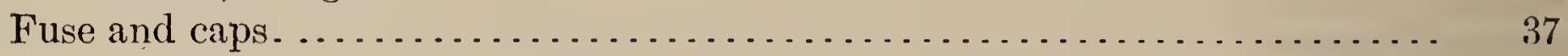

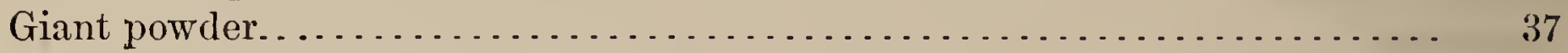

Grade.......................................... $11-12$

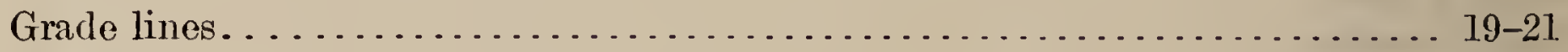

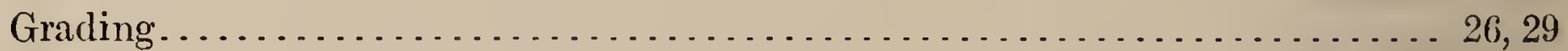

Grade meter.............................................. 16

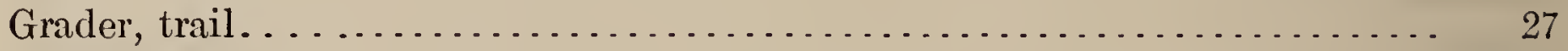

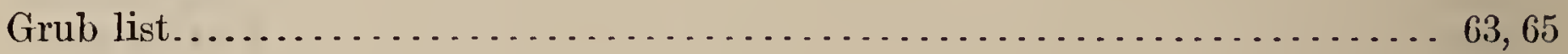

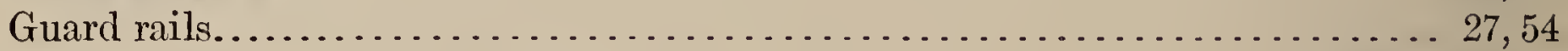

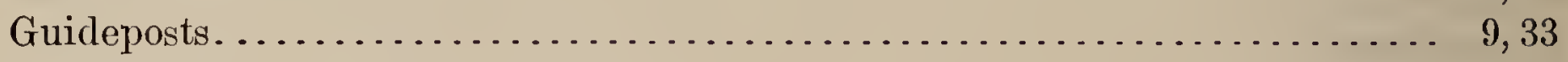

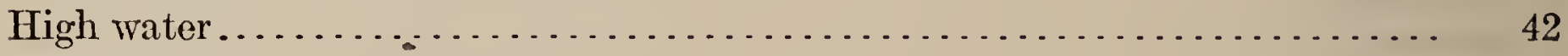

Inspection......................................... $\quad 60$

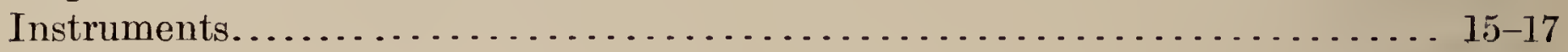

King truss......................................... $43,45,47,48$

Kitchen outfit.............................................. 64

Level, Locke...................................... 15, 17, 43

Location.................................... 10,13

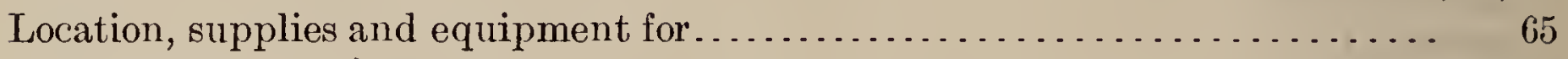

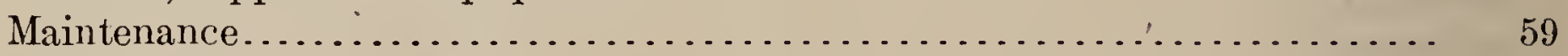

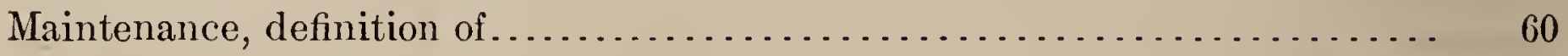

Maps............................................... 17

Marking grade line.............................................. 21

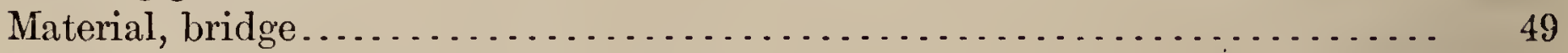

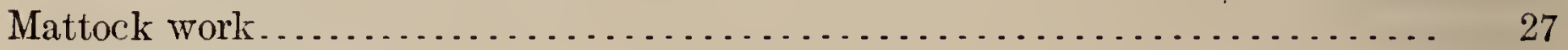

Methods of location........................................... 18

Missed holes.................................................. 39

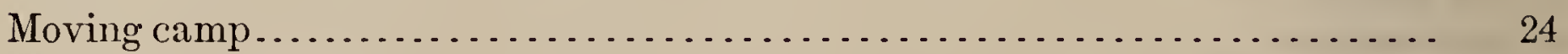

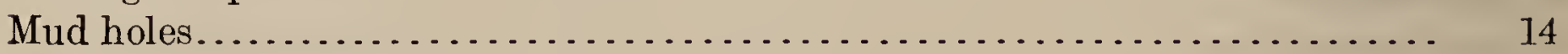

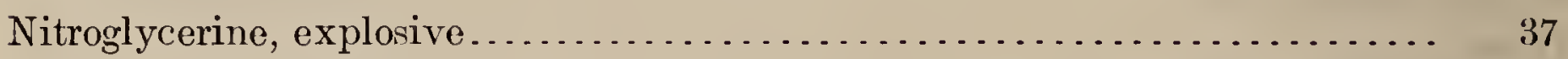

Objectives........................................... ${ }^{13}$

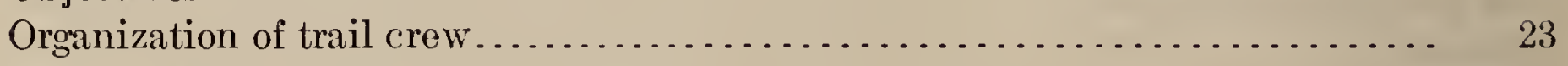

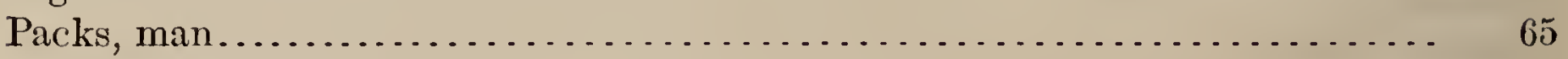

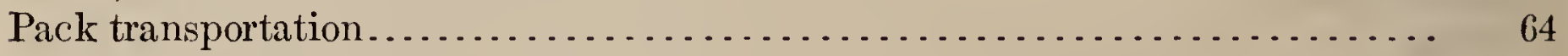

Personnel of trail crews......................................... 57

Piers and abutments............................................. 51

Plans for trails........................................... 55

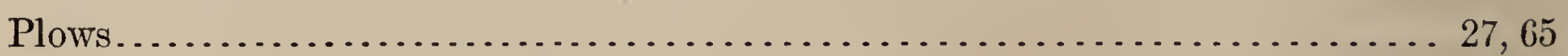

Preliminary work...................................... 9,56

Provision list........................................ 63, 65

Puncheon bridge corduroy ................................... 31,32

Purpose of handbook....................................... 7 
Queen truss

Random line.

Report on bridge.

Reserve fire fighters

Retaining walls.

Reverse grades

Rockwork.

Route.

Rubble slides

Safety, factor of

Sanitation for camps

Selection of powder

Sharpening steel..

Sign boards.

9,33

Shotgun trails.

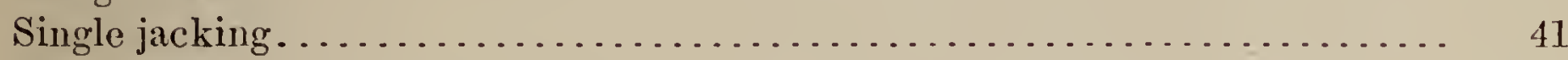

Site, bridge................................................ ${ }_{42}$

Slide, rubble; slides, loose ................................. 34-35

Slope board . . . . . . . . . . . . . . . . . . . . . . . . . . . . . . 16

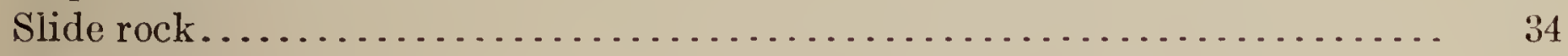

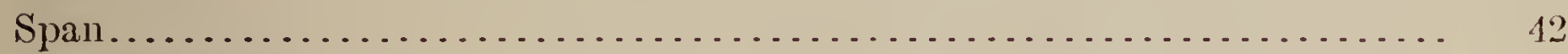

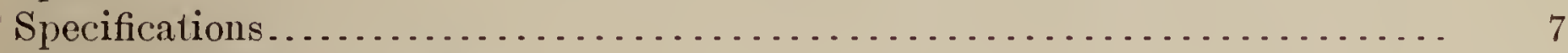

Special problems, blasting ..................................... 41

Speed of saddle horses........................................... 7

Splicing bridge timber........................................... 54

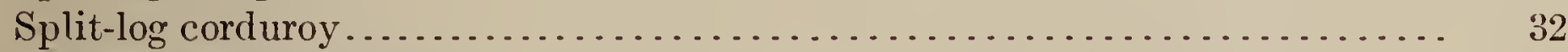

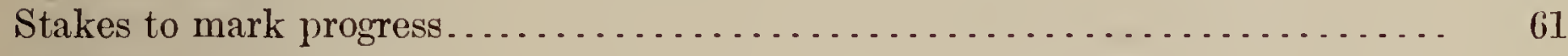

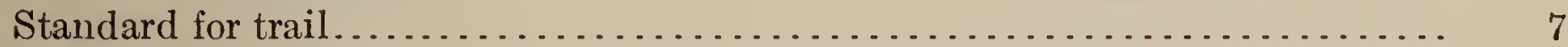

Strength of timber........................................ $49-51$

Stringer, bridge.......................................... 47,48

Students.................................................... 57

Summary of specifications. . . . . . . . . . . . . . . . . . .

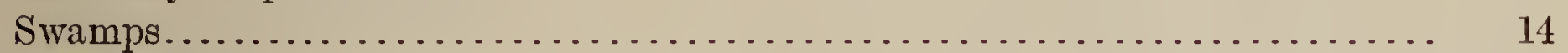

Switchbacks........................................ 8, 12,27

Teams..................................................... 63

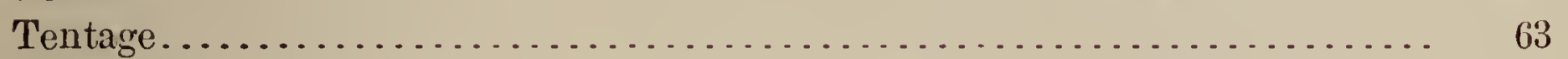

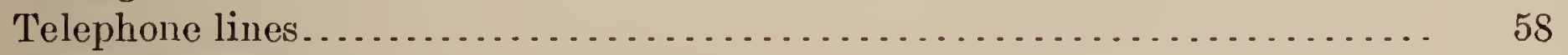

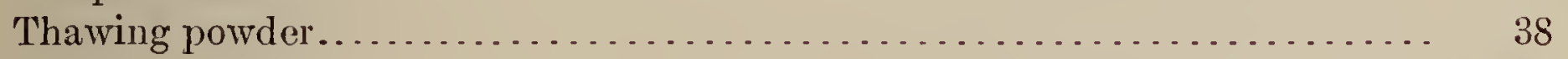

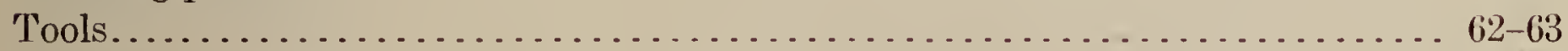

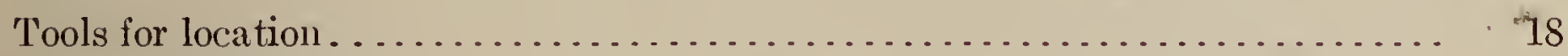

Transportation, pack....................................... 64

Traverse............................................. 18-19

Tread ............................................... $9,25-26$

Trestle bridges............................................. 49

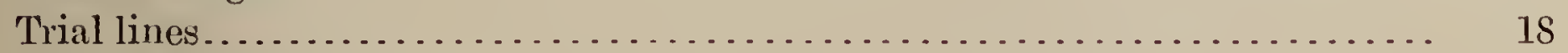

Types of bridges........................................... ${ }_{42}$

Use, classification based on................................... 8

Water bars. . . . . . . . . . . . . . . . . . . . . . . . . . . . . . 28, 29

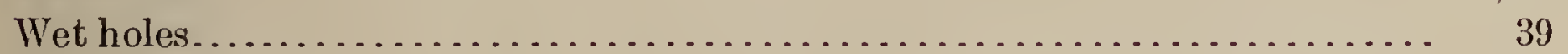

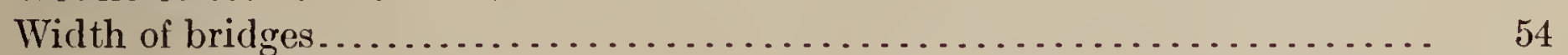

Winter trail reconnaissance................................... ${ }_{56}$

Yardage figures.............................................. 61 




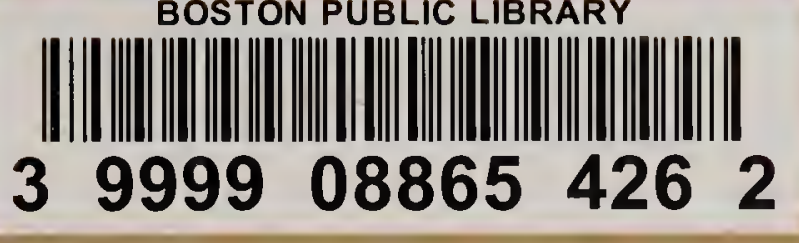




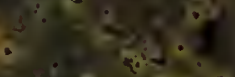

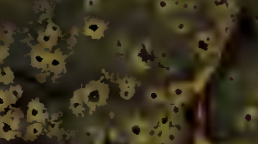

$\stackrel{0}{2}$

2.0. 2.1.8.

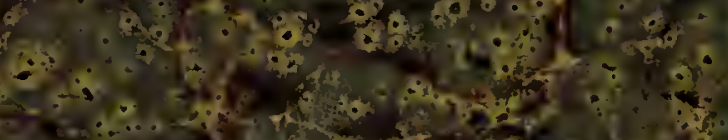

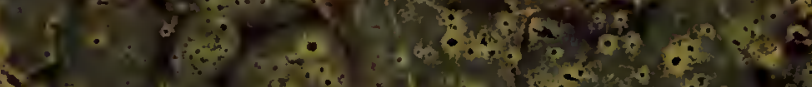

18. 0 in $4: 0$

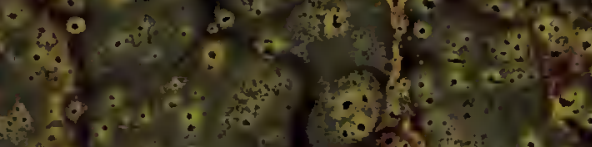

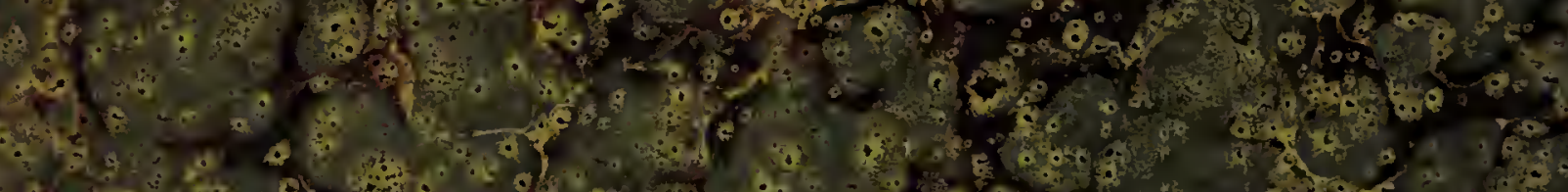

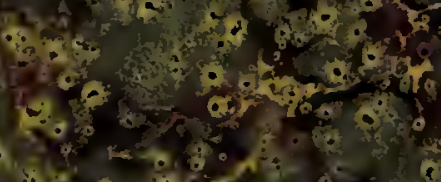

is 8

$$
3_{6}, 8+3
$$

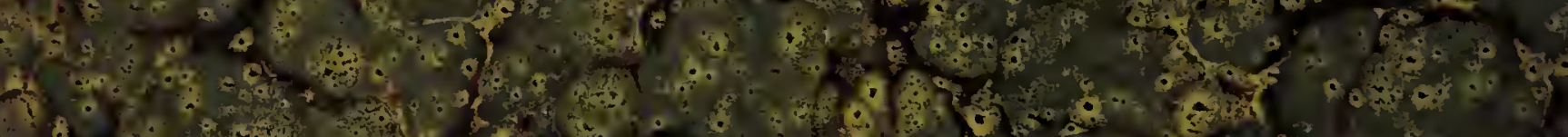

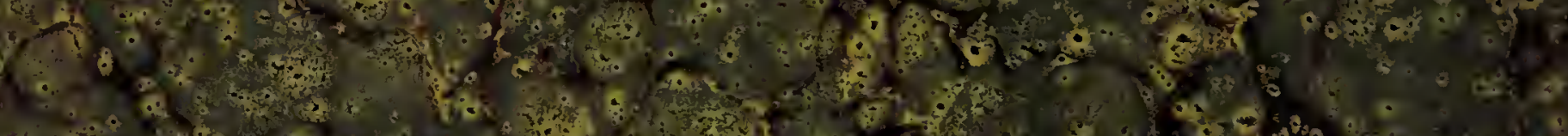

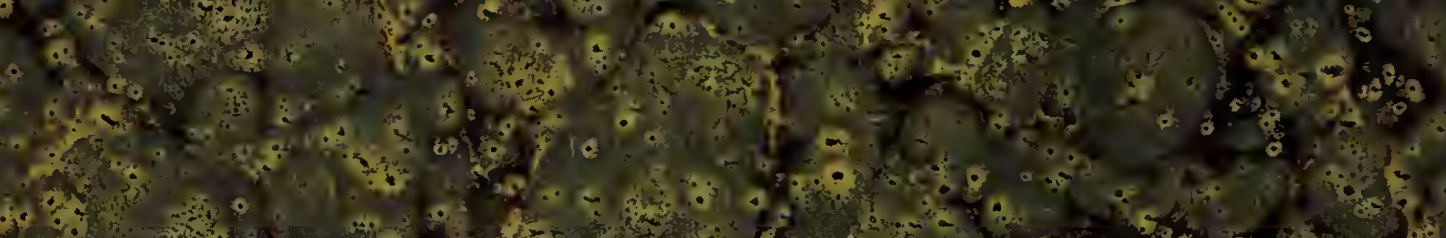

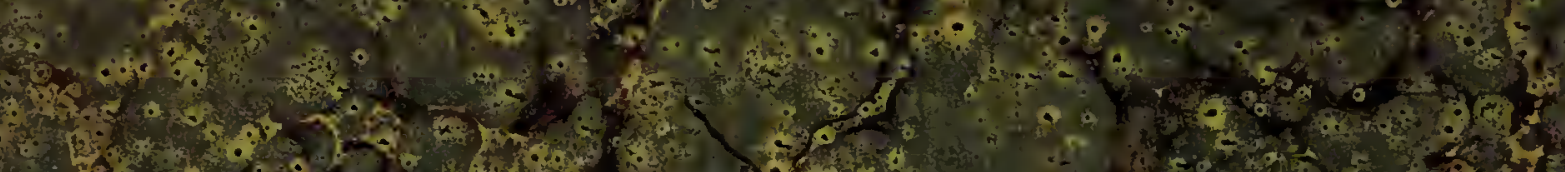

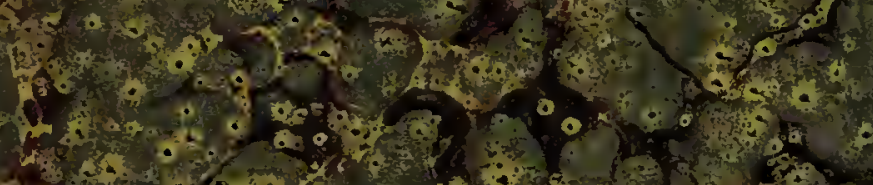
f.

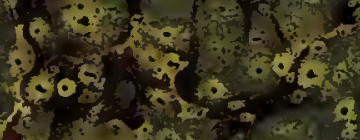
63
$\frac{1}{8}$ (i) 0

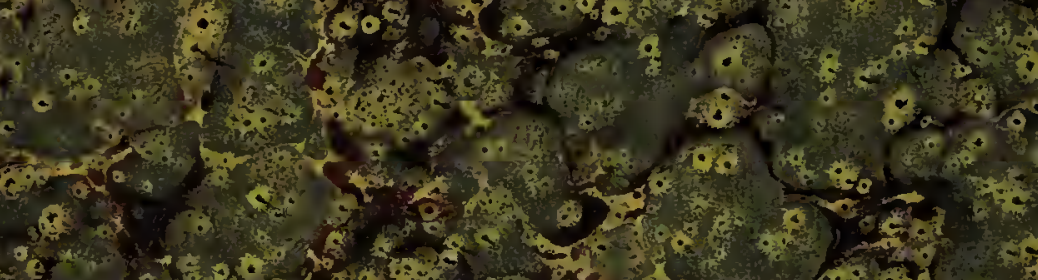

(6.

: 200

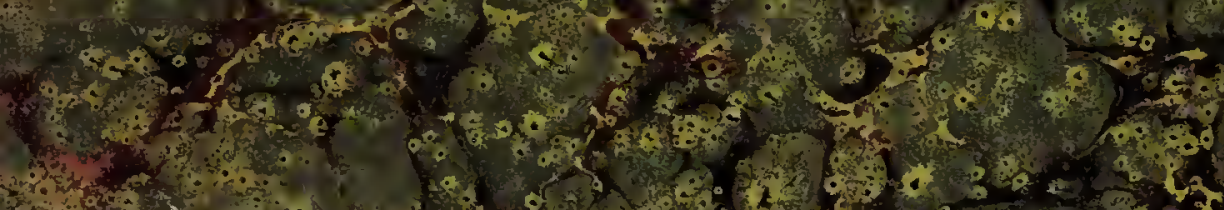

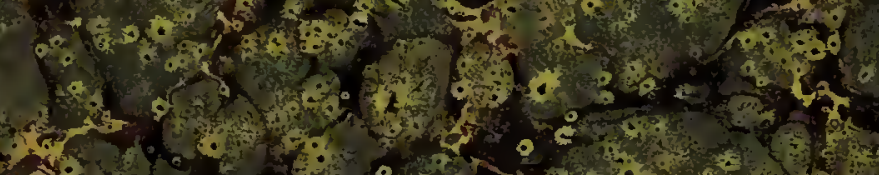

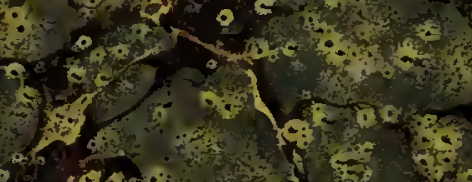

6.5.

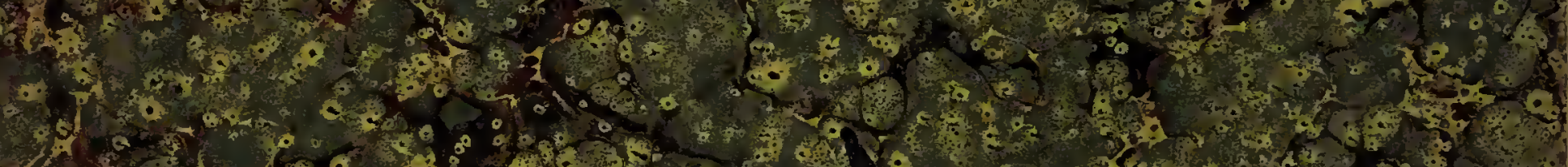

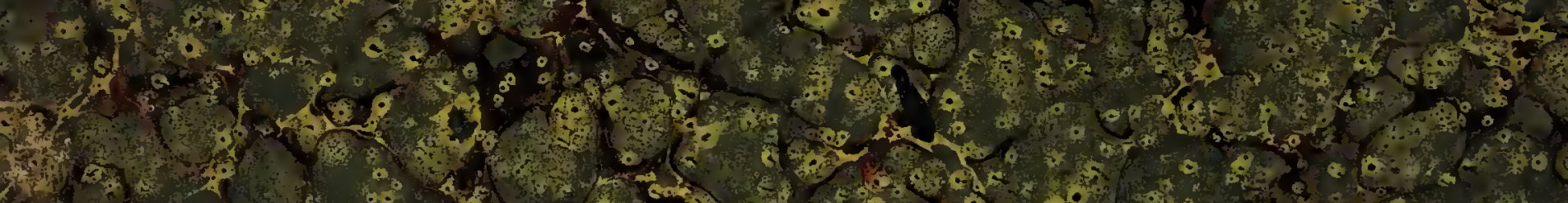

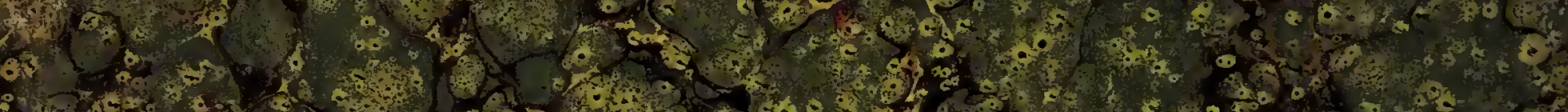

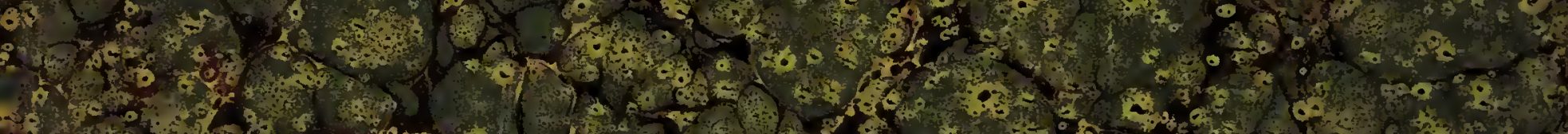

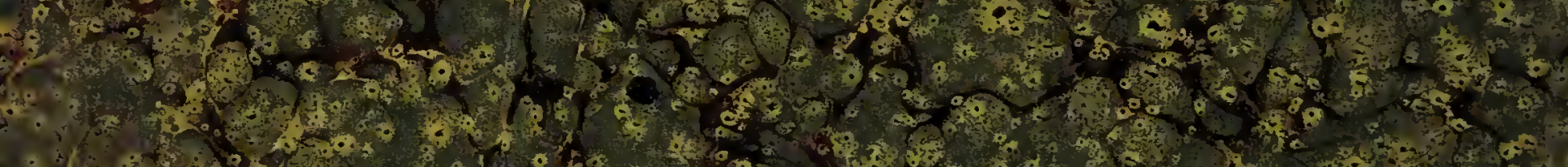

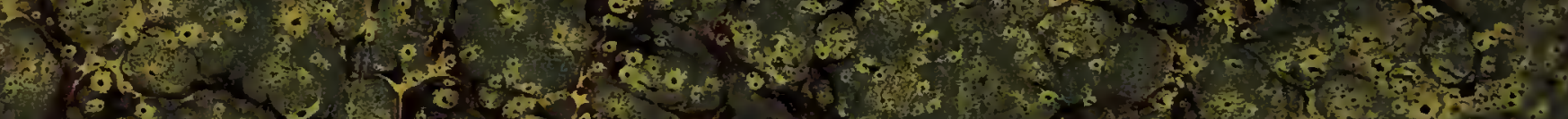

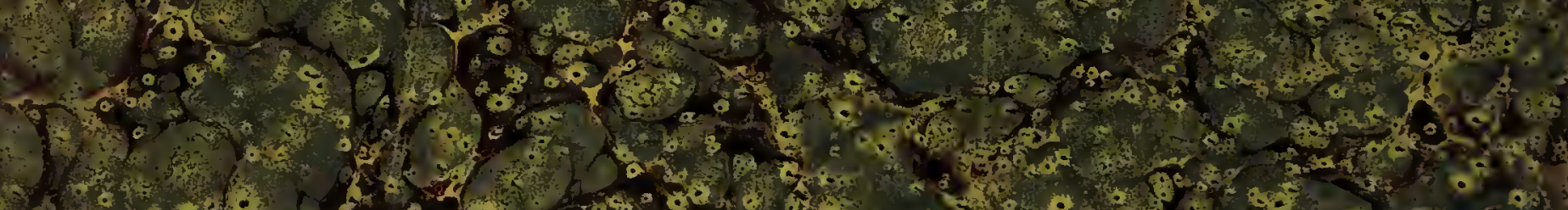

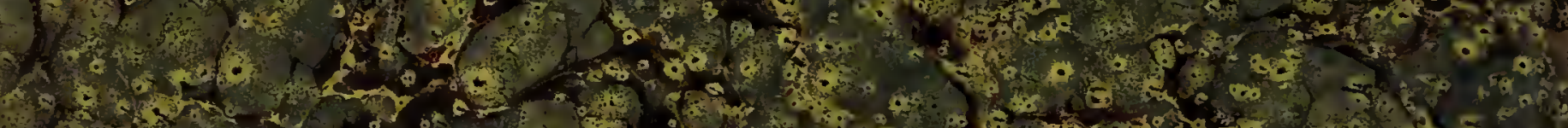

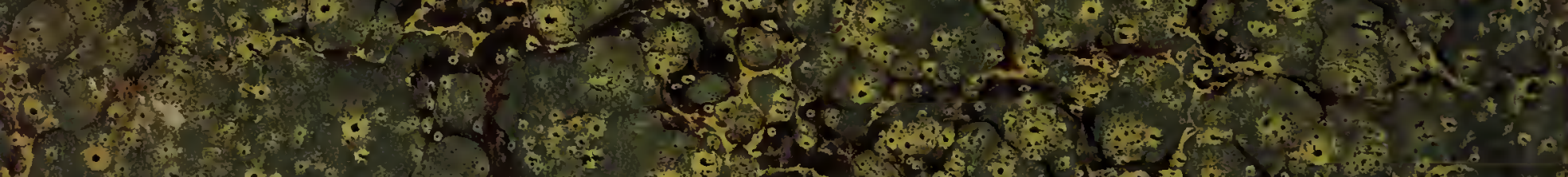
(3)

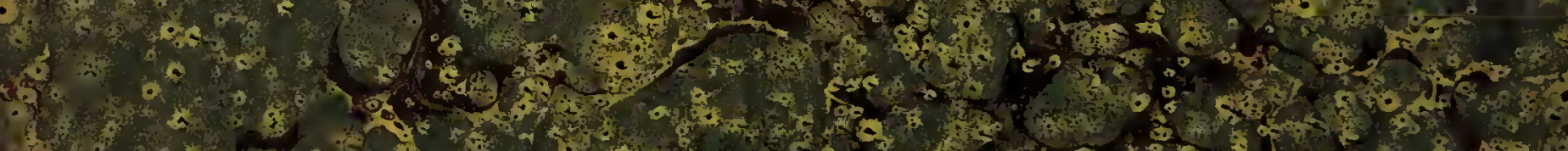

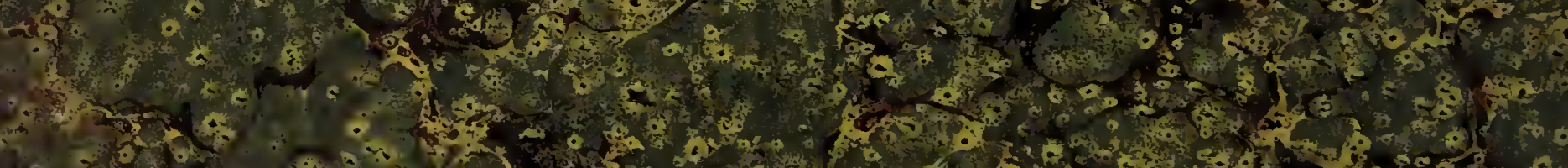

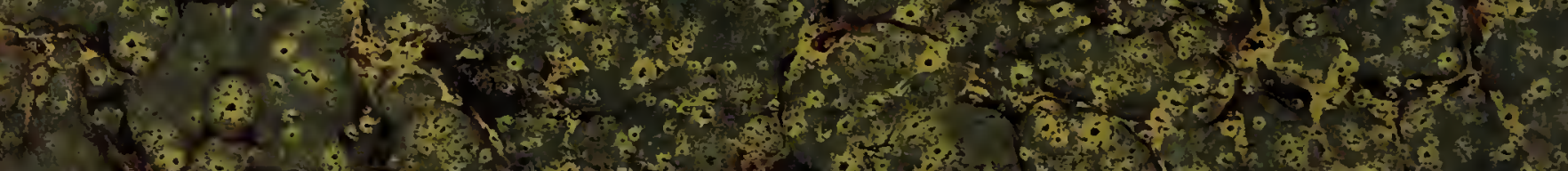

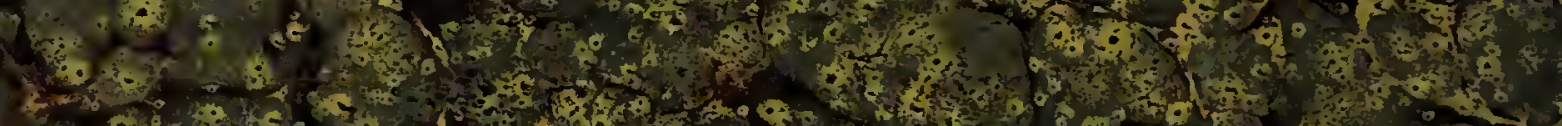

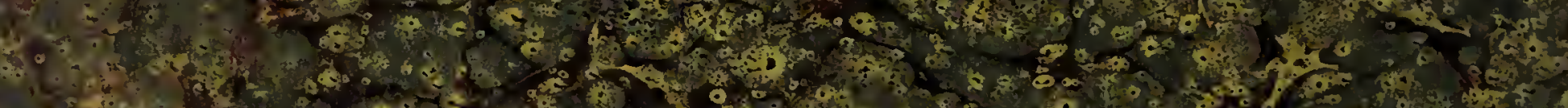

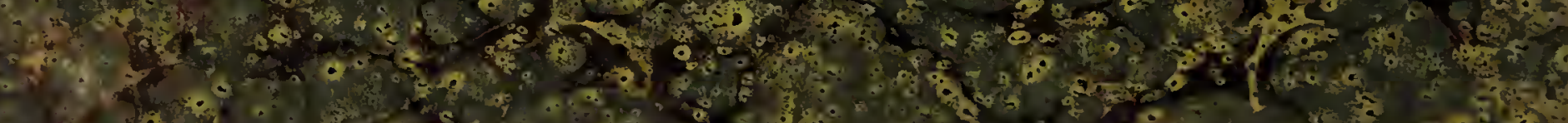

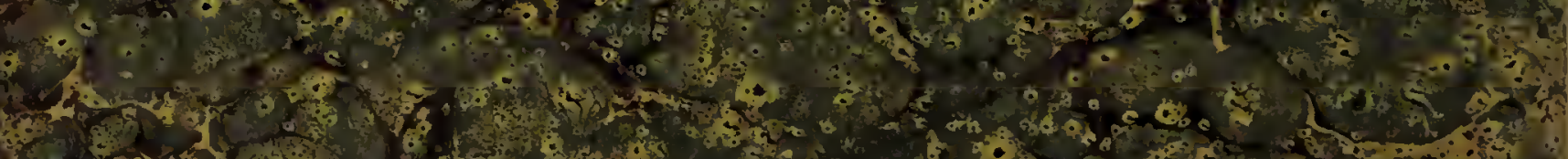

